\title{
CIÊNCIAS DA TERRA: PRINCÍPIOS FUNDAMENTAIS
}

\section{VंOLUME II}

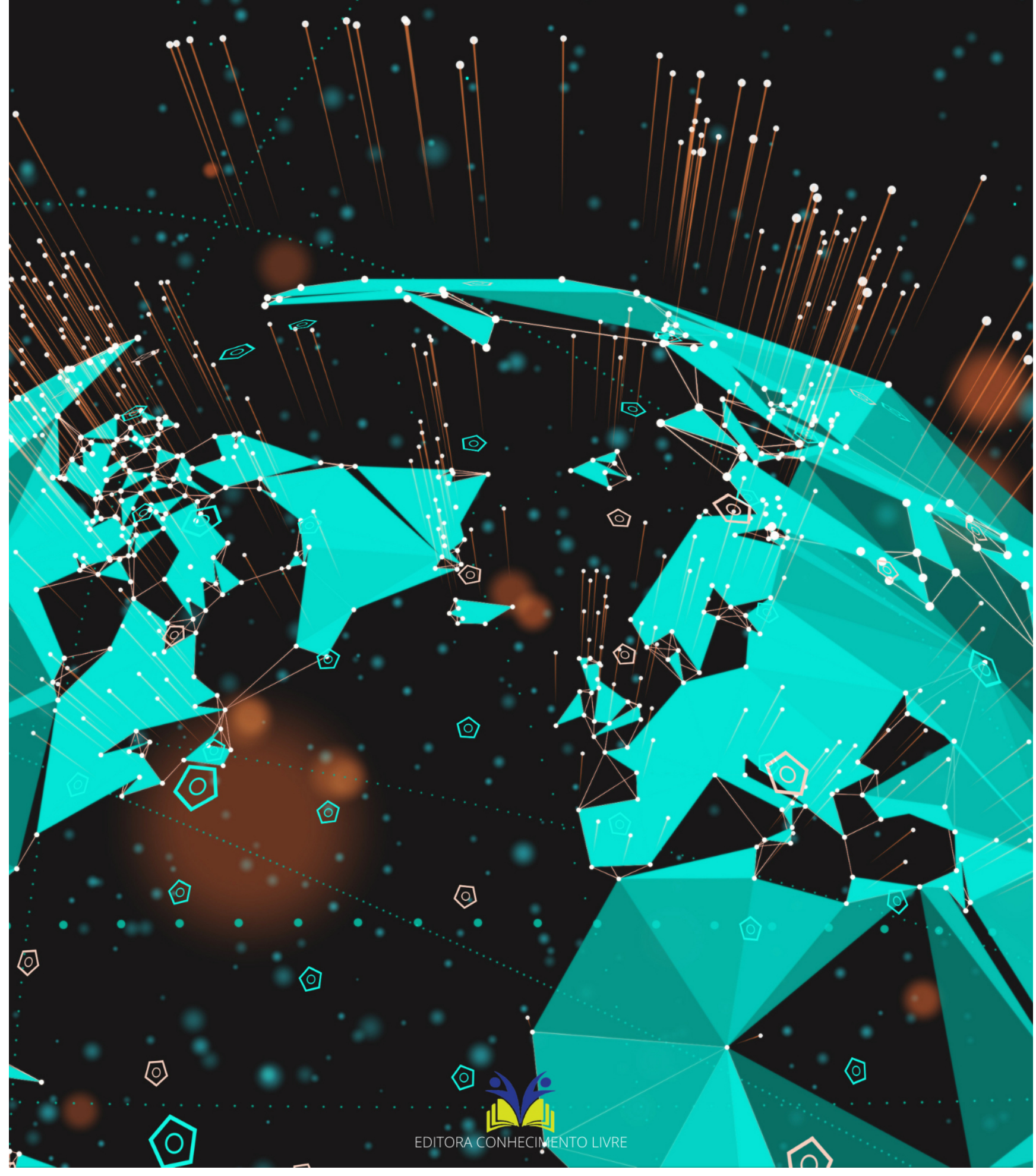


Frederico Celestino Barbosa

Ciências da Terra: princípios fundamentais

$1^{\text {a }}$ ed.

Piracanjuba-GO

Editora Conhecimento Livre

Piracanjuba-GO 
$1^{\mathrm{a}} \mathrm{ed}$

\section{Dados Internacionais de Catalogação na Publicação (CIP)}

Barbosa, Frederico Celestino
B238C Ciências da Terra: princípios fundamentais

/ Frederico Celestino Barbosa. - Piracanjuba-GO

Editora Conhecimento Livre, 2021

129 f.: il

DOI: $10.37423 / 2021$.edcl243

ISBN: 978-65-89145-97-4

Modo de acesso: World Wide Web

Incluir Bibliografia

1. rochas 2. geociências 3. atmosfera 4. placas-tectônicas 5. oceano I. Barbosa, Frederico Celestino

II. Título

CDU: 550

https://doi.org/10.37423/2021.edcl243

O conteúdo dos artigos e sua correção ortográfica são de responsabilidade exclusiva dos seus respectivos autores. 


\section{EDITORA CONHECIMENTO LIVRE}

\section{Corpo Editorial}

Dr. João Luís Ribeiro Ulhôa

Dra. Eyde Cristianne Saraiva-Bonatto

MSc. Anderson Reis de Sousa

$\underline{\text { MSc. Frederico Celestino Barbosa }}$

MSc. Carlos Eduardo de Oliveira Gontijo

MSc. Plínio Ferreira Pires

Editora Conhecimento Livre

Piracanjuba-GO 


\section{SUMÁRIO}

CAPÍTULO 1 6 PRODUÇÃO PISCÍCOLA ESCALONADA NO SEMIÁRIDO DO CEARÁ COM EXTERNALIDADES POSITIVAS.

Maria Enesia da Silva Neta

José de Jesus Sousa Lemos

José Newton Pires Reis

Sandra Maria dos Santos

DOI 10.37423/210504020

\section{CAPÍTULO 2}

INTERDISCIPLINAR - CONHECENDO A PERCEPÇÃO DE ALUNOS DE UMA ESCOLA PÚBLICA ACERCA DA EDUCAÇÃO AMBIENTAL E SUAS PROBLEMÁTICAS NO ENTORNO ESCOLAR.

Patrícia Rodrigues Pê

Fernanda Vieira Amorim

Neyliane Costa de Souza

Clébia Pereira de França

Márcia Ramos Luiz

Nubenia de Lima Tresena

Rosimary Ramos de Oliveira Mascaranhas

DOI 10.37423/210504022

\section{CAPÍTULO 3}

X-RAY DIFFRACTION STUDY OF 9-BROMO-3-(TRICHLOROMETHYL)-3,3A,4,5,6,7,8,9-

CTAHYDROCYCLOOCTA[C]ISOXAZOL-3-OL

Givanildo Santos da Silva

Mariano Alves Pereira

Luciana Almeida Piovesan

Rogério Felix Blanco

Alex Fabiani Claro Flores

Tatiane Luciano Balliano

DOI 10.37423/210504026

CAPÍTULO 4

CARACTERIZAÇÃO ESTRUTURAL E MORFOLÓGICA DE NANOPARTÍCULAS DE

FE/CO/MN:SNO2 PRODUZIDO POR UM MÉTODO SOL-GEL PROTEICO

Maurício de Sousa Pereira

DOI 10.37423/210504028 
LEVANTAMENTO DO ÍNDICE PLUVIOMÉTRICO DO TERRITÓRIO RURAL DO MÉDIO

PIRANHAS

Priscilla Gomes Barbosa

José Ronildo da Silva

Airton Gonçalves de Oliveira

Nivaldo Timóteo de Arruda Filho

João Pedro de Freitas Amandio

Emanoel Ferreira Cardoso

Adrielly Rodrigues de Sales

DOI 10.37423/210504041

CAPÍTULO 6

DIAGNÓSTICO DO PROCESSO DE REESTRUTURAÇÃO PRODUTIVA DAS FAMÍLIAS DE

REASSENTADOS DA USINA HIDRELÉTRICA DE IRAPÉ, MINAS GERAIS, BRASIL

Martionei Leite Gomes

Elida Elizena Carneiro de Matos

Nilton Fernandes de Oliveira

Adriano Campos Lemos

Amanda Cardoso de Oliveira Silveira Cassette

DOI 10.37423/210504044

CAPÍTULO 7

INSTRUMENTO DA OUTORGA COMO INDICADOR DA VARIAÇÃO INTERANUAL DE FONTES

HÍDRICAS

Lara Maria Oliveira Rabelo

Jeftha Amanda de Souza e Silva

Francisco Delfábio Teixeira de Oliveira

DOI 10.37423/210504051

CAPÍTULO 8

ANÁLISE DA PRECIPITAÇÃO PLUVIOMÉTRICA HISTÓRICA DO MUNICÍPIO DE PATOS-PB

Edgleidson Lima Rodrigues

Renato Francisco Cândido Lopes

Francisco de Assis Salviano de Sousa

DOI 10.37423/210504054 
ANÁLISE FLUVIOMÉTRICA DO RIO TAPAJÓS (1985-2015) COM BASE NA ESTAÇÃO

LOCALIZADA NA CIDADE DE SANTARÉM-PA

Fernanda Ravana Da Conceição Silva

Mateus Santos Pereira

William Lopes Pereira

Bernhard Gregor Peregovich

Wilderclay Barreto Machado

DOI 10.37423/210504077

CAPÍTULO 10

ESTIMATIVA DO BALANÇO HÍDRICO CLIMATOLÓGICO EM BACIA HIDROGRÁFICA COSTEIRA DA PARAÍBA

Vanda Maria de Lira

Carlos Alberto Vieira de Azevedo

Karla Luísa Feitosa de Lira

Délio Araújo Lopes

Thiago Pereira de Paiva Silva

DOI 10.37423/210504125

CAPÍTULO 11

AUTOMAÇÃO DA IRRIGAÇÃO DA HORTA UTILIZANDO ÁGUA DE POÇO ARTESIANO

Thiago de Santana Souza

Diego Lopes Coriolano

Denilson Pereira Gonçalves

DOI 10.37423/210504146 


\section{Capítulo 1}

doi $10.37423 / 210504020$

\section{PRODUÇÃO PISCÍCOLA ESCALONADA NO SEMIÁRIDO DO CEARÁ COM EXTERNALIDADES POSITIVAS.}

Maria Enesia da Silva Neta

José de Jesus Sousa Lemos

José Newton Pires Reis

Sandra Maria dos Santos
Secretaria do Desenvolvimento Agrário do Estado do Ceará

Universidade Federal do Ceará

Universidade Federal do Ceará

UniversidadefFederal do Ceará 
Resumo: O presente artigo avalia os efeitos da produção escalonada (produção de peixes e vísceras) de tilápia no Açude Castanhão, Jaguaribara, Ceará, no que concerne aos resultados econômicos e aos impactos ambientais. A pesquisa selecionou por sorteio aleatório 81 dos 300 piscicultores organizados em cooperativas ou não. Utilizou técnica de programação linear para minimizar os custos da produção escalonada trimestral de peixe e vísceras. Os resultados mostraram que é possível obter resultados econômicos satisfatórios se os agricultores adotarem o escalonamento encontrado na pesquisa. Adicionalmente a pesquisa mostra que a retirada e a venda em separado das vísceras para a produção de biodiesel, além de proporcionar renda adicional para os criadores, poupa o ambiente de contaminação considerável, tanto de águas de superfície, como de subsolo e ainda de contaminação terrestre.

Palavras-chave: Piscicultura; Eficiência Econômica; Externalidades ambientais positivas. 


\section{INTRODUÇÃO}

O Ceará é o estado brasileiro que detém, relativamente, a maior área e a maior população no semiárido atualmente reconhecido pelo Governo Federal. No total, 150 dos 184 municípios cearenses estão no Semiárido (MINTER, 2005). A instabilidade de produção provocada pelas condições climáticas se define como um importante fator que induz a emigração dos agricultores cearenses para cidades de médio e grande porte.

O governo cearense criou, no ano de 2004, um programa de piscicultura associativa em tanques rede, baseado na inserção de famílias de pescadores e produtores agrupados em organizações associativas e residentes nas proximidades dos açudes públicos Esses projetos têm múltiplos objetivos, dentre eles os de fomentar renda e ocupação, minimizando os riscos associados às dificuldades hídricas, tendo em vistas que nesses reservatórios se acumulam volumes consideráveis de água nos anos de boa precipitação pluviométrica e procede-se o seu uso racional em tempos de escassez, para que o recurso sempre fique disponível para os seus usos variados: humano, animais, irrigação e aquicultura, como se pratica no Açude Público Padre Cícero que é mais conhecido como Açude Castanhão, situado no município de Jaguaribara, Ceará (OLIVEIRA, 2008).

Os piscicultores do Açude Castanhão executam despescas quatro vezes ao ano, num intervalo de três meses. Isto permite um fluxo de rendas trimestral, quatro vezes ao ano, para as famílias envolvidas nas atividades. Contudo, os piscicultores ainda não dispõem de informações seguras que lhes possibilitem programar a sua produção trimestral, tendo em vistas que há variações dos custos dos insumos ao longo dos trimestres, bem como dos preços dos peixes, nas épocas das despescas. Além disso, aqueles sujeitos sociais não detêm ainda de forma quantificada o potencial econômico que representa a retirada das vísceras dos peixes, antes de vendê-los, e transformá-los em biodiesel. Até porque esta ainda não é uma prática usual. Atualmente, grande quantidade dessas vísceras tem destinos inadequados que provocam contaminação do meio ambiente, portanto externalidades negativas, quando poderiam ser transformadas em fontes de renda monetária e de preservação da qualidade do ambiente naquele município (SCITOVSKY, 1954). Além disso, depois de transformadas em biodiesel o resíduo é uma massa amorfa e inodora que os poucos piscicultores que já adotam a prática chamam de "borra". Esse resíduo é atualmente enterrado, mas avalia-se que pode se transformar em adubo orgânico, carecendo de estudos para que isso se torne viável. (COOPERATIVA DE PRODUTORES DO CURUPATI PEIXE LTDA, 2016). 
Este trabalho tem como objetivo geral estabelece um planejamento de produção e venda escalonados de tilápia (Oreochromis niloticus), com aproveitamento econômico das vísceras, para os piscicultores da Cooperativa Piscícola do Açude Castanhão no município de Jaguaribara, um dos municípios do Ceará inseridos no semiárido brasileiro.

Os objetivos específicos da pesquisa são:

a) a - identificar a alocação economicamente eficiente dos recursos, na perspectiva de produção com custo mínimo por piscicultor, com a produção escalonada de tilápia durante o ano no Açude Castanhão situado no município de Jaguaribara, semiárido cearense;

b) b - avaliar o resultado econômico potencial da venda em separado das vísceras dos peixes produzidos de forma escalonada para a transformação em biodiesel;

c) c - quantificar o montante de resíduos provenientes das vísceras dos peixes que não serão depositados no ambiente do açude e de suas adjacências, mediante a coleta e venda em separado das vísceras e a sua transformação em biodiesel;

d) d-simular de forma comparativa os potenciais resultados com o planejamento que se realiza neste estudo vis a vis a forma como é praticada atualmente a produção e a venda da tilápia no Açude Castanhão.

\section{METODOLOGIA}

A área de estudo desta pesquisa compreende as comunidades piscícolas, localizada no município de Jaguaribara, na região do Médio Jaguaribe, no semiárido cearense. O município dista $250 \mathrm{~km}$ da capital. A sua população é de 10.399 habitantes, sendo $7.212(69,4 \%)$ na zona urbana. A área do município é de 668,29 km² (IBGE, 2016).

Com a construção do Açude Castanhão, a cidade de Jaguaribara teve de ser deslocada para dar lugar a um espelho d'água de $325 \mathrm{~km} 2$. Ao analisar o Castanhão é observado que os projetos de piscicultura podem acarretar externalidades positivas e negativas. As positivas estão associadas à garantia da segurança alimentar, geração de renda e promoção da inclusão social. As externalidades negativas são os associados ao a degradação ambiental, como decorrência da colocação das vísceras dos peixes tratados à beira do açude ou em outros locais inadequados. 
Neste trabalho avaliou-se a possibilidade das vísceras dos peixes coletados pelos piscicultores das Cooperativas se transformarem em fonte de renda, porque podem ser convertidas em biodiesel e serem comercializadas nesse mercado. Para cada quilograma de peixe, aproximadamente 100 gramas são de vísceras. Essas vísceras, se processadas, se transformam em biodiesel a uma taxa de conversão de um para três. Os restantes dois terços desses resíduos processados se transformam numa borra inodora, rica em matéria orgânica que poderia ser utilizada como adubação orgânica em lavouras de hortaliças ou de fruteiras.

\subsection{MÉTODO ANALÍTICO}

O estudo usou dados primários e dados secundários. A natureza da pesquisa é do tipo estudo de caso: piscicultura praticada no Açude Castanhão no município de Jaguaribara, Ceará. Para fazer o levantamento dos dados primários foi realizada uma pesquisa de campo. Delimitou-se uma amostra estatística de tamanho " $n$ " pela equação:

$$
N \geq(z 2 \sigma 2) / d 2
$$

em que:

$z=$ abscissa da distribuição da normal padronizada, fixando um nível de confiança $\alpha ; \sigma=$ desvio padrão do custo associado à produção de tilápia no Açude Castanhão;

d = erro amostral que afere a máxima diferença permitida entre a média populacional e a média que se obtém com a amostra (FÁVERO et all, 2009; KADAM, BHALERAO, 2010).

Contudo, se a população de onde se extrairá a amostra for finita e de tamanho N, como é o caso do presente estudo, a equação (1) toma a forma definida na equação (2) como se depreende dos trabalhos de (COCHRAN, 1977; FÁVERO et all, 2009):

$$
\mathrm{n} \geq(\mathrm{z} 2 \sigma 2 . \mathrm{N}) /\{\mathrm{d} 2(\mathrm{~N}-1)+(\mathrm{z} 2 \sigma 2)\}
$$

\subsection{ALOCAÇÃO ECONÔMICA NA PRODUÇÃO PISCÍCOLA NO VALE DO JAGUARIBE}

Uma fonte de renda dos piscicultores, ainda não plenamente incorporada ao cotidiano da produção é a venda das vísceras para serem transformadas em biodiesel. Buscou-se investigar como seria a nova composição do portfólio anual de custo mínimo, estabelecendo-se limites mínimos para a renda bruta anual, dos piscicultores, caso adotassem a prática de retirar as vísceras e as vendessem em separado. 
No estudo foi utilizada como referência de renda buta mínima a ser auferida pelos piscicultores o valor de um salário mínimo mensal em $2014(\mathrm{R} \$ \mathrm{724,00})$ ou $\mathrm{R} \$$ 8.688,00 por ano. Como as vísceras representam aproximadamente $10 \%$ do peso vivo da tilápia, assume-se como valor a ser remunerado anualmente, como decorrência da venda separada dessas vísceras, uma renda mínima de pelo menos este percentual $(10 \%)$ do salário mínimo anualizado $(\mathrm{R} \$ 868,80)$ por família.

Assim, a programação de minimização de custos adotada nesta pesquisa estabelece dois padrões de remuneração mínima em produção escalonada trimestral. Para a criação de peixe, a remuneração

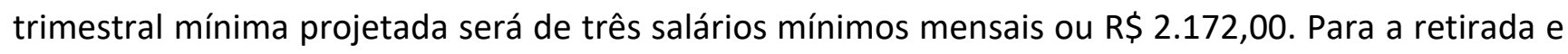
venda das vísceras se estabelece uma remuneração mínima por trimestre de $\mathrm{R} \$ 217,20$ ou dez por cento do salário mínimo trimestral.

Os custos envolvidos na produção de tilápia no Castanhão envolvem a compra de rações, medicamentos, vacinas, depreciação de gaiolas e remuneração de mão de obra quando contratada para alguns poucos serviços específicos, tendo em vistas que predomina a mão de obra familiar.

O modelo de programação linear (PL) utilizado na pesquisa consistiu em definir uma função-objetivo (Z) visando à obtenção de um plano ótimo de cultivo de custo mínimo, compatível com as necessidades mínimas de produção renda trimestral e anual dos piscicultores (LANZER. 1982; SCHULZE, 1998; GALE, 2007, TUTULMAZ, 2014).

Definem as seguintes variáveis de decisão

i) $X 1$ = produção de tilápia no primeiro trimestre; ii) $X 2$ = produção de tilápia no segundo trimestre; iii) X3 = produção de tilápia no terceiro trimestre; iv) X4 produção de tilápia no quarto trimestre.

Além disso, assume-se que os custos de produzir as vísceras separadamente estão associados às produções: Y1, Y2, Y3 e Y4, respectivamente para o primeiro, segundo, terceiro e quarto trimestre. As unidades de medidas dos peixes e das vísceras é o quilograma (kg).

Assume-se ainda custos unitários por quilograma de peixe produzido, ci $(i=1,2,3,4)$ para a produção de tilápia no primeiro, segundo, terceiro e quarto trimestre, respectivamente. Supõe-se ainda custos unitários por quilograma de vísceras de wj $(\mathrm{j}=1,2,3,4)$. Os custos unitários ci e wj são aferidos em reais (R\$) de 2014

Com base nestas informações elabora-se o programa de PL para a produção escalonada (trimestral) de tilápia e vísceras, mediante a minimização da seguinte função de custo total: 


$$
\text { Min.Zij }=\{(c 1 X 1+c 2 X 2+c 3 X 3+c 4 X 4)+(w 1 Y 1+w 2 Y 2+w 3 Y 3+w 4 Y 4)\}(3)
$$

Assume-se como pi $(i=1,2,3,4)$ o preço médio por quilograma da tilápia em despesca escalonada, respectivamente para o primeiro, segundo, terceiro e quarto trimestre. Define-se ainda $r j(j=1,2,3$, 4) como os preços médio do quilograma das vísceras na produção trimestral escalonada de tilápia, respectivamente para o primeiro, segundo, terceiro e quarto trimestre. Os preços de tilápia e das vísceras são aferidos em valores (R\$̦) de 2014. Com estas informações se estabelecem as seguintes restrições ao problema de $\mathrm{PL}$ :

i) Restrição de renda mínima associada à produção e despesca escalonada de tilápia: p1X1 +

$$
p 2 \times 2+p 3 X 3+p 4 \times X 4 \geq R \$ 8.688,00 .
$$

Na equação (4) o valor do lado direito é o salário mínimo anualizado.

ii) Restrição associada à retirada das vísceras para venda em separado: $r 1 Y 1+r 2 Y 2+r 3 Y 3+$

$$
\mathrm{r} 4 \mathrm{Y4} \geq \mathrm{R} \$ 868,80 \text {. (5) }
$$

Na equação (5) o total do lado direito representa dez por cento do valor anualizado do salário mínimo.

iii) Restrição associada à combinação da produção de tilápia e retirada das vísceras para venda em separado no primeiro trimestre:

$$
(p 1 X 1+r 1 Y 1) \geq R \$ 2.389,20 . \quad(6)
$$

Na equação (6) o valor do lado direito totaliza a receita mínima da venda de peixe no primeiro trimestre, equivalente a três salários mínimos $(R \$ 2.172,00)$, acrescido da renda proveniente da venda das vísceras, que equivale a dez por cento deste montante $(R \$ 271,20)$. Estes também foram os limites inferiores de restrição de renda para os lados direitos das restrições representadas pelas equações (7), (8) e (9).

iv) Restrição associada à combinação da produção de tilápia e retirada das vísceras para venda em separado no segundo trimestre:

$$
(p 2 X 2+r 2 Y 2) \geq R \$ 2.389,20 . \quad(7)
$$

v) Restrição associada à combinação da produção de tilápia e retirada das vísceras para venda em separado no terceiro trimestre:

$$
(p 3 X 3+r 3 Y 3) \geq R \$ 2.389,20 \text {. }
$$


vi) Restrição associada à combinação da produção de tilápia e retirada das vísceras para venda em separado no quarto trimestre:

$$
(p 4 X 4+r 4 Y 4) \geq R \$ 2.389,20 \text {. (9) }
$$

vii) Restrição associada à produção mínima trimestral de peixes:

$$
X i \geq, X i \geq 440,00 \mathrm{~kg} \text { em que } i=1,2,3,4 \text {. }
$$

Neste caso a quantidade mínima estabelecida para a produção de peixe foi estimada considerando que o preço médio observado na pesquisa de campo na venda da tilápia foi de $\mathrm{R} \$ 4,94 / \mathrm{Kg}$.

viii) Restrição associada à produção mínima trimestral de vísceras:

$$
Y j \geq 0, Y j \geq 44,00 \text {, em que } j=1,2,3,4 \text {. (11) }
$$

\section{RESULTADOS E DISCUSSÃO}

A pesquisa de campo foi realizada no ano de 2014. Aquele foi um ano de seca no Ceará em que o Açude Castanhão já se encontrava com um armazenamento de água bastante aquém da sua capacidade máxima de 7,5 bilhões de metros cúbicos. Em abril daquele ano o açude acumulava somente 2,5 bilhões de metros cúbicos, que representava apenas $37,0 \%$ da sua capacidade de armazenamento (PEREIRA et al, 2014).

Das 300 famílias que estavam envolvidas nas atividades no ano de 2014 selecionaram-se, aleatoriamente, 81 . Saíram também dos piscicultores componentes desta amostra as informações dos preços por quilograma de peixe vendido que irão fazer parte das restrições associadas ao problema PL utilizado no estudo. O nível fiducial da pesquisa é de $95 \%$ e o desvio "d" é de $3 \%$.

Para realizar o manejo na produção da tilápia são utilizados no sistema de tanque- rede, materiais e equipamentos, tais como: balanças, puçás, baldes, balaios, engradados, kit de análise de água, termômetro, oxímetro, pHmetro, disco de secchi, freezer, cordas, arames, facas, computador (uso no escritório da Cooperativa). Outros equipamentos utilizados são: balsas de apoio; Caiaques e/ou canoas (muitas necessárias a utilização de pequenos motores conhecidos pelos piscicultores como "rabetas"); ainda tem as estruturas de flutuação, amarração e delimitação do cultivo (Pesquisa de Campo, 2015). A comercialização do pescado é feita de forma direta "in natura". Os principais compradores são restaurantes locais e empresas de Fortaleza. O preço médio trimestral, por quilo de peixe, varia de R\$ 4,81 a R\$ 5,15 (Pesquisa de Campo, 2015). 


\subsection{PERFIL DOS PISCICULTORES QUE FORAM PESQUISADOS NO AÇUDE CASTANHÃO.}

A média de idade dos piscicultores é de 44,3 anos, sendo que o mais jovem possuía 25 anos e o mais idoso tinha 80 anos na época da pesquisa. A faixa etária modal ficou entre 25 e 40 anos (51,9\%). Este fato demonstra que a maioria dos piscicultores entrevistados são considerados jovens-adultos. No total os 81 piscicultores utilizaram 1255 tanques redes proporcionando uma média de 16 por piscicultor. A dimensão de cada tanque rede é de três metros de largura, três de comprimento e dois de profundidade.

\subsection{MINIMIZAÇÃO DOS CUSTOS DE PRODUÇÃO PISCÍCOLA NO AÇUDE CASTANHÃO.}

Os coeficientes técnicos associados aos custos e venda de quilograma produzidos de tilápia e vísceras estão mostrados na Tabela 1

Tabela 1: Variáveis de Decisão e Custos Unitários por Trimestre da Tilápia e das Vísceras produzidas no Açude Castanhão em 2014.

\begin{tabular}{l|c|c|c|c|c|c|c|c|}
\hline & \multicolumn{8}{|c|}{ Variáveis de Decisão } \\
\cline { 2 - 9 } & $\mathrm{X}_{1}$ & $\mathrm{X}_{2}$ & $\mathrm{X}_{3}$ & $\mathrm{X}_{4}$ & $\mathrm{Y}_{1}$ & $\mathrm{Y}_{2}$ & $\mathrm{Y}_{3}$ & $\mathrm{Y}_{4}$ \\
\hline $\begin{array}{l}\text { Custos } \\
\begin{array}{l}\text { Unitários } \\
(\mathrm{R} \$)\end{array}\end{array}$ & 3,57 & 3,82 & 3,81 & 3,64 & 3,57 & 3,82 & 3,81 & 3,64 \\
\hline
\end{tabular}

Fonte: Resultados encontrados a partir dos dados da pesquisa de campo.

Na Tabela 2 apresenta-se a matriz dos coeficientes técnicos (preços $/ \mathrm{kg}$ ) associados às restrições do PL. Ainda na Tabela 2 apresentam-se os limites inferiores de cada uma das restrições (lado direito de cada uma delas). 
Tabela 2: Matriz dos coeficientes técnicos (preços / Kg) da tilápia e das vísceras, e valores mínimos associados a cada uma das restrições impostas pelo PL. Coeficientes técnicos (preço por Kg vendido)

\begin{tabular}{|c|c|c|c|c|c|c|c|c|c|}
\hline & \multicolumn{7}{|c|}{ Variáveis de Decisão } & & \\
\cline { 2 - 8 } Restrições & $\mathrm{X}_{1}$ & $\mathrm{X}_{2}$ & $\mathrm{X}_{3}$ & $\mathrm{X}_{4}$ & $\mathrm{Y}_{1}$ & $\mathrm{Y}_{2}$ & $\mathrm{Y}_{3}$ & $\mathrm{Y}_{4}$ & $\begin{array}{c}\text { Limite } \\
\text { Inferior } \\
(\geq)\end{array}$ \\
\hline 1 & 4,81 & 5,15 & 5,14 & 4,91 & 0 & 0 & 0 & 0 & 8688,00 \\
2 & 0 & 0 & 0 & 0 & 4,81 & 5,15 & 5,14 & 4,91 & 868,80 \\
3 & 4,81 & 0 & 0 & 0 & 4,81 & 0 & 0 & 0 & 2389,20 \\
4 & 0 & 5,15 & 0 & 0 & 0 & 5,15 & 0 & 0 & 2389,20 \\
5 & 0 & 0 & 5,14 & 0 & 0 & 0 & 5,14 & 0 & 2389,20 \\
6 & 0 & 0 & 0 & 4,91 & 0 & 0 & 0 & 4,91 & 289,20 \\
7 & 1 & 0 & 0 & 0 & 0 & 0 & 0 & 0 & 440,00 \\
8 & 0 & 1 & 0 & 0 & 0 & 0 & 0 & 0 & 440,00 \\
9 & 0 & 0 & 1 & 0 & 0 & 0 & 0 & 0 & 440,00 \\
10 & 0 & 0 & 0 & 1 & 0 & 0 & 0 & 0 & 440,00 \\
11 & 0 & 0 & 0 & 0 & 1 & 0 & 0 & 0 & 44,00 \\
12 & 0 & 0 & 0 & 0 & 0 & 1 & 0 & 0 & 44,00 \\
13 & 0 & 0 & 0 & 0 & 0 & 0 & 1 & 0 & 44,00 \\
14 & 0 & 0 & 0 & 0 & 0 & 0 & 0 & 1 & 44,00 \\
\hline
\end{tabular}

Os resultados encontrados com modelo de PL utilizado estão apresentados na Tabela 3. Estas evidências sugerem que, se o objetivo dos criadores de tilápia for produzir de forma escalonada com as despescas acontecendo a cada três meses, retirando as vísceras para venda em separado, a combinação média ideal é produzir 451,56 quilogramas de peixe no primeiro trimestre; 455,15 quilogramas peixe no segundo trimestre; 591,60 quilogramas de peixe no terceiro trimestre e 442,36 quilogramas de peixe no quarto trimestre.

A produção de vísceras se distribui da seguinte forma: 45,16 quilogramas no primeiro trimestre; 45,52 quilogramas no segundo trimestre; 59,16 quilogramas no terceiro trimestre e 44,24 quilogramas no quarto trimestre. Nas condições em que é praticada a produção de tilápia no açude Castanhão por aquele grupo de piscicultores o custo mínimo anual, por cooperado, em valores de 2014, seria de R\$7.286,89 (Tabela 3). 
Tabela 3 - Resultados encontrados na Programação de Produção Escalonada de Tilápia e Vísceras no Açude Castanhão.

\begin{tabular}{cccc}
\hline Variável de Decisão & $\begin{array}{c}\text { Produção Ideal } \\
(\mathrm{Kg} / \text { Trim Familia })\end{array}$ & $\begin{array}{c}\text { Coeficientes } \\
\text { Técnicos }\end{array}$ & $\begin{array}{c}\text { Custo mínimo } \\
\text { trimestral } \\
(\mathrm{R} \$)\end{array}$ \\
\hline $\mathrm{X}_{1}$ & 451,56 & 3,57 & 1612,07 \\
$\mathrm{X}_{2}$ & 455,15 & 3,82 & 1738,67 \\
$\mathrm{X}_{3}$ & 591,60 & 3,81 & 2254,00 \\
$\mathrm{X}_{4}$ & 442,36 & 3,64 & 1610,19 \\
$\mathrm{Y}_{1}$ & 45,16 & 3,57 & 16,26 \\
$\mathrm{Y}_{2}$ & 45,52 & 3,82 & 17,30 \\
& & & \\
$\mathrm{Y}_{3}$ & 59,16 & & 22,48 \\
$\mathrm{Y}_{4}$ & 44,24 & 3,81 & 15,93 \\
\hline \multicolumn{2}{c}{ Custo Mínimo Anual Projetado } & 3,64 & $7.286,89$ \\
\hline
\end{tabular}

Fonte: Resultados encontrados a partir dos dados da pesquisa de campo.

Na Tabela 4 estão apresentados os resultados encontrados para os valores projetados com as restrições de rendas e os valores alcançados como decorrência da proposta de otimização de alocação de recursos desta pesquisa. Observa-se que se a produção e venda for apenas dos peixes (primeira restrição) a renda alcançada em produção escalonada seria de $\mathrm{R} \$$ 9.728,24.

Na segunda restrição apresenta-se o que seria o resultado da receita com a venda das vísceras, que proporcionaria a renda anual de $\mathrm{R} \$ 972,95$. Somando-se as duas rendas observa-se que o total anual potencial da venda de peixes com vísceras seria de $\mathrm{R} \$ 10.702 .39$. (Tabela 4).

Tabela 4: Receitas mínimas programadas, alcançadas e folga em relação ao mínimo planejado

\begin{tabular}{|c|c|c|c|c|}
\hline $\begin{array}{c}\text { Restrições } \\
(1)\end{array}$ & $\begin{array}{c}\text { Valor mínimo } \\
\text { programado } \\
(\mathrm{R} \$)\end{array}$ & $\begin{array}{c}\text { Valor alcançado } \\
\text { na pesquisa } \\
(\mathrm{R} \$)\end{array}$ & $\begin{array}{c}\text { Folga } \\
(\mathrm{R} \$)\end{array}$ & $\begin{array}{c}\text { Acréscimo percentual do } \\
\text { valor alcançado em } \\
\text { relação ao mínimo } \\
\text { programado } \\
(4) /(2) * 100\end{array}$ \\
\hline Primeira & 8688,00 & 9728,24 & 1040,24 & 12,0 \\
Segunda & 868,80 & 972,95 & 104,15 & 12,0 \\
Terceira & 2389,20 & 2389,82 & 0,62 & 0,0 \\
Quarta & 2389,20 & 2578,45 & 189,25 & 7,9 \\
Quinta & 2389,20 & 3344,91 & 955,71 & 40,0 \\
Sexta & 289,20 & 289,21 & 0,01 & 0,0 \\
\hline
\end{tabular}

Fonte: Resultados encontrados a partir dos dados da pesquisa de campo. 
Os resultados alcançados na pesquisa e mostrados na Tabela 4 sugerem que todas as restrições de renda mínima foram atendidas. E confirmam que a produção de peixes com a retirada das vísceras para venda em separado pode ser uma alternativa econômica importante para os piscicultores que trabalham no Açude Castanhão (Tabela 4).

\subsection{POTENCIALIDADES DA PROGRAMAÇÃO EFETUADA EM PRESERVAR O AMBIENTE.}

Os resultados decorrentes do potencial de produção de tilápia no Açude Castanhão, sem contaminar o seu espelho d'água, as suas margens ou as áreas adjacentes parecem se constituir numa das grandes conquistas e contribuições deste trabalho. Este trabalho tenta mostrar que há a possibilidade de ser encontrado um destino mais nobre para essas vísceras que ainda podem prover renda monetária para os piscicultores. São estes resultados potenciais que estão mostrados na Tabela 5.

Das evidencias mostradas na Tabela 5 depreende-se que, dentro da programação estabelecida nesta pesquisa a produção anual de peixe das 300 famílias envolvidas seria de 582,2 toneladas, distribuídos assim: 135,5 toneladas no primeiro trimestre; 136,5 toneladas no segundo; 177,5 toneladas no terceiro; e 132,7 toneladas no quarto trimestre.

A produção total de vísceras seria de 58,22 toneladas que, na forma em que a produção e a venda são atualmente processadas, praticamente iria ser depositada em valas, enterradas, colocadas nas margens do Açude ou em algum outro local inadequado.

Tabela 5: Quantidades produzidas de peixes, vísceras, biodiesel e resíduos (borra) pelos piscicultores do Açude Castanhão de acordo com a Programação efetuada na pesquisa.

\begin{tabular}{|c|c|c|c|c|c|c|}
\hline Trin & $\begin{array}{l}\text { Quantidade } \\
\text { produzida } \\
\text { de Peixe } \\
\text { por família } \\
(\mathrm{Kg})\end{array}$ & $\begin{array}{l}\text { Quantidade } \\
\text { total de } \\
\text { peixe } \\
\text { produzia } \\
\text { nos } 300 \\
\text { produtores } \\
(\mathrm{Kg})\end{array}$ & $\begin{array}{c}\text { Produção } \\
\text { de Peixe } \\
\text { por } \\
\text { Tanque } \\
\text { (Kg/Tan- } \\
\text { que) }\end{array}$ & $\begin{array}{l}\text { Quantidade } \\
\text { total de } \\
\text { vísceras } \\
\text { produzida } \\
\text { pelos } 300 \\
\text { produtores } \\
(\mathrm{Kg})\end{array}$ & $\begin{array}{l}\text { Quantidade } \\
\text { total de } \\
\text { Biodiesel } \\
\text { que seria } \\
\text { produzido } \\
\text { pelas } 300 \\
\text { famílias } \\
\text { (Litros) }\end{array}$ & $\begin{array}{l}\text { Quantidade } \\
\text { Total de } \\
\text { resíduo } \\
\text { (borra) } \\
\text { produzido } \\
\text { pelas 300 } \\
\text { famílias } \\
(\mathrm{Kg})\end{array}$ \\
\hline Primeiro & 451,56 & 135468,00 & 107,9 & 13546,80 & 4515,60 & 9031,20 \\
\hline Segundo & 455,15 & 136545,00 & 108,8 & 13654,50 & 4551,50 & 9103,00 \\
\hline Terceiro & 591,60 & 177480,00 & 141,4 & 17748,00 & 5916,00 & 11832,00 \\
\hline Quarto & 442,36 & 132708,00 & 105,7 & 13270,80 & 4423,60 & 8847,20 \\
\hline TOTAIS & 1940,67 & 582201,00 & 463,9 & 58220,10 & 19406,70 & 38813,40 \\
\hline
\end{tabular}

Fonte: Resultados encontrados a partir dos dados da pesquisa de campo. 
Na programação feita na pesquisa, essas vísceras se transformariam em 19.406,70 litros de biodiesel que seriam fontes adicionais relevantes de renda para as 300 famílias. Do processamento das vísceras para serem transformadas em biodiesel sobraria um resíduo não poluente, conhecido como "borra" num total de 38,8 toneladas. Os poucos piscicultores que já trabalham nesta perspectiva informaram que atualmente essa borra é enterrada, mas tem potencial para ser usada como adubo orgânico. Para tanto precisa ser analisada em laboratório especializado.

\section{CONSIDERAÇÕES FINAIS}

A pesquisa mostrou que a produção escalonada de peixes no Açude Castanha tem um potencial relevante de formatação de renda mais promissora para os criadores de tilápia no Açude. Essa alternativa desnudada na pesquisa sugere que, se em vez de venderem os peixes da forma que são coletados, extraírem as vísceras e as venderem separadas, podem usufruir renda adicional não desprezível.

Considerando a forma como atualmente é praticada a piscicultura no Açude Castanhão, e a produção potencial segundo a programação efetuada nesta pesquisa, iria gerar para as 300 famílias envolvidas um total de 19406,70 quilogramas de vísceras que seriam depositadas em valas, enterradas, ao ar livre, ou nas margens do açude, ou em outra alternativa inadequada. Em qualquer uma dessas formas com evidentes externalidades ambientais negativas.

Seguindo a programação efetuada nesta pesquisa as vísceras coletadas antes da venda dos peixes produziriam 19.406,70 litros de biodiesel. Sobraria um resíduo inodoro chamado de "borra" que pode ser avaliada a sua capacidade de ser transformado em ração para aves ou adubação orgânica. Em qualquer uma dessas alternativas, além de poupar o ambiente de contaminação, ainda seria responsável por fonte adicional de renda. A programação efetuada na pesquisa geraria zero de externalidade negativa. 


\section{REFERÊNCIAS}

CARVALHO, O. Nordeste semiárido: transformação de potencialidades em possibilidades econômicas. IN: Semiárido. Brasilia. Câmara dos Deputados. 2010. P. 143-176.

COCHRAN, W. G. Sampling techniques New York: John Wiley \& Sons . 3rd ed. 1977. COOPERATIVA DE PRODUTORES DO CURUPATI PEIXE LTDA, Piscicultura no Açude Castanhão. Jaguariabara, Ceará. 2016 (Manuscrito n.p.).

FÁVERO, L.P.; BELFIORE, P.; SILVA, F.L.; CHAN, B.L. Análise de dados: modelagem multivariada para tomada de decisões. São Paulo, SP. Campus. 2009.

<https://www.econstor.eu/bitstream/10419/63141/1/323440673.pdf>. Acesso em 13. jul. 2016

GALE, D. Linear Programming and the Simplex Method. Notices of the AMS. Volume 54, Number 3. March, 2007. Disponivel em: <http://www.ams.org/notices/200703/fea-gale.pdf.>. Acesso em 13. jul. 2016

KADAM, P.; BHALERAO, S. Sample size calculation. International Journal of Ayurveda Research. Volume 1. Jan-Mar, 2010. Disponivel em:

<http://www.ncbi.nlm.nih.gov/pmc/articles/PMC2876926/>. Acesso em 13 jul. 2016.

LANZER, E. Programação Linear: Conceitos e Aplicações. Rio de Janeiro. Instituto de Planejamento Econômico Social-IPEA. 1982.

MINTER: MINISTÉRIO DA INTEGRAÇÃO NACIONAL. Nova delimitação do Semiárido brasileiro. Secretaria de Políticas de Desenvolvimento Regional, Brasília: mar. 2005.

OLIVEIRA, G. G. Políticas públicas para a aqüicultura no Estado do Ceará: uma comparação dos governos estaduais de 1998 a 2008. 2008, 85p. Dissertação (Mestrado em Engenharia de Pesca), Universidade Federal do Ceará.

PAGE JR, J.M. Technical Efficiency and Economic Performance: Some Evidence from Ghana. Oxford Economic Papers. New Series, Vol. 32, No. 2 (Jul., 1980), pp. 319-339. Disponivel em: http://www.jstor.org/stable/2662688?origin=JSTOR- pdf\&seq=1\#page_scan_tab_contents. Consulta em 20/07/2016.

PEREIRA, F.A.C., LUNA, R.M., STUDART, T.M.C., ROCHA, J.T., CYSNE, A.P. Complexo Industrial e Portuário do Pecém (Ce): Diagnóstico E Perspectivas Do Seu Sistema Hídrico. In: XII Simpósio de Recursos Hidrícos do Nordeste. Natal, RN.

4-7 de novembro de 2014. Disponível em:

http://www.abrh.org.br/xiisrhn/anais/papers/PAP018444.pdf. Consulta em 15/0/2016.

SCHULZE, M.A. Linear programming for otimization. Perspective Scientific Instruments, Inc. 1998. Disponível em: <https://www.markschulze.net/LinearProgramming.pdf>. Acesso em 14 jul. 2016. 
SCITOVSKY, T. Two concepts of external economies. The Journal of Political Economy. Vol 62; №2. P. 143-151. 1954. Disponivel em: http://www.colorado.edu/economics/morey/externalitylit/scitovskyjpe1954.pdf. Consulta em 19/07/2016.

SIPAÚBA-TAVARES, L. H. S. Limnologia aplicada à aquicultura. Jaboticabal: FUNEP. 1995. 70 pag.

TUTULMAZ, O. The Relationship of Technical Efficiency with Economical or Allocative Efficiency: An Evaluation. Quest Journals Journal of Research in Business and Management Vol. 2 № 9. pp: 01-12. 2014. 


\section{Capitulo 2}

doi) $10.37423 / 210504022$

INTERDISCIPLINAR - CONHECENDO A PERCEPÇÃO DE ALUNOS DE UMA ESCOLA PÚBLICA ACERCA DA EDUCAÇÃO AMBIENTAL E SUAS PROBLEMÁTICAS NO ENTORNO ESCOLAR.

Patrícia Rodrigues Pê

Fernanda Vieira Amorim

Neyliane Costa de Souza

Clébia Pereira de França

Márcia Ramos Luiz

Nubenia de Lima Tresena

Rosimary Ramos de Oliveira Mascaranhas
Universidade Federal de Campina Grande

Universidade Federal de Pernambuco

Universidade Federal do Ceará

Universidade/Federal de Campina Grande

Universidade Federal de Campina Grande

Universidade Federal de Campina Grande

Universidade Federal de Pernambuco 
Resumo: As práticas ambientais são consideradas fundamentais para o desenvolvimento de uma comunidade que quer adotar uma postura interdisciplinar no processo educativo. Contudo, a Educação Ambiental necessita ser reconhecida como prática efetiva, alcançando o mesmo status das disciplinas ditas científicas. Desse modo, objetivou-se com este estudo discutir os saberes sobre a questão ambiental dentro do espaço escolar, como processo de contribuição de todos que compõem a Instituição promovendo conhecimentos e articulando ações promissoras para o meio ambiente. A pesquisa baseou-se nos princípios da pesquisa participante e foi realizada em uma escola pública no estado da Paraíba e contou com um universo de 20 alunos do ensino médio em Fevereiro de 2018. Conclui-se a partir dos resultados obtidos que o desenvolvimento de um trabalho em Educação Ambiental dentro do contexto da prática pedagógica ajuda os alunos a construírem uma consciência global das questões relativas ao meio ambiente, ao mesmo tempo em que assume posições afinadas com os valores referentes à sua proteção e melhoria, mediante ações coletivas.

Palavras-chave: Meio Ambiente, Ensino, Interdisciplinaridade. 


\section{INTRODUÇÃO}

As práticas ambientais são consideradas fundamentais para o desenvolvimento de uma comunidade, que procura preservar o meio ambiente. Nesse contexto, é extremamente importante, implantá-las nas comunidades, demonstrando aspectos positivos e benéficos provenientes da Educação Ambiental (EA), em relação ao modelo de desenvolvimento adotado pela sociedade.

A Educação Ambiental como tema transversal exige uma postura interdisciplinar no processo educativo. Porém Locatelli e Hendges (2005) alertam que a Educação Ambiental nas escolas tem sido confundida com ações pontuais em resposta ao que a sociedade espera da escola, ou seja, o currículo escolar precisa se adequar para que a Educação Ambiental deixe de ser um conteúdo aplicado, apenas em datas comemorativas ou em projetos de curto prazo, mas que se efetive como prática permanente na escola e alcance o mesmo status das disciplinas ditas científicas.

Como educador, deve-se contribuir para a formação de uma geração consciente em relação ao seu papel como cidadão voltado para uma valoração ética, social, econômica e ambiental, além de pensar numa escola que promova esse aprendizado, a fim de se ensinar a importância de atitudes de preservação.

De acordo com BRASIL (2001), de todo modo, os recursos naturais e o próprio ambiente tornam-se uma prioridade, um dos componentes mais importantes para [...] as políticas econômicas e ambientais em cada parte do mundo.

Assim, o presente trabalho tem como questionamento: como se fazer compreender dentro das condições concretas das escolas, que crianças, adolescentes e jovens percebam e entendam as consequências ambientais de suas ações no espaço em que vivem? Enquanto aluno, ele sabe diferenciar o Meio Ambiente de Educação Ambiental? Para aluno e professor, a responsabilidade quanto ao ato de preservar tem delimitação de tempo definido?

Desse modo, este trabalho se justifica pela necessidade em se discutir os saberes sobre a questão ambiental dentro do espaço escolar, como processo de contribuição de todos que compõem a Instituição promovendo conhecimentos e articulando ações promissoras para o meio ambiente. Como também, para a formação dos alunos que se espera sair com um novo estímulo de ações concretas para uso coletivo, seja desenvolver atitudes em prol da sociedade, do profissionalismo, no seio familiar e também na parte humana como um todo. 


\section{METODOLOGIA}

A pesquisa foi realizada em uma escola pública no estado da Paraíba. A pesquisa contou com um universo de 20 alunos do ensino médio em Fevereiro de 2018.

O presente trabalho baseou-se nos princípios da pesquisa participante, que é realizada dentro de um espaço de interlocução onde os atores implicados participam na identificação e na resolução dos problemas, com conhecimentos diferenciados (THIOLLENT; SILVA, 2007).

Nessa concepção, procura-se um entendimento da visão de todos os participantes, com relação ao nível de consciência e envolvimento escolar no cuidado ambiental, buscando sugestões no que concernem as propostas de melhorias aos desafios enfrentados, isto é, mudanças comportamentais dos envolvidos.

O critério seguido para a coleta de dados se deu com base na coleta de registros no âmbito escolar, dos quais os participantes foram abordados e convidados a participar da pesquisa, recebendo uma numeração consecutiva, como apresentado em

Martins e Domingues (2011).

\section{DESENVOLVIMENTO}

A temática socioambiental abrange uma série de questões de ordem política, econômica, cultural e social não apenas ecológica. Por conseguinte, para se alcançar uma mudança de hábitos na sociedade é preciso sensibilizar as pessoas dos problemas socioambientais em seu caráter multidisciplinar e pluralista. A prática da educação ambiental nas escolas pode ser considerada uma das formas mais eficientes para a conquista de uma sociedade sustentável, pois é no âmbito educacional que o ser humano desperta para questões de perspectivas futuras.

De acordo com Franco (2014), do ponto de vista das propostas e ações de formação de professores, e por analogia, aos profissionais do magistério que atuam em atividades de suporte pedagógico (coordenação, assessoramento, planejamento, administração, supervisão ou orientação educacional) existem especificidades inerentes a essa área que, possibilitam resultados diferenciados quando da atuação nas escolas e nos sistemas de educação.

Guimarães (2007) e Bonatto et al. (2012) apontam que a construção do conhecimento sobre os conteúdos escolares é influenciada pelo meio ambiente, pelos meios de comunicação, por professores e colegas. O professor deve lançar problemas atuais, além dos tradicionais, explorar mais como usar 
símbolos, ideias, imagens que reflitam a realidade, não partindo necessariamente de um projeto científico. Pode por exemplo, ser incorporada no plano de trabalho dos professores de modo contínuo; pode ser realizada por um professor que atua em uma só disciplina ou por aquele que dá mais uma, dentro da mesma área ou não; pode finalmente, ser objeto de um projeto, com um planejamento específico, envolvendo dois ou mais professores, com tempos e espaços próprios.

Todavia Chizzotti (2006) explica que existem no ensino interdisciplinar relativo à Educação Ambiental dificuldades de submeter uma experimentação, isto é, na adoção de um método de comprovação de conhecimentos. São, pois essas dificuldades que devem provocar os objetos de pesquisa que são maiores em ciências humanas e sociais porque estas analisam fenômenos coletivos, como ocorre em Sociologia, na Economia e na Demografia. Desse modo, o aprendizado do educando se apóia no pressuposto de que os conhecimentos opinativos ou intuitivos e as afirmações genéricas sejam substituídas por conhecimentos rigorosamente articulados, submetidos ao controle de verificação empírica e comprovados por meio de técnicas precisas de controle.

Araruna (2009) disse que embora o "conjunto escolar" (professores, alunos, diretores) saiba da importância da Educação Ambiental, ainda existe uma tímida preocupação por parte dessas escolas em trabalhar esses temas, de transformar os estudantes em cidadãos conscientes dos problemas ambientais e de utilizar mais a interdisciplinaridade em projetos e buscar colocá-los na prática cotidiana.

Costa (2011) diz que em se tratando de educação ambiental, sabemos que os currículos das disciplinas tradicionais, da forma como vem sendo desenvolvidos, oferecem ao aluno apenas um acúmulo de informações pouco ou nada relevantes para sua vida profissional, principalmente porque o desenvolvimento tecnológico atual é de tal diversidade que se torna impossível processar, com a velocidade adequada, a esperada sistematização que a escola requer. Em se tratando da temática Educação Ambiental, é um tema que deve ser obrigatoriamente abordado nas escolas, é interdisciplinar, podendo perpassar em todas as disciplinas, pois o aprendizado está fundamentado na interdisciplinaridade e todas as matérias podem ser desenvolvidas na Educação Ambiental, ou viceversa.

Bonatto et al. (2012) salienta sobre a importância da interdisciplinaridade que pode integrar-se em outras áreas específicas, com o propósito de promover uma interação entre o aluno, o professor e o cotidiano, pois nos dias de hoje podemos considerar as ciências naturais como uma das mais diversas em função de seus vários campos de trabalho. 
Segundo Garrido e Meirelles (2014), as pesquisas mostram que os indivíduos percebem e reagem diferentemente às ações sobre o ambiente em que vivem. As respostas são resultados das percepções (individuais e coletivas) dos processos cognitivos, julgamentos e expectativas de cada pessoa, influenciadas também por elementos culturais. Estes estudos como apontam Vasco e Zakrzevski (2010) são importantes para compreender as interrelações entre homem e ambiente, suas expectativas, anseios, satisfações e insatisfações, julgamentos e condutas em relação ao espaço onde está inserido.

A interdisciplinaridade para Bonatto et al. (2012) é uma proposta que visa superar a fragmentação do conhecimento científico, em que conhecimentos se interrelacionam por conhecimentos diversificados, no entorno da realidade da comunidade ao qual o aluno está envolvido e assim, se busca instruir a nova prática curricular, produzindo uma nova ambiência social na qual os conhecimentos das ciências venham a fazer parte de novas formas de interlocução, interpretação e ação, valorizando relações com o dia-a-dia fora da escola através de saberes sistematicamente enriquecido de novos discursos, olhares e vozes com novas formas de pensamento e ação articuladas numa perspectiva transformadora de culturas diversificadas.

Em cima dessas discussões e desses pontos de vista, Araruna (2009) enfatiza que a interdisciplinaridade é necessária para a educação ambiental que incorpora a perspectiva dos sujeitos sociais e permite estabelecer uma prática pedagógica contextualizada, crítica, que explica os problemas estruturais de nossa sociedade, as causas do baixo padrão qualitativo da vida que levamos e da utilização do patrimônio natural como mercadoria e uma externalidade em relação a nós. É por meio da atuação coletiva e individual, intervindo no funcionamento excludente e desigual das economias capitalistas, que os grupos sociais hoje vulneráveis podem ampliar a democracia e a cidadania.

A Educação Ambiental se apresenta como aliada nesse contexto por promover junto dos educadores, com o apoio das leis e documentos que validam sua ação educadora, a oportunidade de educar e incentivar mudanças que contribuam para uma vida sustentável. A relevância educacional e socioambiental que o tema possui proporciona uma abordagem interdisciplinar, tanto na teoria quanto na prática.

Nesse interim este trabalho utilizou-se de questionários de caráter quali-quantitativo aplicados a alunos que abordaram as relações e inter-relações dos fenômenos naturais e sociais, a utilização dos recursos naturais, ética e aspectos relevantes quanto às ideias sobre problemas ambientais 
decorrentes. A partir da relação aluno com o ensino e aprendizagem, aplicaram-se questionários com os seguintes itens:

Item1: Quais conteúdos foram trabalhados com mais frequência na educação ambiental?

Item 2: Aponte o grau de frequência em que são abordados assuntos ligados ao Meio Ambiente nas disciplinas.

Item 3: Como você define a Educação Ambiental?

Item 4: Quais disciplinas abordam com mais frequência a Educação Ambiental?

Item 5: Quais problemas ambientais são identificados no município onde a escola está localizada?

Item 6: Comente sobre a existência e sua participação em eventos do meio ambiente.

Item 7: Você participa de algum projeto relacionado a Educação Ambiental?

Item 8: Você participou/participa de alguma ação na escola relacionada a Educação Ambiental?

Item 9: Qualifiquem seu interesse pelos assuntos relacionados ao Meio Ambiente?

Item 10: Quais práticas sustentáveis de consumo você considera mais importantes para implementar na escola?

Item11: Quais ações sustentáveis para os resíduos sólidos você considera mais importantes para ser implementadas na escola?

Item12: Na escola existem áreas verdes e praças para estudo, convivência e/ou descanso?

\section{RESULTADOS E DISCUSSÃO}

A partir da aplicação dos questiónarios foram escolhidas as respostas mais condizentes para interpretação do questionário. De acordo com a Questão 1, foram obtidas as respostas a seguir:

A2: "Queimadas, falta de água, desmatamento".

A5: "Desmatamento, falta de água, poluição, etc".

A12: "Poluição do solo, Poluição dos rios, poluição do ar".

Ao avaliar as respostas, pode-se dizer que existe uma boa diversidade de conteúdos ministrados com frequência na educação ambiental. Os conteúdos se apresentam ainda como sendo questões do cotidiano dos alunos, o que facilita o entendimento do que ocorre a sua volta, com o auxílio dos conceitos científicos pertinentes. Esse entrosamento do aluno com os assuntos despertam a 
consciência de preservação e de cidadania, trazendo um maior equilíbrio entre homem e natureza e do uso racional dos recursos naturais.

De acordo com a Questão 2, a frequência em se abordar assuntos relacionados ao meio ambiente tem se dado de uma forma corriqueira, ao qual comprovam os resultados, $60 \%$ para a alternativa "Sempre" e 40\% para "Com alguma frequência". Vê-se diante desses percentuais que a escola pesquisada busca em construir cidadãos conscientes, críticos e participantes na sociedade. A Universidade Federal de Uberlândia ao realizar uma pesquisa de opinião nesse mesmo seguimento pelo projeto "Formação de Agentes Ambientais" atualizada em março de 2018 ouviu 1232 pessoas sendo 896 estudantes, 224 técnicos administrativos e 112 professores, dos quais 33\% destes disseram que "Raramente" são tratados em sala assuntos ligados ao meio ambiente, enquanto que $30 \%$ afirmaram ter "Com alguma frequência" assuntos abordando o meio ambiente (BRASIL, 2018).

De acordo com a Questão 3, os que tiveram respostas mais relevantes foram:

A1: "Ensinar que tem de jogar lixo no lixo e reciclar o que da (sic.)".

A9: "Ela é essencial para a formação de um cidadão".

A20:"Onde aprendemos e colocamos em pratica (sic.) alguns conhecimentos". Observa-se que apesar de muito jovens, os alunos tem uma boa percepção acerca da definição de educação ambiental; não se limitando apenas a caracterizar os elementos da natureza, mas citando os cuidados em relação a eles. Expuseram ainda o respeito perante o meio ambiente como fundamental para a preservação do mesmo.

De acordo com a Questão 4, os alunos apontaram como respostas: $100 \%$ dos participantes concordaram em dizer que a disciplina de geografia trabalha de forma constante a temática Educação Ambiental, seguida ainda da disciplina de biologia. No entanto, seria interessante que essa abordagem se desse além das disciplinas mencionadas. A escola por ser um local de socialização e de construção de conhecimentos torna-se ideal para desenvolver práticas de Educação Ambiental, tendo em vista a fácil vantagem de envolver a comunidade local, facilitando a interdisciplinaridade, promovendo assim, o senso crítico na resolução dos problemas ambientais.

Machado (2013) ressalta que cada disciplina apresenta um processo diferenciado de aprendizagem, possuindo uma linguagem apropriada e um processo de investigação. Entretanto, todos os professores podem encontrar pontos comuns para desenvolver um trabalho em conjunto, que pode abordar a temática dentro da especificidade de sua área explorando nos alunos habilidades como expressões corporais (educação física), verbais/linguagens (letras - português e língua estrangeira), a 
sensibilização (artes, ensino e religioso), pensamento crítico (história e geografia), pensamento investigativo (ciências) e a racionalização (matemática).

De acordo com a Questão 5, verificando-se os resultados dispostos, observa-se que o maior número de problemas percebidos pelo alunado se deu para "Esgoto a céu aberto", com 18 votos, existindo uma concordância por parte de 90,0\% destes e ainda numa mesma proporção a problemática "Rios assoreados e poluídos", com 18 votos, como sendo os maiores desafios municipais vivenciados.

De acordo com a Questão 6, os alunos apontaram como respostas:

A4: "algumas (sic.) vez (sic.) sim eu participava dos eventos".

A13: "Pra ter uma vida melhor no futuro e todos nós devíamos fazer uma parte melhora (sic.) o nosso planeta".

A20: "Porque vale pontos".

Percebe-se diante das respostas que não há uma forma de pensar divergente. Tem-se demonstrado alunos com "sede" em aprender dispostos a colaborar com eventos, pois vê nessa oportunidade uma forma de poder conscientizar mais alunos. Por outro lado, veem-se alunos descompromissados ou que parece participar como forma de obrigação para ganhar pontos. Chama atenção essa questão o fato de $40 \%$ dos alunos ter deixado essa questão em branco, dando a entender que diferente da conscientização que vem ocorrendo no campo profissional, na área estudantil ainda serão necessários novas estratégias de incentivo com vias de alcançar esse público apático.

De acordo com a Questão 7, com a intenção de identificar melhor o perfil desse aluno a pesquisa trouxe como respostas:

A8: "Não. Porque não me identifico com o assunto".

A10: "Sim. Para adquirir maiores conhecimentos e melhorar o lugar em que vivo".

A18: "Não. Porque não senti interesse".

Em proporções menores, contudo não menos preocupante, $20 \%$ dos participantes deixaram em branco o espaço de resposta, enquanto que a maioria dos alunos apresentou um comportamento satisfatório tanto no que diz respeito à finalidade da existência de um projeto em si, quanto de pertencer ativamente dele. É possível ainda, identificar através das falas dos alunos A8, A10 e A18 que a decisão em se envolver ou não em um projeto direcionado a Educação Ambiental, parte do lado emotivo, isto é, porque gosta ou porque não se identifica/não sente interesse. Fato que não deveria acontecer, já que não só em nível escolar, o intuito do projeto vai além de uma mera transmissão de conhecimentos, ele (o projeto) é e deve ser capaz de se sobrepor aos "muros" da escola levando o 
aluno a inquietar-se e querer mudar primeiramente em seu lar e depois em sua comunidade as atitudes que restringem um bom andamento socioambiental.

Logo, vê-se que existe uma falha de comunicação ocasionada possivelmente pela falta de entendimento do que venha a participar de um projeto e suas ações contemplativas ou mesmo a imaturidade do conceito de Educação Ambiental não construído ainda de forma correta pelo alunado.

De acordo com a Questão 8 , no que diz respeito a essa questão $40 \%$ dos alunos se absteve em responder. Já entre os que preferiram responder mencionaram em sua maioria a gincana ecológica, como a ação de maior participação entre o público alvo estudado, seguido de uma horta sustentável criada por alunos e professores e ainda foi mencionado por um dos alunos o recolhimento de produtos recicláveis. Segundo Salvan (2004), toda prática de ensino contém uma teoria de aprendizagem predominante, explicitada de forma consciente ou inconsciente pelo professor. Mesmo aquele que assume conscientemente uma teoria, deve-se reconhecer um elevado grau de indeterminação na aprendizagem e nas interações, pois tanto o docente como o discente se envolve de forma particular numa situação cuja dinâmica é difícil de prever.

De acordo com a Questão 9, tem-se potenciais cidadãos a desenvolverem uma consciência crítica em relação aos assuntos direcionados ao meio ambiente em virtude das opções escolhidas "Muito interessado" e "Razoavelmente interessado" com os respectivos percentuais: 55 e 45 para alunos. Resultados análogos a esses também foram verificados em estudos realizados por Siccha e Brasil (2016), que constataram as mesmas escolhas observadas nesse trabalho.Tais premissas sugerem que o processo de conscientização já tenha ocorrido, contudo BRASIL (2006) enfatiza que há uma recorrência nas atividades em poluir, agindo com desrespeito ao meio ambiente.

De acordo com a Questão 10, partindo da curiosidade em saber como anda a conscientização dos alunos quanto ao consumo,constatou-se que de um modo geral todas as práticas sustentáveis como: "Uso do papel reciclado", "Lâmpadas e equipamentos de baixo consumo de energia", "Papéis reutilizados para fazer blocos de anotações/rascunhos" e "Material da limpeza sem químicos que agridam o meio ambiente", foram bem aceitas pelos alunos pesquisados, contudo o destaque se deu para a opção: "Reutilização da água da chuva para limpeza e irrigação dos jardins e hortas" que obteve uma maior apreciação, resultando num percentual de 90,0\% das opiniões válidas.

Bigotto (2008) argumenta que não é obrigação da escola resolver problemas ambientais como a poluição do ar e da água, a questão do lixo, entre outros, mas é papel de cada um desenvolver o 
interesse pelo conhecimento e a capacidade de julgamento nas pessoas que compartilham a mesma realidade.

De acordo com a Questão 11, nas respostas observadas pelos alunos, "Coleta seletiva dos resíduos recicláveis com 18 votos e "Compostagem do lixo orgânico da merenda" com 14 votos, vê-se que as práticas sustentáveis foram bem aceitas, demonstrando que se, implantadas de fato pela escola terão boas chances de participação e, por conseguinte, êxito em seus efeitos esperados.

De acordo com a Questão 12, vislumbram-se os percentuais de existência de áreas verdes segundo a opinião dos alunos, com 95\% para "Sim" e 5\% para "Não", nota-se que há quase uma totalidade de alunos em concordância quanto à presença de áreas verdes na escola, destoando apenas 5\%, que por motivos desconhecidos ignora esse fato. Um dos motivos atribuídos pode ser a falta de áreas verdes em sua comunidade local ou ainda, a falta de conscientização vinda de seu convívio familiar e por isso, a indiferença.

\section{CONSIDERAÇÕES FINAIS}

Mediante os objetivos específicos definidos inicialmente, conclui-se a partir dos resultados obtidos que eles responderam a pesquisa, alcançando, portanto um desfecho satisfatório. Partindo do primeiro e segundo objetivos que buscava apontar a percepção dos alunos acerca da Educação Ambiental e suas discussões relativas às problemáticas ambientais inerentes às esferas internas e no entorno da escola, observou-se que o desenvolvimento de um trabalho em Educação Ambiental dentro do contexto da prática pedagógica, ajuda os alunos a construírem uma consciência global das questões relativas ao meio ambiente, ao mesmo tempo em que assume posições afinadas com os valores referentes à sua proteção e melhoria, mediante ações coletivas.

Dentro dessa conjuntura, permite-se trabalhar valores que permeiam a sociedade, contribuindo com a mudança de comportamentos ao mesmo tempo em que serve de subsídio para progredir nos cuidados com a natureza. Pode-se assim dizer que esse pensamento faz inferência ao quarto objetivo específico, ou seja, faz menção a um estado de reflexão sobre alternativas viáveis para resolver ou minimizar impactos ambientais negativos, promovendo mudanças na prática de valores e atitudes ambientalmente adequadas no cotidiano, através de ações educativas.

Ademais se buscou fazer com que esse ciclo fosse quebrado para que em um futuro próximo, se tenham gerações mais comprometidas a partir de ações educativas concretas e não apenas sendo vista como utopia ou de cunho específico àqueles ligados à área. 


\section{REFERÊNCIAS}

BIGOTTO, Antonio Cesar. Educação Ambiental e o desenvolvimento de atividades de ensino na escola pública. Dissertação (Mestrado em Educação/Área de Didática, Teorias de Ensino e Práticas Escolares). Universidade de São Paulo. 2008.

BRASIL. Ministério da Educação. Propostas de Diretrizes da Educação Ambiental para o ensino formal - Resultado do II Encontro Nacional de representantes de EA das Secretarias Estaduais e Municipais (capitais) de Educação - 2001.

BRASIL. MEC. SEF. Ciências da natureza, matemática e suas tecnologias / Secretaria de Educação Básica. - Brasília : Ministério da Educação, Secretaria de Educação Básica, 2006. 135 p. (Orientações curriculares para o ensino médio ; volume 2).

BRASIL. UFU SUSTENTÁVEL - Pesquisa de Opinião. Planejamento sustentável da UFU tem colaboração da comunidade acadêmica. Universidade federal de Uberlândia. 2018.

LOCATELLI, O. C.; HENDGES, C. D. A. Educação Ambiental na perspectiva de um currículo interdisciplinar. Cadernos do CEOM, v. 21, n.29, p. 231-242, 2005.

MACHADO, Márcia Kaipers. A interdisciplinaridade na educação ambiental. UFSM. SIFEDOC. 2013.

MARTINS, Gilberto de Andrade.; DOMINGUES, Osmar. Estatística geral e aplicada. 4.ed. São Paulo: Atlas, 2011.

SALVAN, A. F. M. Avaliando as dificuldades da aprendizagem em matemática. 2004. 61f. Especialização. (Trabalho de Monografia em Educação da Matemática) - Universidade do Extremo Sul Catarinense, UNESC.

SICCHA, Katy Yovana Mendes.; BRASIL, Davi do Socorro Barros. Consciência e Percepção Ambiental dos alunos da Faculdade Estácio do Amazonas - Brasil. Revista Espacios. v. 38, n. 20, 2017. p. 7.

THIOLLENT, M; SILVA, G. de O. Metodologia da pesquisa ação na área de gestão de problemas ambientais. Recus: Revista Eletrônica de Comunicação Informação, Inovação em Saúde, Rio de Janeiro - RJ, v. 1, n. 1, 2007. 


\section{Capítulo 3}

doi) $10.37423 / 210504026$

X-RAY DIFFRACTION STUDY OF 9-BROMO-3(TRICHLOROMETHYL)-3,3A,4,5,6,7,8,9CTAHYDROCYCLOOCTA[C]ISOXAZOL-3-OL

Givanildo Santos da Silva

Mariano Alves Pereira

Luciana Almeida Piovesan

Rogério Felix Blahco

Alex Fabiani Claro Flores

Tatiane Luciano Balliano
Universidade Federal de Alagoas

Universidade Federal de Alagoas

Universidade Federal de Santa Maria

Universidade/Federal de Santa Maria

Universidade Federal de Santa Maria

Universidade Federal de Alagoas 
Abstract - In order to identify new inhibitors of acetylcholinesterase by compounds previously synthesized are checked some physico-chemical properties such as obtained by X-ray diffraction of the compound 9-bromo-3-(trichloromethyl) -3,3 a,4,5,6,7,8,9-octahydrocycloocta [c] isoxazol-3-ol. Must be considered that the compound exhibits analogy to metabolic intermediates of the $\gamma^{-}$ aminobutyric acid (GABA), which suggests that the test compound may show any kind of modulating activity of the enzyme acetylcholinesterase. 


\section{INTRODUCTION}

Parts of different types of the $\gamma$-aminobutyric acid (GABA) receptors were originally defined by independent drug sensitivities. GABA A receptors are activated by Muscimol, GABA B receptors, which are activated by Baclofen.

In order to identify novel inhibitors for acetylcholinesterase, search through previously synthesized compounds, verification of its pharmacodynamic and pharmacokinetic properties, as well as its physico-chemical and mechanistic characteristics related to acetylcholinesterase. It should be appreciated that the compounds exhibit metabolic intermediates which have analogy with GABA, suggesting that the test compounds may have some type of modulation of enzyme activity. The compound presented in this paper shows similarity to the GABA agonists by display structural similarity to Muscimol [1]. For this structural study by X-ray diffraction was performed to confirm the structural proposal, furthermore studies were performed to explain the crystalline intermolecular interactions.

\section{EXPERIMENTAL}

Single crystals of the compound were obtained by slow evaporation from methanol. Crystallographic characteristics and structure refinement statistics are given in Table 1. The structure was determined by direct methods and refined with anisotropic displacement parameters for atoms not hydrogenated. The hydrogen atoms were placed geometrically and refined using a model of equivalence.

A X-ray diffraction analysis of the single crystal was performed on a KAPPA CCD diffractometer (Enraf Nonius) [2]. $X$ ray experimental details and selected results for the title compound are given in Table 1. The structure was solved using SHELXS97 [3] and was interpreted and refined with the aid of the SHELX97 software package $[3,4]$. The hydrogen atoms that are involved in the $\mathrm{H}$-bond formation were determined from the difference electron-density map and isotropically refined. The positions of other hydrogen atoms were calculated from geometric considerations and refined within the riding model. A graphical representation (figure 1) of the molecule was constructed using the ORTEP3 software [5]. The CIF file deposited in the Cambridge Structural Database was obtained using the WinGX software package [6] (CCDC no. 941096). 
Table 1. Crystallographic and $\mathrm{X}$ ray data, collect and the refinement results for the crystal structure of 9-bromo-3-(trichloromethyl)-3,3a,4,5,6,7,8,9-ctahydrocycloocta[c]isoxazol-3-ol.

\begin{tabular}{|c|c|}
\hline Molecular weight (g/mol) & 365.50 \\
\hline $\mathrm{T}(\mathrm{K})$ & 293(2) \\
\hline Crystaline system & Orthorhombic \\
\hline Sp. Gr., Z & P 212121,4 \\
\hline$a, b, c(\AA)$ & $7.7155(2), 9.0432(1), 19.8073(4)$ \\
\hline$\alpha=\beta=\gamma(\operatorname{deg})$ & 90 \\
\hline$V\left(\AA^{3}\right)$ & $1382.01(0)$ \\
\hline$\lambda(\AA)$ & 0.71073 \\
\hline $\mathrm{d}_{\text {calc }}\left(\mathrm{g} / \mathrm{cm}^{3}\right)$ & 1.757 \\
\hline$\mu\left(\mathrm{mm}^{-1}\right)$ & 3.543 \\
\hline$F(000)$ & 728 \\
\hline$\theta_{\max }(\mathrm{deg})$ & 27.88 \\
\hline Number of reflections measured & 13809 \\
\hline Number of unique reflections & 3288 \\
\hline Number of reflection with $1>2 \sigma(I)$ & 2922 \\
\hline Number of parameters refined & 154 \\
\hline $\mathrm{R} 1 / \mathrm{wR}_{2}[\mathrm{I}>2 \sigma(\mathrm{I})]$ & $0.0562 / 0.1326$ \\
\hline $\mathrm{R} 2 / \mathrm{wR}_{2}$ [all reflections] & $0.0651 / 0.1385$ \\
\hline GOF & 1.051 \\
\hline$\Delta \mathrm{Pmax} / \Delta \mathrm{Pmin}\left(\mathrm{e} / \AA^{3}\right)$ & $1.344 /-0.824$ \\
\hline
\end{tabular}




\section{RESULTS AND DISCUSSION}

All non-hydrogen atoms were refined anisotropically and hydrogen atoms were positioned geometrically, with $d(C-H)=0.970 \AA$. Some distances chosen bond, bond angles, and torsion angles are shown in Table 2.

The molecular structure is shown in Fig. 1 with atom numbering scheme. In the asymmetric unit, there is one molecule. In the compound, the hydrogen atom, of hydroxyl group, form one intermolecular $\mathrm{H}$ bond with the $\mathrm{N}$ atom:O2-H2...N1=0.8200(0) $\AA$, H2 ...N1 = 2.200(0) $\AA, 02 \ldots \mathrm{N} 1=2.977(6) \AA$, and the angle $\left.\mathrm{O} 2-\mathrm{H} 2 \ldots \mathrm{N} 1=153.00(0)^{\circ}\right)$. The symmetric transformation is: $1-x,-1 / 2+y, 1 / 2-z$. The measures of the angles and lengths of bonds are represented by acceptable values. As shown in Figure 2.

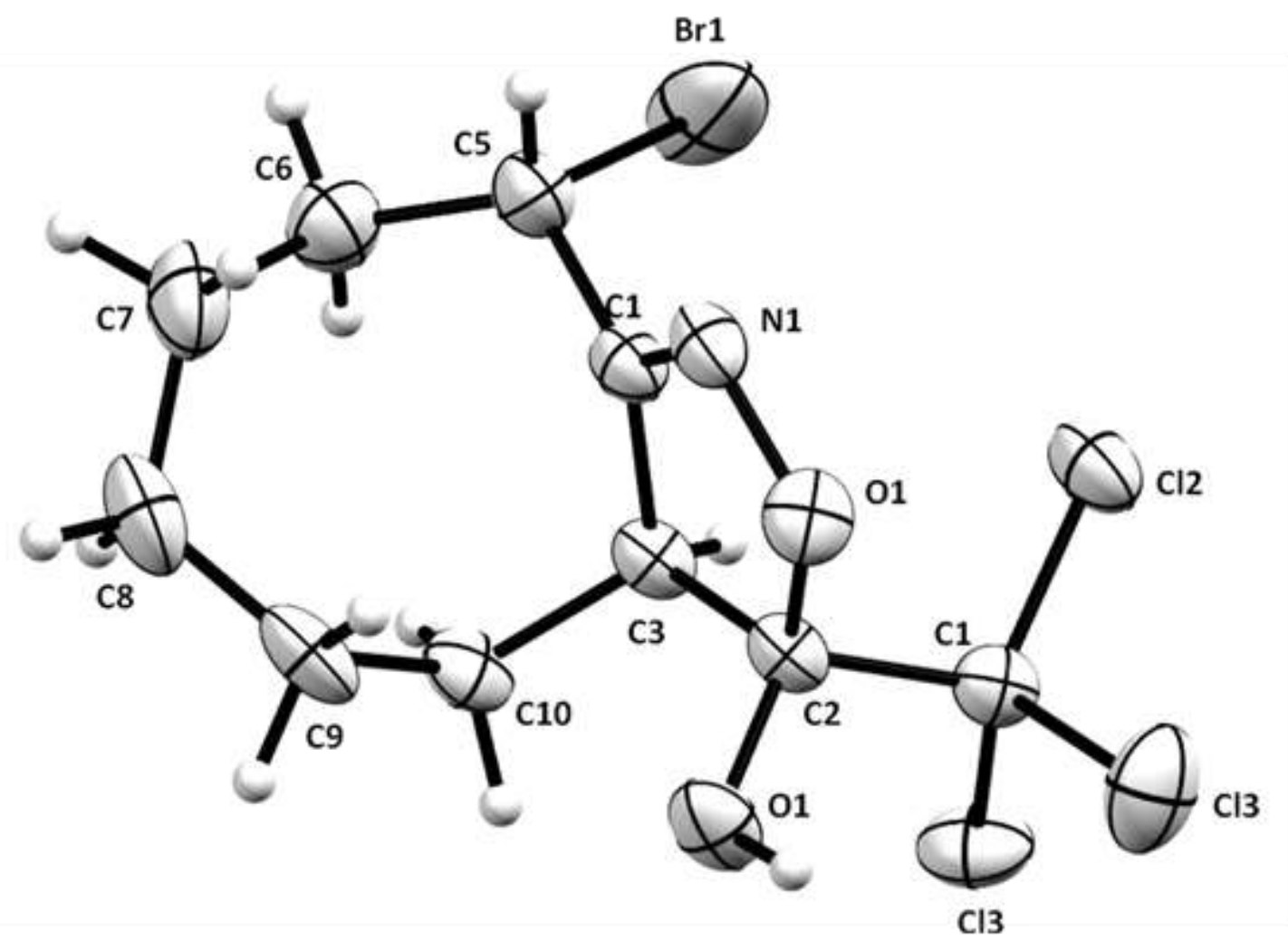

Fig.1. The asymmetric unit of the title compound, represented with displacement ellipsoids drawn at $30 \%$ probability level and showing the labeling scheme. 


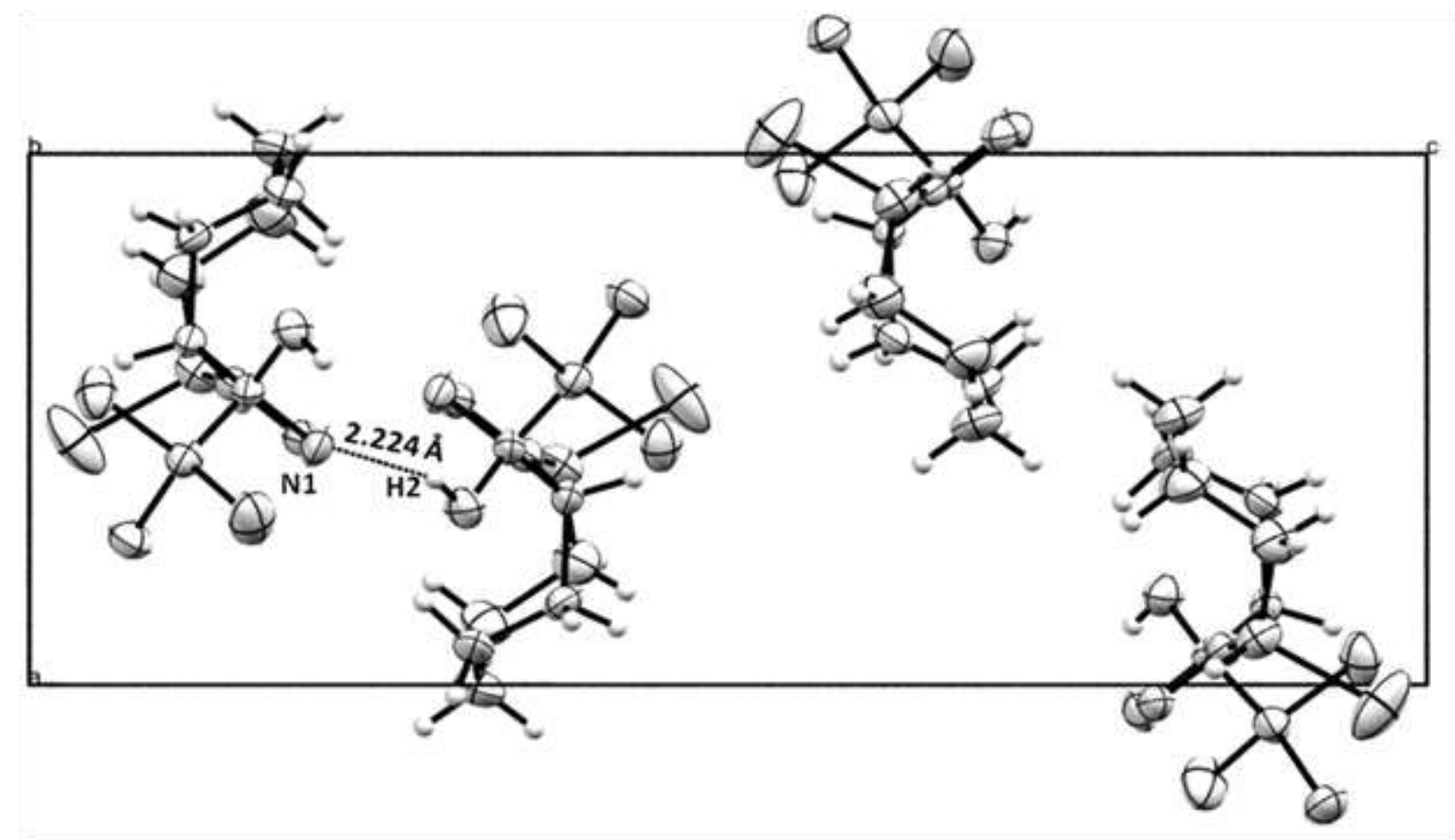

Fig. 2. View of the crystal packing of the title compound. 
Table 2. Selected geometric parameter.

\begin{tabular}{|c|c|c|c|c|c|}
\hline Bond & Distance $(\AA)$ & \multicolumn{2}{|c|}{ Angle $\left(^{\circ}\right)$} & \multicolumn{2}{|c|}{ Torsion Angle $\left(^{\circ}\right)$} \\
\hline $\mathrm{C}(1)-\mathrm{Cl}(2)$ & $1.763(5)$ & $\mathrm{C}(2)-\mathrm{C}(1)-\mathrm{Cl}(3)$ & $108.3(3)$ & N1-O1-C2-C1 & $114.9(4)$ \\
\hline $\mathrm{C}(1)-\mathrm{Cl}(3)$ & $1.771(5)$ & $\mathrm{Cl}(2)-\mathrm{C}(1)-\mathrm{Cl}(3)$ & $109.1(2)$ & N1-O1-C2-C3 & $-3.9(5)$ \\
\hline $\mathrm{C}(1)-\mathrm{Cl}(1)$ & $1.774(5)$ & $\mathrm{C}(2)-\mathrm{C}(1)-\mathrm{Cl}(1)$ & $110.8(3)$ & $\mathrm{N} 1-\mathrm{O} 1-\mathrm{C} 2-\mathrm{O} 2$ & $-126.0(4)$ \\
\hline $\mathrm{C}(2)-\mathrm{O}(2)$ & $1.383(6)$ & $\mathrm{Cl}(2)-\mathrm{C}(1)-\mathrm{Cl}(1)$ & $109.0(3)$ & O1-N1-C4-C3 & $2.3(6)$ \\
\hline $\mathrm{C}(2)-\mathrm{O}(1)$ & $1.439(6)$ & $\mathrm{Cl}(3)-\mathrm{C}(1)-\mathrm{Cl}(1)$ & $109.1(3)$ & O1-N1-C4-C5 & $-174.0(4)$ \\
\hline $\mathrm{C}(4)-\mathrm{N}(1)$ & $1.279(6)$ & $\mathrm{O}(2)-\mathrm{C}(2)-\mathrm{C}(1)$ & $109.8(4)$ & $\mathrm{C} 13-\mathrm{C} 1-\mathrm{C} 2-\mathrm{C} 3$ & $-61.9(4)$ \\
\hline & & $\mathrm{C}(4)-\mathrm{C}(5)-\mathrm{Br}(1)$ & $105.3(3)$ & $\mathrm{O} 2-\mathrm{C} 2-\mathrm{C} 3-\mathrm{C} 4$ & $125.1(4)$ \\
\hline & & & & $\mathrm{N} 1-\mathrm{C} 4-\mathrm{C} 5-\mathrm{Br} 1$ & $106.6(5)$ \\
\hline & & & & N1-C4-C5-C6 & $-133.0(5)$ \\
\hline & & & & $\mathrm{C} 3-\mathrm{C} 4-\mathrm{C} 5-\mathrm{Br} 1$ & $-69.2(6)$ \\
\hline & & & & Br1-C5-C6-C7 & $176.9(4)$ \\
\hline
\end{tabular}

After analysis of the angles of torsion, isoxizol atoms present in the ring, there is an essentially planar geometry. For the torsion angles between atoms present in the ring are $1.2^{\circ}$ for the atoms $\mathrm{C} 2-\mathrm{C} 4-\mathrm{O} 1$ $\mathrm{N} 1$, and $2.3^{\circ}$ for the atoms O1-N1-C3-C4.

\section{CONCLUSIONS}

The structure determination of the two compounds under study was performed from the studies by X-ray crystallography. From these studies it was found that conformational changes associated with the replacement of the ligands occurs along the octaisoxazol ring, with other compounds that are characterized and phase structure determination. 


\section{REFERENCES}

[1] Jorgensen, E.M. GABA (August 31, 2005), WormBook, ed. The C. elegans Research Community, WormBook, doi/10.1895/wormbook.1.14.1, http://www.wormbook.org.

[2] Enraf-Nonius (1997-2000). COLLECT. Nonius BV, Delft, The Netherlands.

[3] Sheldrick, G.M. SHELXS-97. Program for Crystal Structure Resolution. Univ. of Göttingen: Göttingen, Germany, 1997.

[4] Sheldrick, G.M. SHELXL-97. Program for Crystal Structures Analysis. Univ. of Göttingen: Göttingen, Germany, 1997.

[5] C. F. Macrae, I. J. Bruno, J. A. Chisholm, P. R. Edgington, P. McCabe, E. Pidcock, L. Rodriguez-Monge, R. Taylor, J. van de Streek and P. A. Wood, J. Appl. Cryst., 41, 466-470, 2008

[6] FARRUGIA, L. J. WingGX Suite for Small - Molecule Single - Crystal Crystallography. J. Appl. Cryst. v. 32, p. $837-838$.

[7] Elufioye, T. O.; ObuOtoR, E. M.; SennugA, A. T.; AgbedahunsI, J. M.; AdesanyA, S. A. Acetylcholinesterase and butyrylcholinesterase inhibitory activity of some selected Nigerian medicinal plants. Revista Brasileira de Farmacognosia, v. 20, n. 4, 2010. 


\title{
doi) $10.37423 / 210504028$
}

\section{Capitulo 4}

\author{
CARACTERIZAÇÃO ESTRUTURAL E \\ MORFOLÓGICA DE NANOPARTÍCULAS DE \\ FE/CO/MN:SNO2 PRODUZIDO POR UM MÉTODO \\ SOL-GEL PROTEICO
}


Resumo: Nanopartículas semicondutoras de $\mathrm{Sn}_{1-\mathrm{x}} \mathrm{M}_{\mathrm{x}} \mathrm{O}_{2}(\mathrm{M}=\mathrm{Fe}$, Co e $\mathrm{Mn}$ ) dopadas com ferro, cobalto ou manganês com concentrações $x=0,02$. 0,05 e 0,08 foram preparados por um método sol-gel proteico. O pó precursor foi caracterizado por análise termogravimétrica e calorimetria de varredura diferencial para determinação da decomposição térmica e temperatura de formação dos óxidos. Estudos de espectroscopia de absorção de raios-x próximo à borda revelaram que os íons dopantes são incorporados de forma substitutiva como $\mathrm{Fe}^{3+}, \mathrm{Co}^{2+}$ and $\mathrm{Mn}^{2+}$. As análises dos padrões de difração de raios- $x$ revelaram que todos os compostos apresentaram a estrutura de rutilo tetragonal esperada para $\mathrm{SnO}_{2}$, sugerindo que $\mathrm{Fe}^{3+}, \mathrm{Co}^{2+}$ and $\mathrm{Mn}^{2+}$ foram incorporados na rede cristalina de $\mathrm{SnO}_{2}$. Nenhuma fase de impureza foi detectada por esta técnica. Os parâmetros de rede obtidos pelo refinamento de Rietveld a partir da análise dos padrões de difração de raios-x reforçam que os íons dopantes são incorporados na matriz cristalina substituindo os íons $\mathrm{Sn}^{4+}$. Os resultados da microscopia eletrônica de transmissão de uma amostra de $\mathrm{SnO}_{2}$ mostraram nanopartículas com formato esférico e diâmetro médio entre 5 e $10 \mathrm{~nm}$.

Palavras-chave: Nanopartículas $\mathrm{Sn}_{1-\mathrm{x}} \mathrm{M}_{\mathrm{x}} \mathrm{O}_{2}$; Método sol-gel proteico; Espectroscopia de absorção de raios-x próximo à borda; Difração de raios-x; Microscopia eletrônica de transmissão 


\section{INTRODUÇÃO}

O desenvolvimento de materiais nanoestruturados que podem apresentar diversas propriedades físico-químicas simultaneamente, tem atraído a atenção de vários grupos de pesquisa nas últimas décadas. Muitos avanços já foram alcançados nessa área e, o resultada dessa evolução pode ser percebida em todas as áreas da engenharia, na indústria e na tecnologia. Os nanomateriais, em particular, têm se destacado nesse cenário e, continuam despertando o interesse de pesquisadores em diversas nas áreas do conhecimento. $O$ grande diferencial desses materiais está na capacidade de potencializar as propriedades físicas e químicas dos materiais e, isso tem proporcionado um imenso interesse e crescente importância para futuras aplicações tecnológicas.

A possibilidade de fabricar estruturas semicondutoras em escala nanométrica conduziu o surgimento de novas áreas de pesquisa básica, tanto em magnetismo quanto em semicondutores. $\mathrm{O}$ desenvolvimento e as diversas aplicações desses materiais originaram um novo ramo da tecnologia chamado spintrônica, na qual as funções dos dispositivos são fundamentadas não apenas no controle do movimento dos elétrons, como anteriormente, mas também no controle da orientação dos spins desses elétrons.

Os materiais óxidos semicondutores magnéticos diluídos (O-SMD) descobertos na última década possuem vários aspectos interessantes do ponto de vista industrial, sobretudo, na eletrônica. Os OSMD além de apresentarem propriedades elétricas como os semicondutores convencionais, a inserção proposital de impurezas magnéticas a estes materiais lhes confere também propriedades magnéticas. O diferencial desses materiais está na existência de magnetização espontânea acima da temperatura ambiente, o que os tornam candidatos potenciais para aplicações em dispositivos óptico-elétricos e magneto-ópticos (FENG et al., 2015; MOHAGHEGHI et al., 2018).

Vários óxidos semicondutores tais como, óxido de zinco (ZnO) (BELTRÁN et al. 2015), dióxido de estanho $\left(\mathrm{SnO}_{2}\right)$ (PEREIRA et al., 2020), dióxido de titânio $\left(\mathrm{TiO}_{2}\right)$ (MATSUMOTO et al. 2001), etc, podem ser utilizados como matrizes para a obtenção dos O-SMD. O $\mathrm{SnO}_{2}$ se destaca por ser um semicondutor com uma larga banda de gap direto de 3,6 eV à temperatura ambiente, com excelentes estabilidades química e mecânica (Pereira et al., 2018). 


\section{1 ÓXIDOS SEMICONDUTORES MAGNÉTICOS DILUÍDOS (O-SMD)}

Os óxidos semicondutores são materiais ideais para aplicações na indústria microeletrônica e na emergente nanoeletrônica, pois além de possuírem sua condução de portadores aumentada com o acréscimo de temperatura, assim como em outros semicondutores, pelo fato de serem óxidos, são extremamente estáveis em ambientes como o ar atmosférico. A maioria dos óxidos são considerados bons isolantes, mas ainda assim existem alguns óxidos que são semicondutores, como é o exemplo do $\mathrm{TiO}_{2}, \mathrm{SnO}_{2}, \mathrm{ZnO}$ entre outros. Os óxidos semicondutores possuem muitos aspectos de interesse tecnológico, por isso eles vêm sendo estudados com grande frequência. Novas técnicas de crescimento de filmes nos permitem tratar os óxidos semicondutores como componentes convencionais para a produção de semicondutores magnéticos, sendo um excelente componente hospedeiro (FUKUMURA et al. 2005).

Seguindo o ímpeto das pesquisas em semicondutores magnéticos diluídos dopados com manganês, no início da década passada a comunidade científica foi beneficiada com a descoberta de um novo material que exibe magnetização espontânea acima da temperatura ambiente. Os O-SMD, como foram denominados essa nova classe de material, são compostos por uma matriz óxida semicondutora não magnética (exemplo: $\mathrm{TiO}_{2}, \mathrm{SnO}_{2}, \mathrm{ZnO}$ ) dopada com elementos metálicos de transição com valência 3d como $\mathrm{Mn}, \mathrm{Fe}$, Co e Ni.

Portanto, desde os primeiros relatos da existência de ferromagnetismo acima da temperatura ambiente nos semicondutores óxidos $\mathrm{TiO}_{2}$ por (MATSUMOTO et al. 2001), em ZnO por (UEDA et al. 2001) e em $\mathrm{SnO}_{2}$ por (OGALE et al. 2003) dopados com cobalto, esses materiais se tornaram alvo de intensas pesquisas devido as suas possíveis aplicações em temperaturas práticas. O estudo dos O-SMD tem ganho crescente interesse devido as suas aplicações potenciais em dispositivos magneto-ópticos e em tecnologias baseadas na spintrônica (FUKUMURA et al. 2005).

\subsection{DIÓXIDO DE ESTANHO $\left(\mathrm{SNO}_{2}\right)$}

O dióxido de estanho $\left(\mathrm{SnO}_{2}\right)$, normalmente conhecido como cassiterita, é um típico semicondutor do tipo $n$ com um largo gap de energia $\left(E_{\mathrm{g}} \sim 3,6 \mathrm{eV}\right.$ a $\left.300 \mathrm{~K}\right)$ e, é um dos semicondutores óxidos mais largamente usado devido a sua estabilidade química e mecânica (Zhang e Gao, 2004). A cassiterita pertence a uma estrutura cristalina do tipo rutílio tetragonal com grupo espacial $\mathrm{P} 4_{2} / \mathrm{mnm}$, com parâmetros de rede $(a=b=4,738 \AA, c=3,185 \AA$ ) (PEREIRA et al., 2017) e com os átomos de estanho ocupando posições octaédricas da célula unitária, como mostrado na Fig. 1. 
Figura 1. Estrutura cristalina tetragonal do $\mathrm{SnO}_{2}$ mostrando a coordenação octaédrica dos átomos de Sn.

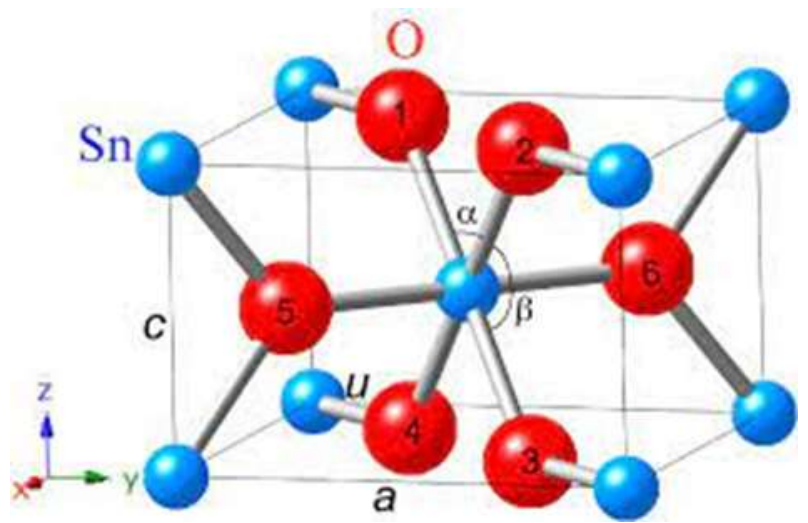

Fonte: YINMEI LU, 2015.

$\mathrm{O} \mathrm{SnO}_{2}$ possui várias aplicações industriais tais como suporte catalítico e sensores de gás de materiais tóxicos (BELTRAN et al., 2010). Ainda pode ser usado como eletrodo transparente para células solares (PEREIRA et al., 2017), displays de cristais líquidos, ânodos para baterias de lítio e membranas de ultrafiltração (ZHANG e GAO, 2004).

\section{$1.3 \mathrm{SNO}_{2}$ DOPADO COM MN, FE E CO}

Nos últimos anos, o $\mathrm{SnO}_{2}$ dopado com metais de transição como ferro (Fe), cobalto (Co) e manganês (Mn) tem sido objeto de intensas investigações devido suas promissoras aplicações na spintrônica. 0 SnO2 dopado com metais de transição com valência 3d forma um O-SMD com fórmula química $\mathrm{Sn}_{1-}$ ${ }_{x} \mathrm{M}_{\mathrm{x}} \mathrm{O}_{2}$, onde $\mathrm{x}$ é a concentração de material dopante e $\mathrm{M}$ o metal de transição. O estanho (Sn) possui valência maior que o Fe, Co e Mn. Dessa forma esses materiais serão impurezas receptoras, tornando o composto um semicondutor do tipo $p$.

\section{PROCEDIMENTO EXPERIMENTAL}

As amostras de $\mathrm{SnO}_{2}$ e $\mathrm{Sn}_{1-\mathrm{x}} \mathrm{M}_{\mathrm{x}} \mathrm{O}_{2}(\mathrm{M}=\mathrm{Fe}, \mathrm{Co}, \mathrm{Mn})$ estudados nesse trabalho de pesquisa foram sintetizadas por um método de baixo custo conhecido como método sol-gel proteico. Trata-se uma variação do método sol-gel convencional no qual se emprega gelatina comercial como precursor orgânico para a formação do óxido e, nitratos e cloretos como precursores metálicos.

O processo de síntese é constituído basicamente por quatro etapas: dissolução dos íons metálicos a partir sais precursores, formação dos quelatos metálicos, secagem e calcinação. A primeira etapa consiste em dissociar os íons dos sais precursores utilizando água destilada. A partir da dissociação é 
realizado a mistura desses íons com a gelatina, formando os quelatos metálicos (gel). Os íons metálicos se juntam aos grupos funcionais (aminoácidos) da gelatina. A secagem é feita para retirada da água, formando uma substância denominada puff que consiste num polímero formado pela gelatina e os íons. Por último, é feito a calcinação para retirada da matéria orgânica e, consequentemente, associação dos íons metálicos e formação dos óxidos pretendidos. A temperatura de calcinação é geralmente baixa, suficiente para evaporação somente de matéria orgânica, não afetando de forma indesejável os íons metálicos.

Nanopartículas de $\mathrm{SnO}_{2}$ e $\mathrm{Sn}_{1-\mathrm{x}} \mathrm{M}_{\mathrm{x}} \mathrm{O}_{2}(\mathrm{M}=\mathrm{Fe}, \mathrm{Co}, \mathrm{Mn})(\mathrm{x}=0,02 ; 0,05 ; 0,10)$ foram produzidas seguindo um método experimental descrito em outros trabalhos (PEREIRA et al, 2017; PEREIRA et al, 2018). A Fig. 2 mostra uma ilustração simplificada do método sol-gel proteico usado na síntese dos compostos. 
Figura 2. Representação esquemática do método sol-gel proteico usado na síntese das nanopartículas de $\mathrm{SnO}_{2}$ e $\mathrm{Sn}_{1-x} \mathrm{M}_{x} \mathrm{O}_{2}$. M representa $\mathrm{Fe}^{3+}, \mathrm{Co}^{3+}$ ou $\mathrm{Mn}^{3+}$.

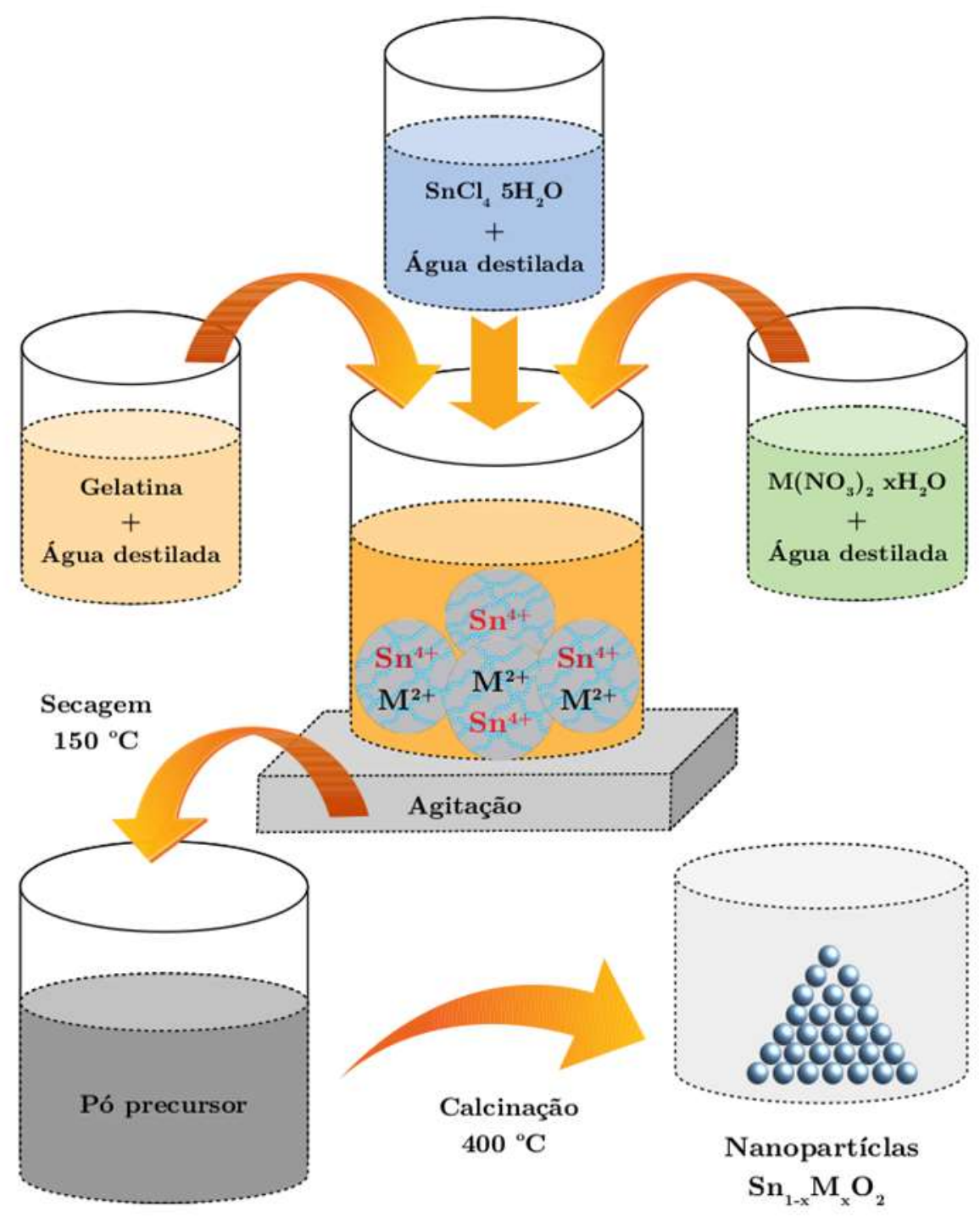

Fonte: Autor

Para a produção dos compostos foram utilizados $\mathrm{SnCl}_{4} 5 \mathrm{H}_{2} \mathrm{O}$ (Sigma-Aldrich, $99 \%$ ), $\mathrm{Fe}\left(\mathrm{NO}_{3}\right)_{2} 9 \mathrm{H}_{2} \mathrm{O}$ (Sigma-Aldrich, 98\%), $98 \%$ ), $\mathrm{Co}\left(\mathrm{NO}_{3}\right)_{2} 6 \mathrm{H}_{2} \mathrm{O}$ (Sigma-Aldrich, $98 \%$ ) e $\mathrm{Mn}\left(\mathrm{NO}_{3}\right)_{2} \mathrm{xH}_{2} \mathrm{O}$ (Sigma-Aldrich, 98 \%) comercial como percussores metálicos $\mathrm{Sn}^{4+}, \mathrm{Fe}^{3+}, \mathrm{Co}^{3+}$ ou $\mathrm{Mn}^{3+}$ e gelatina comercial (Sigma-Aldrich, Tipo B) de pele bovina como percussor orgânico.

Inicialmente, realizou-se os balanços estequiométricos para cada composto pretendido. Os sais (cloretos e nitratos) foram dispersados em água destilada (solução) sob agitação constante a temperatura ambiente até sua completa dissolução. A gelatina foi dispersada em água destilada sob agitação constante a temperatura ambiente até se obter um gel uniforme (gel). Cada solução foi 
adicionada ao gel e mantida sob agitação constante a temperatura ambiente por $2 \mathrm{~h}$. Os compostos resultantes foram secados a 150 ㄷ por $6 \mathrm{~h}$ para a remoção da água e produtos voláteis, obtendo uma substância escura conhecida como pó precursor (puff).

Antes da calcinação foram realizadas análise termogravimétrica (TGA) e calorimetria de varredura diferencial (DSC) em uma amostra de $\mathrm{SnO}_{2}$ com finalidade de determinar a temperatura de formação do óxido. Com base nos resultados de TGA/DSC os pós precursores de todas as amostras foram calcinados a $400 \stackrel{\circ}{\circ}$ por $2 \mathrm{~h}$, seguindo uma taxa de aquecimento de 5 o $/ \mathrm{min}$, resultando nos compostos $\mathrm{SnO}_{2}$ e $\mathrm{Sn}_{1-\mathrm{x}} \mathrm{M}_{\mathrm{x}} \mathrm{O}_{2}$.

As análises térmicas TGA/DSC nos pós precursores foram realizadas usando um equipamento NETZSCH STA 449F3 Jupiter. As medidas foram obtidas sob ar atmosférico aplicando uma taxa de aquecimento de $5 \stackrel{\circ}{\mathrm{C}} / \mathrm{min}$.

Os padrões de difração de raios-x (DRX) foram obtidos a temperatura ambiente com o auxílio de um difratômetro Rigaku modelo DMAXB, utilizando uma fonte de radiação monocromática $\mathrm{Cu}-\mathrm{K} \alpha(\lambda=1$, $54 \AA$ ) , operando com tensão de $40 \mathrm{kV}$ e uma corrente de $30 \mathrm{~mA}$. Os padrões foram ajustados pelo método Rietveld (RIETVELD, 1967; RIETVELD, 1969) usando o softwere GSAS (TOBY, 2001). Os procedimentos de refinamento Rietveld se basearam na estrutura cristalina padrão do SnO2 catalogada pela Inorganical Crystal Structure Database com o número 39173 (ICSD-39173). Os tamanhos médios de partículas foram estimados pela equação de Scherrer e, quando possível corrigido pelo método de Williamson-Hall (WILLIAMSON e HALL, 1953).

A valência dos metais dopantes foi determinada por espectroscopia de absorção de raios-X próximo à borda (XANES). As medidas de XANES foram realizadas no Laboratório Nacional de Luz Síncrotron (LNLS), Brasil. Os dados de XANES nas bordas K do Fe (7112 eV), Co (7709 eV) e Mn (6539 eV) foram obtidas na linha XAFS2 com energia e corrente do feixe de elétrons no anel de armazenamento de 1,37 GeV e $250 \mathrm{~mA}$, respectivamente. Os espectros foram colhidos a temperatura ambiente utilizando um monocromador de duplo cristal de Si (111) e calibrado com folhas metálicas de Fe, Co ou Mn.

\section{RESULTADOS E DISCUSSÃO}

\subsection{ANÁLISE TÉRMICA}

A Fig. 3 mostra uma curva de análise térmica TGA/DSC obtida do pó precursor da amostra de $\mathrm{SnO}_{2} . \mathrm{O}$ comportamento térmico observado pode ser dividido em três estágios principais, conforme indicado 
na Fig. 3: degradação térmica das cadeias de gelatina (reação endotérmica); formação de óxidos (reação exotérmica); e decomposição de grupos carbônicos (reação exotérmica).

Figura 3. Curvas TGA/DSC do pó precursor da amostra $\mathrm{SnO}_{2}$.

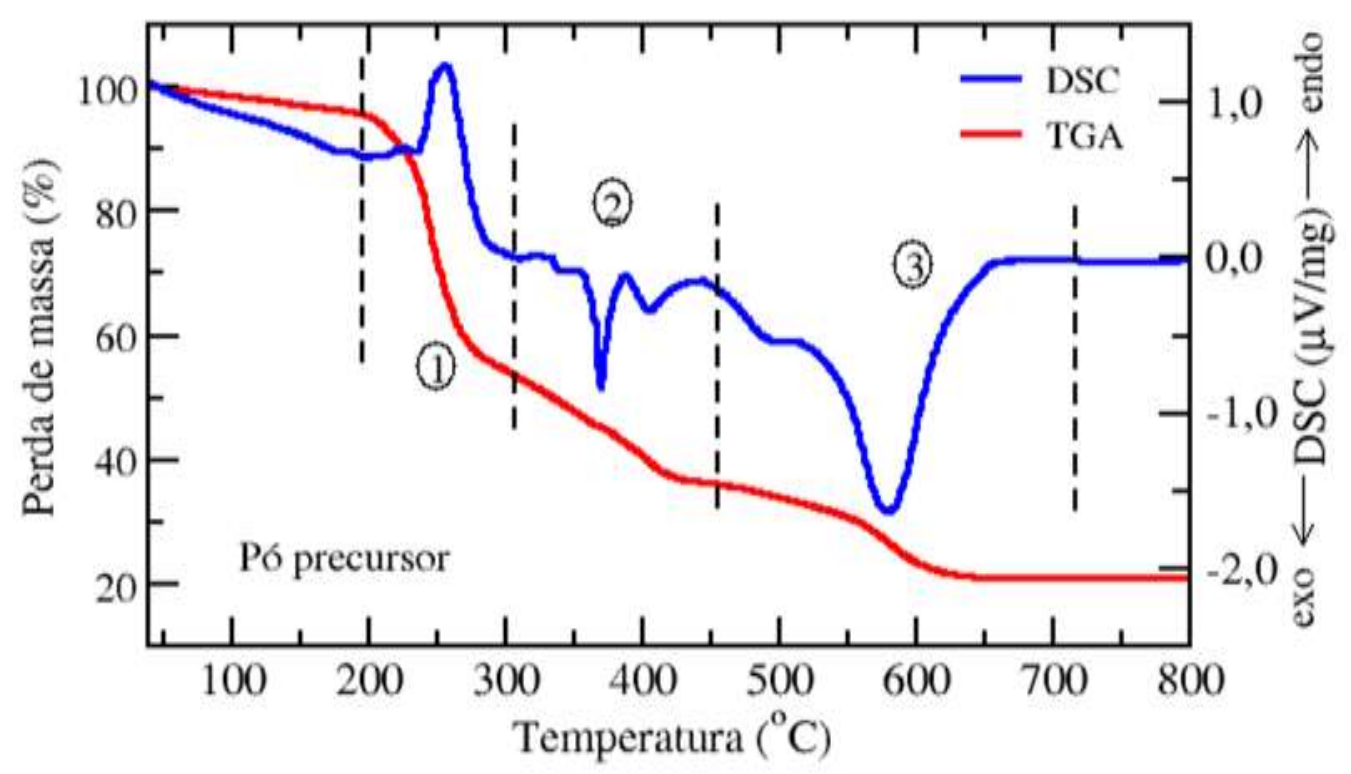

Fonte: Autor

A curva DSC apresenta um pico endotérmico em torno de 250 으 devido a decomposição da gelatina, um pico exotérmico em torno de 370 ㅇ C atribuído a formação e cristalização do $\mathrm{SnO}_{2}$ e um pico exotérmico em torno de $480 \stackrel{\circ}{ } \mathrm{C}$ devido a decomposição de grupos carbônicos. Estes resultados sugerem que a formação dos óxidos ocorre na extensão entre 300-400 ㄷ.

\subsection{XANES}

A substituição de átomos ou íons por elementos de uma matriz hospedeira pode modificar fundamentalmente a estrutura cristalina e as propriedades físicas de tal composto. Assim, características como estado de oxidação, afinidade eletrônica e tamanho dos íons dopantes são parâmetros relevantes no processo de dopagem.

Os raios iônicos dos íons metálicos usados na síntese dos compostos são: $\mathrm{Sn}^{4+}\left(0,69 \AA\right.$ Å), $\mathrm{Fe}^{3+}(0,64 \AA$ ) $\mathrm{Co}^{2+}(0,72 \AA)$ e $\mathrm{Mn}^{2+}(0,80 \AA)$, respectivamente. Pode se observar que os raios iônicos dos dopantes $\left(\mathrm{Fe}^{3+}, \mathrm{Co}^{2+}\right.$, e $\left.\mathrm{Mn}^{2+}\right)$ e do elemento da matriz $\left(\mathrm{Sn}^{4+}\right)$ possuem dimensões aproximadas. 
A valência dos metais dopantes foi determinada por espectroscopia de absorção de raios-x próximo à borda (XANES). A Fig. 4 mostra espectro XANES próximo a borda de absorção $\mathrm{K}$ do $\mathrm{Fe}$, Co e $\mathrm{Mn}$ de amostras $\mathrm{Sn}_{1-\mathrm{x}} \mathrm{M}_{\mathrm{x}} \mathrm{O}_{2}(\mathrm{x}=0.05)$ e os espectros dos padrões dos óxidos selecionados.

Figura 3. Espectro XANES próximo a borda $\mathrm{K}$ do $\mathrm{Fe}$, $\mathrm{Co}$ e $\mathrm{Mn}$ de amostras $\mathrm{Sn}_{1-\mathrm{x}} \mathrm{M}_{\mathrm{x}} \mathrm{O}_{2}(x=0.05)$ e dos compostos de referência.

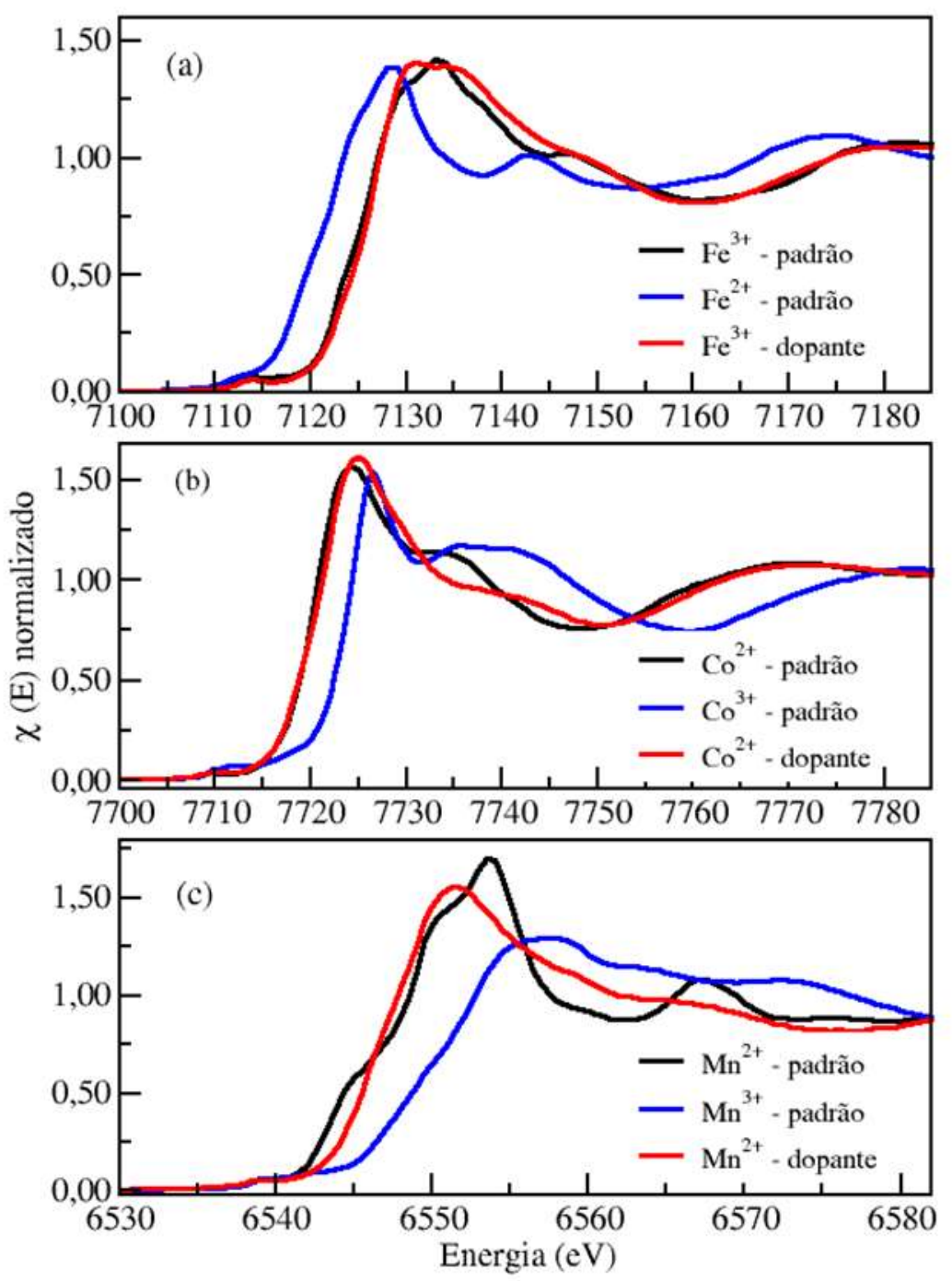

Fonte: Autor

Verifica-se que a energia da borda de absorção da amostra contendo Fe coincide com a referência padrão $\mathrm{Fe}^{3+}$ (Fig. 4a). Assim, os resultados de XANES confirma que o Fe entra na matriz hospedeira $\mathrm{SnO}_{2}$ como $\mathrm{Fe}^{3+}$.

De forma similar, a borda de absorção da amostra dopada com Co coincide com aquela do padrão $\mathrm{Co}^{2+}$ (Fig. 4b) e a borda de absorção da amostra com Mn coincide com aquela do padrão $\mathrm{Mn}^{2+}$ (Fig. 4c). 


\subsection{DIFRAÇÃO DE RAIOS-X}

Todas as amostras estudadas neste trabalho foram caracterizadas estruturalmente por difração de raios-x (DRX). Os difratogramas de DRX foram analisados por meio do refinamento de Rietveld.

As Figs. 5, 6 e 7 mostram os padrões de DRX e as curvas de Williamson-Hall das amostras $\mathrm{Sn}_{1-\mathrm{x}} \mathrm{Fe}_{\mathrm{x}} \mathrm{O}_{2}(\mathrm{x}$ $=0,02,0,05$ e 0,10), $\mathrm{Sn}_{1-\mathrm{x}} \mathrm{Co}_{\mathrm{x}} \mathrm{O}_{2}\left(\mathrm{x}=0,02,0,05\right.$ e 0,10) e $\mathrm{Sn}_{1-\mathrm{x}} \mathrm{Mn}_{\mathrm{x}} \mathrm{O}_{2}(\mathrm{x}=0,02,0,05$ e 0,10), respectivamente.

Os padrões de DRX (círculos escuros) foram analisados pelo método de refinamento Rietveld e os melhores ajustes estão mostrados como linhas sólidas (vermelhas). Todos os picos de difração das amostras analisadas correspondem a estrutura tetragonal rutílio do $\mathrm{SnO}_{2}$ padrão ICSD - 39173 (barras azuis). Nenhuma fase secundária foi detectada por esta técnica. A ausência de fase secundária pode ser atribuída à eficiência do método de sol-gel proteico em produzir amostras com dopantes distribuídos homogeneamente sem agrupamento ou segregação.

Os Parâmetros de rede, os tamanhos médios de cristalito obtidos pela equação de Scherrer (Ds) e pela relação de Williamson-Hall $\left(D_{W H}\right)$ e microdeformação $(\epsilon)$ residual obtida a partir do refinamento Rietveld são mostradas na Tabela 1. Todas as amostras mostraram tamanho de cristalito no faixa nanométrica com níveis desprezíveis de microdeformação. Pode-se observar um aumento nos tamanhos médios de cristalitos das amostras dopadas em relação a amostra pura. Isso sugere que os íons dopantes agem como catalizadores e aceleram o processo de formação dos compostos. Quanto as variações observadas nos parâmetros de rede, estas podem estar associadas tanto as diferenças dos raios iônicos dos íons dopantes e o da matriz hospedeira, quanto as deformações que eles podem introduzir na rede cristalina do $\mathrm{SnO}_{2}$. 
Figura 5. (a) Padrões de difração de raios-x de nanopartículas $\mathrm{Sn}_{1-x} \mathrm{Fe}_{x} \mathrm{O}_{2}$. Pontos e linhas sólidas são os dados experimentais e os melhores ajustes respectivamente. As barras representam o padrão ICSD-39173 padrão. (b) Curvas Williamson-Hall.
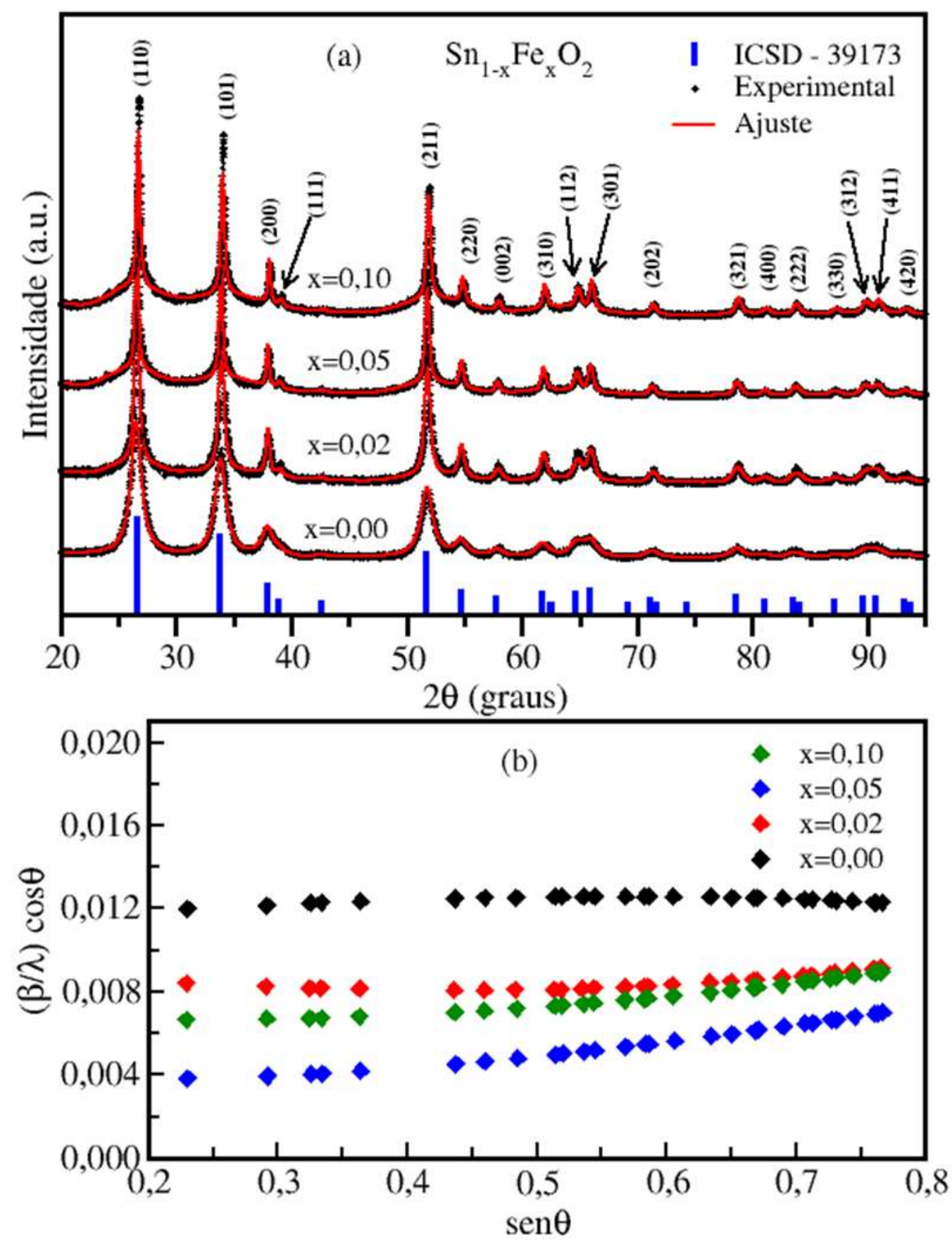

Fonte: Autor 
Figura 5. (a) Padrões de difração de raios-x de nanopartículas Sn1-xCoxO2. Pontos e linhas sólidas são os dados experimentais e os melhores ajustes respectivamente. As barras representam o padrão ICSD-39173 padrão. (b) Curvas Williamson-Hall.

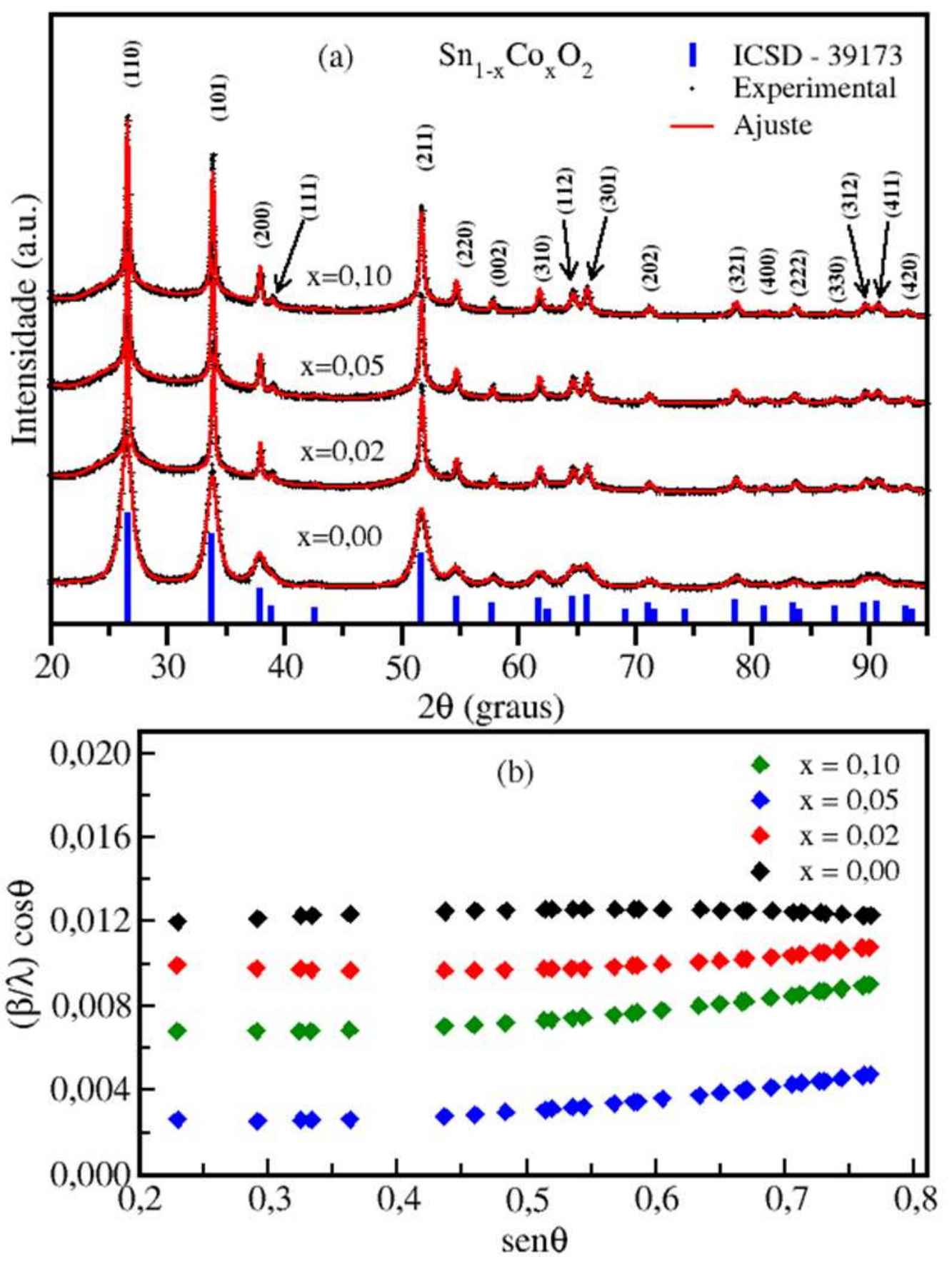

Fonte: Autor 
Figura 5. (a) Padrões de difração de raios-x de nanopartículas $\mathrm{Sn}_{1-x} \mathrm{Mn}_{x} \mathrm{O}_{2}$. Pontos e linhas sólidas são os dados experimentais e os melhores ajustes respectivamente. As barras representam o padrão ICSD-39173 padrão. (b) Curvas Williamson-Hall.

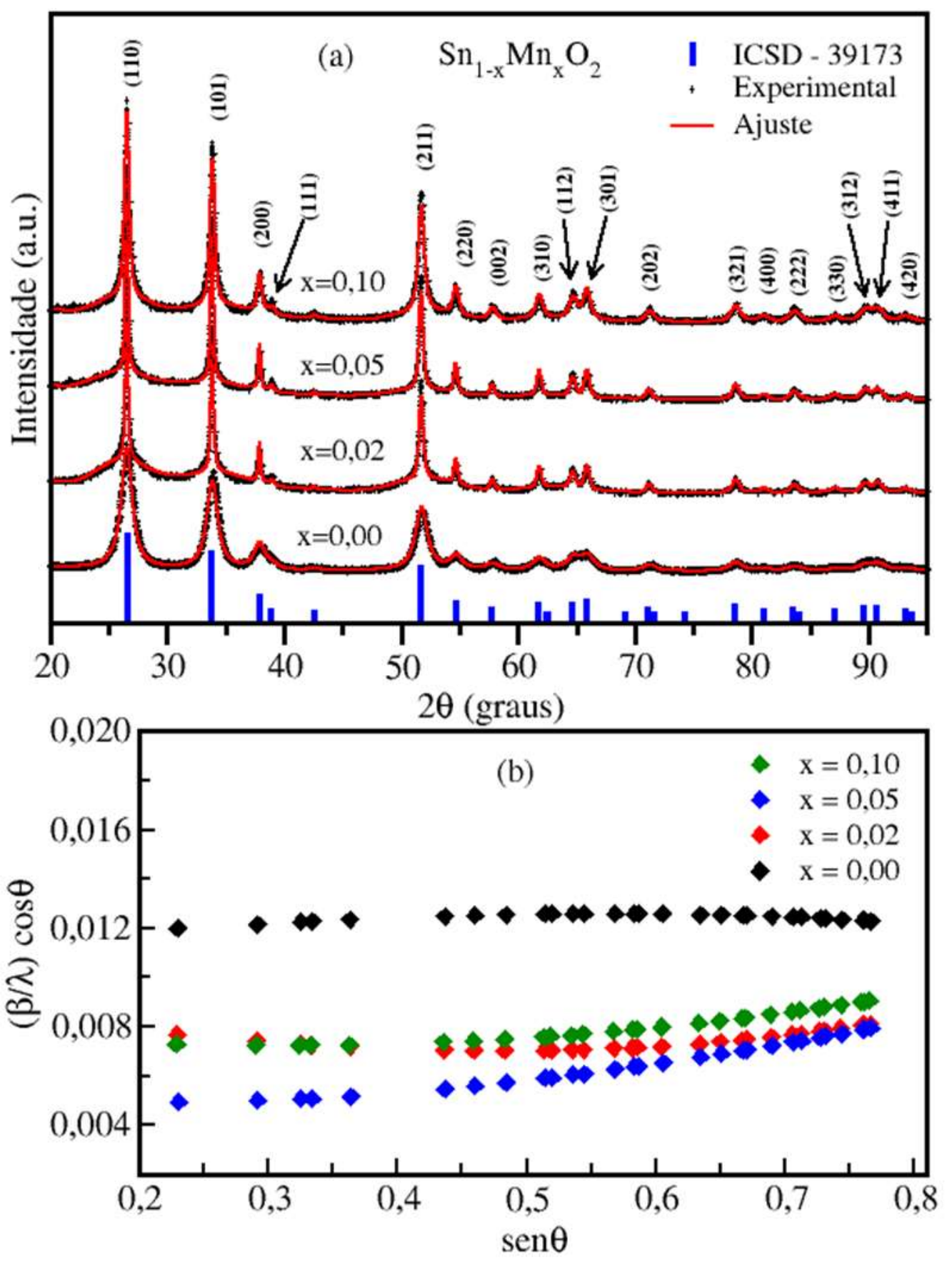

Fonte: Autor 
Tabela 1. Parâmetros de rede, volume de célula unitária, tamanho médio de cristalito e microdeformação de amostras de $\mathrm{Sn}_{1-\mathrm{x}} \mathrm{M}_{\mathrm{x}} \mathrm{O}_{2}$. Scherrer $\left(D_{S}\right)$, Williamson-Hall $\left(D_{W H}\right)$ e microdeformação $(\epsilon)$.

\begin{tabular}{ccccccc}
\hline Amostras & $\mathbf{a}=\mathbf{b}(\AA)$ & $\mathbf{c}=(\AA)$ & Vol. $\left._{(} \AA^{\mathbf{3}}\right)$ & $\mathbf{D}_{\mathbf{S}}(\mathbf{n m})$ & $\mathbf{D}_{\mathbf{W H}}(\mathbf{n m})$ & $\boldsymbol{\epsilon}(\boldsymbol{\%})$ \\
\hline $\mathrm{SnO}_{2}$ & 4,740 & 3,185 & 71,55 & 8,0 & 8,2 & 0,01 \\
\hline $\mathrm{Sn}_{1-\mathrm{x}} \mathrm{Fe}_{\mathrm{x}} \mathrm{O}_{2}$ & & & & & & \\
\hline $\mathrm{x}=0,02$ & 4,746 & 3,189 & 71,83 & 12,0 & 13,0 & 0.07 \\
$\mathrm{x}=0,05$ & 4,743 & 3,187 & 71,70 & 19,0 & $* *$ & $* *$ \\
$\mathrm{x}=0,10$ & 4,742 & 3,183 & 71,60 & 13,0 & 19,0 & 0,17 \\
\hline $\mathrm{Sn}_{1-\mathrm{x}} \mathrm{CO}_{\mathrm{x}} \mathrm{O}_{2}$ & & & & & & \\
\hline $\mathrm{x}=0,02$ & 4,746 & 3,189 & 71,80 & 25,0 & 32,0 & 0,07 \\
$\mathrm{x}=0,05$ & 4,743 & 3,187 & 71,70 & 25,0 & $* *$ & $* *$ \\
$\mathrm{x}=0,10$ & 4,744 & 3,187 & 71,73 & 17,0 & 34,0 & 0,28 \\
\hline $\mathrm{Sn}_{1-\mathrm{x}} \mathrm{M}_{\mathrm{x}} \mathrm{O}_{2}$ & & & & & & \\
\hline $\mathrm{x}=0,02$ & 4,744 & 3,188 & 71,75 & 29,0 & $* *$ & $* *$ \\
$\mathrm{x}=0,05$ & 4,740 & 3,185 & 71,58 & 16,0 & 34,0 & 0,24 \\
$\mathrm{x}=0,10$ & 4,745 & 3,187 & 71,75 & 15,0 & 29,0 & 0,27 \\
\hline
\end{tabular}

\subsection{MICROSCOPIA ELETRÔNICA DE TRANSMISSÃO.}

A Fig. 8 mostra as imagens de microscopia eletrônica de transmissão (MET) (duas diferentes magnificações) da amostra de $\mathrm{SnO}_{2}$. Pode se observar que as nanopartículas de $\mathrm{SnO}_{2}$ possuem morfologia aproximadamente esférica com diâmetro médio entre 5 e $10 \mathrm{~nm}$, em concordância com os tamanhos obtidos pelos dados de DRX.

Uma imagem ampliada de uma nanopartícula está mostrada na Fig. 8a. O padrão de difração de elétrons de área selecionada (DEAS) está mostrado no inserto da Fig. 8b. A distância interplanar mostrada na Fig.8a foi estimada em aproximadamente $0,33 \mp 0,02$, o que corresponde aos planos de difração $\{110\}$ da estrutura cristalina rutílio. Vale ressaltar que esses planos de difração são comumente encontrados em compostos de $\mathrm{SnO}_{2}$. Esses valores estão de acordo com os relatados na literatura (Aragón et al. 2015). 
Figura 8 Imagens de MET (duas diferentes magnificações) das nanopartículas de $\mathrm{SnO}_{2}$. Inserto: Uma imagem ampliada de uma nanopartícula e o padrão corresponde da difração de elétrons de área selecionada (DEAS).

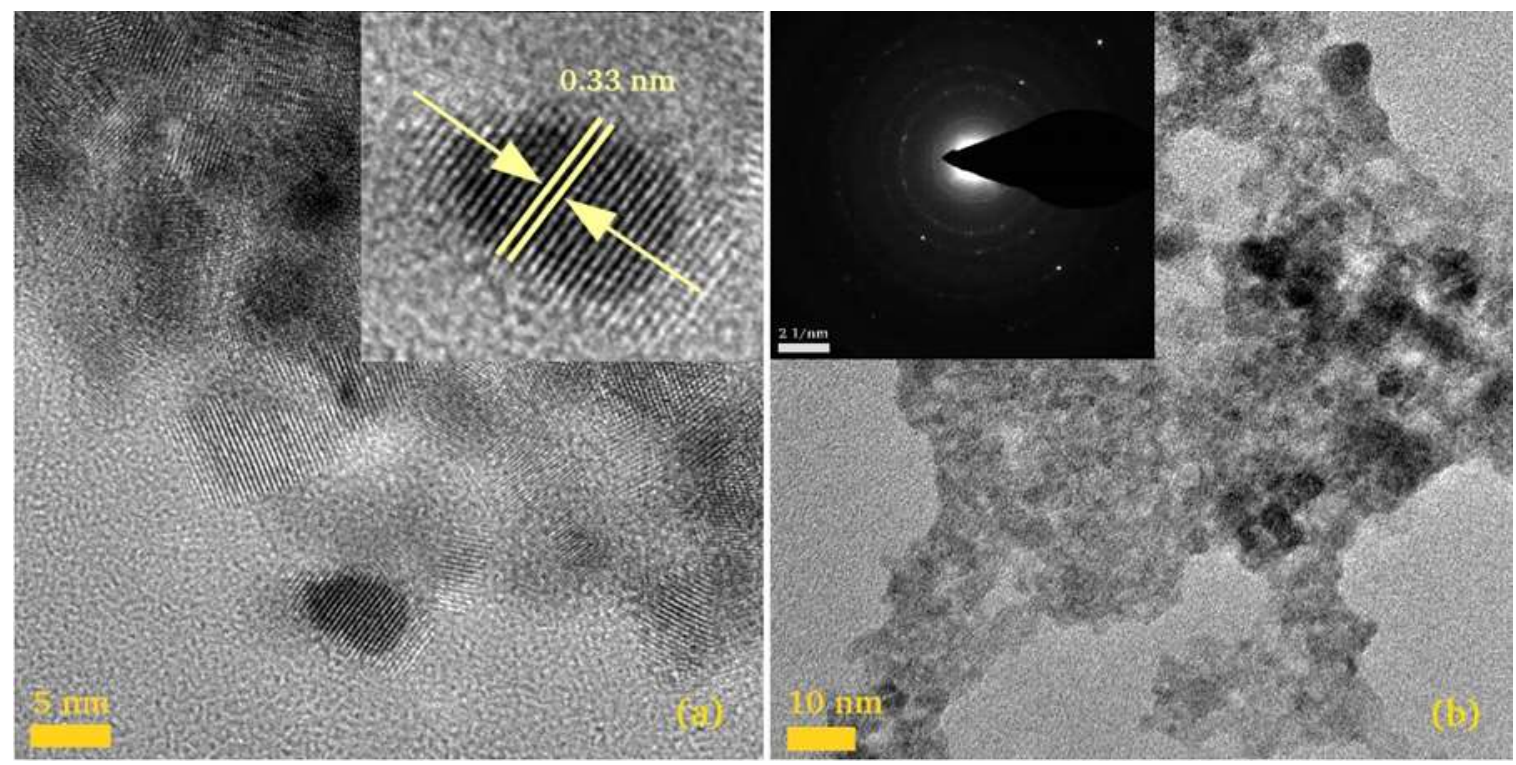

Fonte: Autor

\section{CONCLUSÃO}

O método de sol-gel proteico foi aplicado com sucesso para produzir nanopartículas de $\mathrm{Sn}_{1-\mathrm{x}} \mathrm{M}_{\mathrm{x}} \mathrm{O}_{2}$ ( $\mathrm{M}$ $=$ Fe. Co ou $\mathrm{Mn} ; \mathrm{x}=0,02,0,05$ e 0,10). A análise térmica sugeriu a formação do $\mathrm{SnO}_{2}$ ocorre em temperaturas entre 300 e $400^{\circ} \mathrm{C}$. Análises de XANES revelaram que os íons dopantes são incorporados de forma substitutiva como $\mathrm{Fe}^{3+}, \mathrm{Co}^{2+}$ and $\mathrm{Mn}^{2+}$ na estrutura cristalina do $\mathrm{SnO}_{2}$. Os resultados de $\mathrm{DRX}$ para todas as amostras mostraram a presença de uma única fase do $\mathrm{SnO}_{2}$ com estrutura tetragonal rutílio. Isso significa que os íons $\mathrm{Fe}^{3+}, \mathrm{Co}^{2+}$ e $\mathrm{Mn}^{2+}$ foram dopados em a estrutura cristalina do $\mathrm{SnO}_{2}$.

A substituição dos íons $\mathrm{Fe}^{3+}, \mathrm{Co}^{2+}$ e $\mathrm{Mn}^{2+}$ por $\mathrm{Sn}^{4+}$ no composto $\mathrm{SnO}_{2}$ acarreta mudanças significativas em suas propriedades estruturais. Verifica-se que há variações nos tamanhos médios dos cristalitos, assim como nos parâmetros estruturais das amostras como resultado da dopagem. Os resultados de MET uma amostra de $\mathrm{SnO}_{2}$ mostraram nanopartículas com formato aproximadamente esférico e diâmetro médio entre 5 e $10 \mathrm{~nm}$.

O presente trabalho representa uma evolução na produção de nanopartículas por um processo alternativo de sol-gel e representa um caminho promissor para aplicações em tecnologias emergentes. 


\section{AGRADECIMENTOS}

O autor gostaria de agradecer as agências brasileiras de fomento à pesquisa Fundação Cearense de Apoio ao Desenvolvimento Científico e Tecnológico (FUNCAP) e Conselho Nacional de Desenvolvimento Científico e Tecnológico (CNPq) pelo suporte financeiro.

Ao Laboratório de Materiais Avançados do Programa de Pós-Graduação em Engenharia e Ciências de Materiais da Universidade Federal do Ceará por disponibilizar sua estrutura para o desenvolvimento da pesquisa. Ao Laboratório de Difração de Raios-X da Universidade Federal do Ceará e ao Laboratório Nacional de Luz Síncroton (LNLS) pelas análises usadas nesse trabalho de pesquisa. 


\section{REFERÊNCIAS}

ARAGÓN, F. H., COAQUIRA, J. A. H., NAGAMINE, et al. Thermal-annealing effects on the structural and magnetic properties of $10 \%$ Fe-doped $\mathrm{SnO} 2$ nanoparticles synthetized by a polymer precursor method. J. Magn. Magn. Mater., v. 375, p. 74-79, 2015.

BELTRÁN, J. J., BARRERO, C. A., PUNNOOSE, A. Understanding the role of iron in the magnetism of Fe doped ZnO nanoparticles. Phys. Chem. Chem. Phys., v. 17, p. 15284, 2015.

BELTRAN, J. J.; SANCHEZ, L. C; OSORIO, J et al. Crystallographic and magnetic properties of Fe-doped SnO2 nanopowders obtained by a sol-gel method. J. Mater. Sci., v. 45, p. 5002-5011, 2010.

FENG, Y., JI, W.-X., HUANG, B.-J., et al. The magnetic and optical properties of $3 \mathrm{~d}$ transition metal doped SnO2 nanosheets. RSC Adv., v. 5, p. 24306-24312, 2015.

FUKUMURA, T; TOYOSAKI, H.; YAMADA, Y. Magnetic oxide semiconductors. Semicond. Sci. Technol., v. 20, p. 103, 2005.

MATSUMOTO, Y.; MURAKAMI, M.; SHONO, T. et al. Room-temperature ferromagnetism in transparent transition metal-doped titanium dioxide. Science, v. 291, p. 854, 2001.

MOHAGHEGHI, M. M. B., YAZDI, S. T., MOUSAVI, M. Magnetotransport and magneto-optical studies on $\mathrm{SnO} 2$ transparent semiconducting thin films alloyed with $\mathrm{Mn}$ over a wide range of concentration. Appl. Phys. A, v. 124, p. 274, 2018.

OGALE, S. B.; CHOUDHARY, R. J.; BUBAN, J. P. et al. High Temperature Ferromagnetism with a Giant Magnetic Moment in Transparent Co-doped SnO2. Phys. Rev. Lett., v. 91, p. 77205, 2003.

PEREIRA, M. S., MENDES, G. M. S. L., RIBEIRO, T. S. et al. Influence of Thermal-Treatment Effects on the Structural and Magnetic Properties of Sn1-xFexO2 Nanopowders Produced by Mechanical Milling. J. Supercond. Nov. Magn., v. 33, p. 1721-1728, 2020.

PEREIRA, M. S., RIBEIRO, T. S., LIMA, F. A. S., et al. Synthesis and properties of Sn1-xFexO2 nanoparticles obtained by a proteic sol-gel method. J. Nanopart. Res., v. 20, p. 212, 2018.

PEREIRA, M. S., LIMA, F. A. S., SILVA, C. B., et al. Structural, morphological and optical properties of SnO2 nanoparticles obtained by a proteic sol-gel method and their application in dye sensitized solar cells. J. Sol-Gel. Sci. Technol., v. 84, p. 206-213, 2017.

TOBY, B.H. EXPGUI, a graphical user interface for GSAS. J. Appl. Cryst., v. 34, p. 210, 2001.

UEDA, $\mathrm{K} ; \mathrm{H}$. TABATA, $\mathrm{H}$; KAWAI, T. Magnetic and electric properties of transition-metal-doped ZnO films. Appl. Phys. Lett., v. 79, p. 988, 2001.

RIETVELD, H. M. Line Profiles of neutron powder-diffraction peaks for structure refinement. Acta Cryst., v. 22, p. 151, 1967.

RIETVELD, H.M.: A profile refinement method for nuclear and magnetic structures. J. Appl. Cryst., v. 2, p. 65, 1969. 
WILLIAMSON, G.K.; HALL, W. H. X-ray line broadening from filed aluminium and wolfram. Acta Metall., v. 1, p. 22, 1953.

YINMEI LU. SnO2 Thin Films - Chemical Vapor Deposition and Characterization. Dissertation. JustusLiebig-Universität Giessen, 2015.

ZHANG, J; GAO, L. Synthesis and characterization of nanocrystalline tin oxide by sol-gel method. J. Solid State Chem., v. 177, p. 1425-1430, 2004. 


\section{Capítulo 5}

doi) $10.37423 / 210504041$

\section{LEVANTAMENTO DO ÍNDICE PLUVIOMÉTRICO DO TERRITÓRIO RURAL DO MÉDIO PIRANHAS}


Resumo: É de conhecimento comum, a preocupação com a irregularidade pluviométrica na região semiárida, uma vez que, este tipo de distribuição ocasiona fortes impactos nos mais diversos setores. É importante destacar o agravamento destes problemas nos últimos anos, em consequência das atividades humanas sobre o ambiente. O presente artigo busca fazer uma relação entre o índice pluviométrico e estudo de políticas públicas de prevenção e minimização das problemáticas sociais com as irregularidades da estação chuvosa ou seca, dos últimos 11 (onze) anos de 16 (dezesseis) cidades paraibanas, com a fragilidade ambiental encontrada na área em estudo, fazendo uso da técnica de geoprocessamento a partir do Soft livre QGIS. A região estudada abrange 16 municípios inseridos na região do território rural do médio piranhas, ocupando uma área de, aproximadamente, $5.645,593 \mathrm{~km}^{2}$, com a população total estimada em 168.296 habitantes. O relevo, a paisagem, as atividades econômicas (agricultura, pecuária, piscicultura, entre outros) e o próprio meio social, sentem as mudanças provocadas. Esses impactos alteram o regime hídrico e consequentemente a vivencia neste lugar. A partir do levantamento do índice pluviométrico da região e através da caracterização climática da pluviometria dos municípios entre os anos de 2005 e 2015, é possível identificar uma alta fragilidade ambiental da área estudada. A água, na condição de agente modelador do relevo, e a ausência de precipitação resultam em pouca ou nenhuma atividade intempérica, dificultando a formação e a qualidade do solo. Isso tudo, gera impactos econômicos e sociais, dificultando a geração de renda e a vivência das pessoas neste tipo de ambiente. Neste contexto, torna-se urgente a efetivação de políticas sociais e de gestão ambiental capazes de mitigar e apresentar soluções para tais problemas, facilitando assim, a geração de renda e a vivência na região semiárida.

Palavras-chave: Fragilidade ambiental, geoprocessamento, pluviometria, semiárido. 


\section{INTRODUÇÃO}

A qualidade ambiental de um ecossistema expressa as condições e os requisitos básicos que ele detém, de natureza física, química, biológica, social, econômica, tecnológica, cultural e política (TAUK, 1995). O índice pluviométrico é fator determinante tanto para o ciclo hidrológico quanto para a manutenção da vida no planeta. As secas constituem sério problema para a sociedade humana e para os ecossistemas naturais (DINPASHOH et al., 2004). Silva (2004) observou tendências significativamente decrescentes em várias localidades desta região, e sugeriu que tal variabilidade pode estar relacionada com mudanças climáticas no Nordeste do Brasil, que atinge não apenas o semiárido da região, mas, também, a área litorânea.

O semiárido nordestino é uma região conhecida pelos longos períodos de estiagem, caracterizando uma localidade seca. Sabendo que parte da população sobrevive de atividades agrícolas, a variação pluvial torna-se fator determinante nas condições de produção e consequentemente para sobrevivência, uma vez que longos períodos sem chuva acarretam impactos consideráveis nos recursos naturais utilizados para a produtividade dos moradores da região. Logo o objetivo do trabalho é avaliar a fragilidade ambiental a partir do levantamento pluviométrico do Territorio do Médio Piranhas, fazendo uma associação com as políticas públicas pertinentes, tomando como base o plano diretor do estado da Paraíba.

Referindo-se as transformações que sociedade promove nas paisagens, Tricart (1977) afirma que o homem participa efetivamente dos ambientes onde vive, modificando-os, permanentemente, para atender seus anseios e necessidades. Ao enfatizar a importância das relações intrínsecas entre a sociedade e a natureza, Ross (1994) ensina que as sociedades humanas não devem ser tratadas como elementos estranhos à natureza e, portanto, aos ambientes onde vivem; ao contrário, devem ser vistas como parte fundamental do sistema de relações, enfatizando que: As progressivas alterações até então inseridas pelas sociedades humanas nos diferentes componentes naturais, afetam cada vez mais a funcionalidade do sistema e com frequência induzem a grave processos degenerativos ao ambiente natural, em um primeiro momento, e a própria sociedade em prazos mais longos.

Segundo Ross (2009), a fragilidade ambiental é a perda do estado "clímax" em que os processos mecânicos atuam em equilíbrio dinâmico, predominando a pedogênese em detrimento da morfogênese; ou melhor, com essa fragilidade a perda do potencial ambiental repercute no desenvolvimento social da área. Ainda conforme o autor, a fragilidade diz respeito à quebra do potencial ecológico de um geossistema diretamente relacionado com as condições do meio físico 
natural, principalmente com a cobertura vegetal, e revela o potencial de degradação provocada pelas atividades antrópicas.

Segundo (Tricart, Ross, 1977, 2003), a fragilidade ambiental do relevo é crucial na análise integrada da paisagem, porque possibilita que a sociedade use e ocupe a paisagem de forma mais harmônica. A dinâmica do relevo é influenciada pela ação da declividade topográfica. Numa área de declividade suave, quase plana, o intemperismo é forte e o processo erosivo é pequeno. Quando os declives são acentuados, como nas áreas montanhosas e nas escarpas das serras, o processo erosivo é intenso.

\section{METODOLOGIA}

A figura 1 mostra o mapa da Paraíba e destaca a região do médio piranhas. Abrangendo os 16 (dezesseis) municípios inseridos, ocupando uma área de, aproximadamente, 5.645,593 km², com a população total estimada em 168.296 habitantes.

Figura 1: Mapa do Estado da Paraíba, em desta que o território rural do médio piranhas.

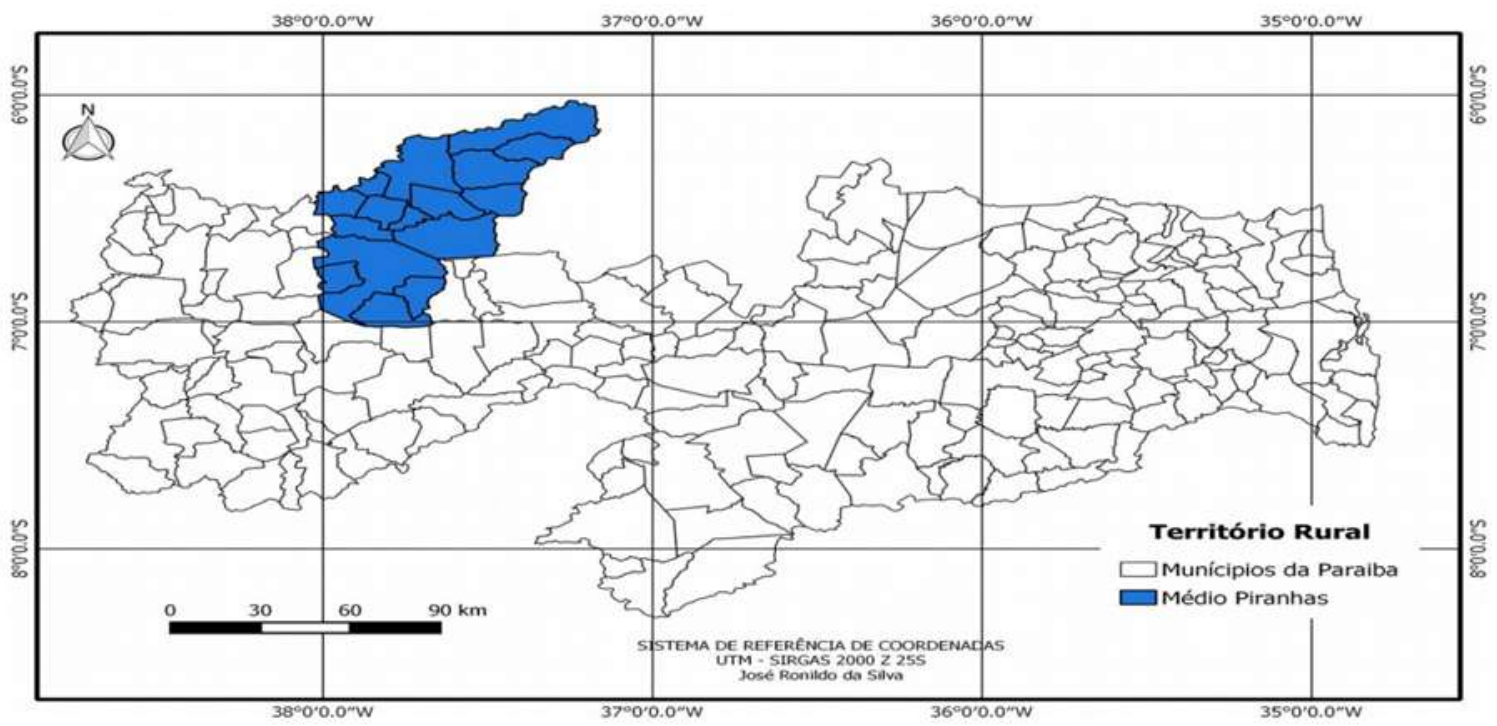

Fonte: Autoria própria.

No presente estudo utiliza-se a perspectiva teórica geossistêmica, que integra os elementos da paisagem e subsidia o entendimento dos fenômenos de forma mais abrangente, considerando os elementos naturais e artificiais e a ação antrópica. Desse modo, destaca-se o uso de técnicas de geoprocessamento na identificação e na análise do grau de fragilidade dos ambientes que permite aos gestores Municipais, Estaduais e Federais um olhar mais crítico e minucioso para as cidades apresentados com menor índice pluviométrico, pautando-se em um enfoque de ampliação de desenvolvimento de políticas públicas de convivência com o semiárido. Tais estudos representam uma 
importante ferramenta na busca por soluções para as políticas de gestão territorial a serem implantadas.

A economia da região está baseada em serviços indústrias de pequeno porte e agropecuária. Têm como principal fonte de renda atividades agropecuárias, com destaque para a produção de milho, feijão e criação de bovinos, caprinos, ovinos e aves.

Segundo a classificação de Köppen-Geiger o clima local é do tipo BSh, semiárido, quente, seco e com longos períodos de estiagem, além de chuvas irregulares em quatro ou cinco meses do ano.

A vegetação é composta por Caatinga xerófila ou hiperxerófila, com a presença de cactáceas, arbustos e árvores de pequeno a médio porte, predominando na paisagem espécies como Caesalpinia pyramidalis Tul., Croton blanchetianus Baill., Mimosa tenuiflora (Wild) Poir., Cereus jamacaru L.

Foi realizado levantamento pluviométrico entre os anos de 2005 até 2015 da região, utilizando o banco eletrônico de informações da Agência Executiva de Gestão das Águas do Estado da Paraíba (AESA) e utilizou-se da ferramenta de Soft livre de geoprocessamento QGIS 2.8.9 para geração dos mapas. Por fim foi realizado um levantamento bibliográfico e estudo do plano diretor do estado da Paraíba para avaliação de políticas públicas de interesse do trabalho.

\section{RESULTADOS E DISCUSSÃO}

A tabela subsequente mostra as médias pluviométricas dos 16 (dezesseis) municípios em questão. 
Tabela 1 - Corresponde à média de precipitação dos últimos 11 (onze) anos de 16 (dezesseis) municípios da região do médio piranhas a partir de dados obtidos junto à AESA (2015).

\begin{tabular}{|c|c|c|c|c|}
\hline ID & CIDADE & $\mathbf{S}$ & W & MÉDIA (mm) \\
\hline 1 & BELEM DO B DO CRUZ & -061120 & -373209 & 786,43 \\
\hline 2 & BOM SUCESSO & -062642 & -375544 & 685,65 \\
\hline 3 & BREJO DO CRUZ & -062056 & -352952 & 842,17 \\
\hline 4 & BREJO DOS SANTOS & -062237 & -374930 & 747,1 \\
\hline 5 & CAJAZEIRINHAS & -065739 & -374821 & 830,15 \\
\hline 6 & CATOLE DO ROCHA & -062038 & -374449 & 828,05 \\
\hline 7 & JERICÓ & -063314 & -374832 & 704,95 \\
\hline 8 & LAGOA & -063415 & -375457 & 808,5 \\
\hline 9 & MATO GROSSO & -063202 & -374330 & 800,09 \\
\hline 10 & PAULISTA & -063538 & -373726 & 778,49 \\
\hline 11 & POMBAL & -064612 & -374807 & 819,89 \\
\hline 12 & RIACHO DOS CAVALOS & -062634 & -373903 & 719,27 \\
\hline 13 & SÃO BENTINHO & -065403 & -374344 & 808,71 \\
\hline 14 & SÃO BENTO & -062909 & -372703 & 835,85 \\
\hline 15 & SÃO DOMINGOS & -064850 & -375631 & 668,65 \\
\hline 16 & SÃO J DO B DO CRUZ & -061246 & -372107 & 692,33 \\
\hline
\end{tabular}

O município de Brejo do Cruz foi o que obteve a maior média pluviométrica 842,17 mm durante os 11 (onze) anos analisados (Tabela 1), enquanto que o município de São Domingos ficou com o menor índice de chuvas $668 \mathrm{~mm}$, sendo que os outros 14 (quatorze) municípios tiveram a média compreendida entre $668,35 \mathrm{~mm}$ e $842,17 \mathrm{~mm}$.

Para a maioria dos municípios analisados, o ano de 2012 foi o menos chuvoso, enquanto que os anos de 2008 e 2009 destaca-se o período com maior índice pluviométrico registrado. Em meio a essas irregularidades pode-se destacar que a ocorrência de veranicos em meio ao período estudado, resultando em impactos consideráveis para o meio e para a vivência social e econômica da região, especialmente por promover o aumento da condição de aridez local.

A figura 2 indica o mapa do índice pluviométrico com os 16 (dezesseis) postos analisados na região do médio piranhas e a interpolação dos mesmos através das isoietas. 
Figura 2: Mapa do índice pluviométrico do Território Rural do Médio Piranhas para a série histórica de 2005-2015.

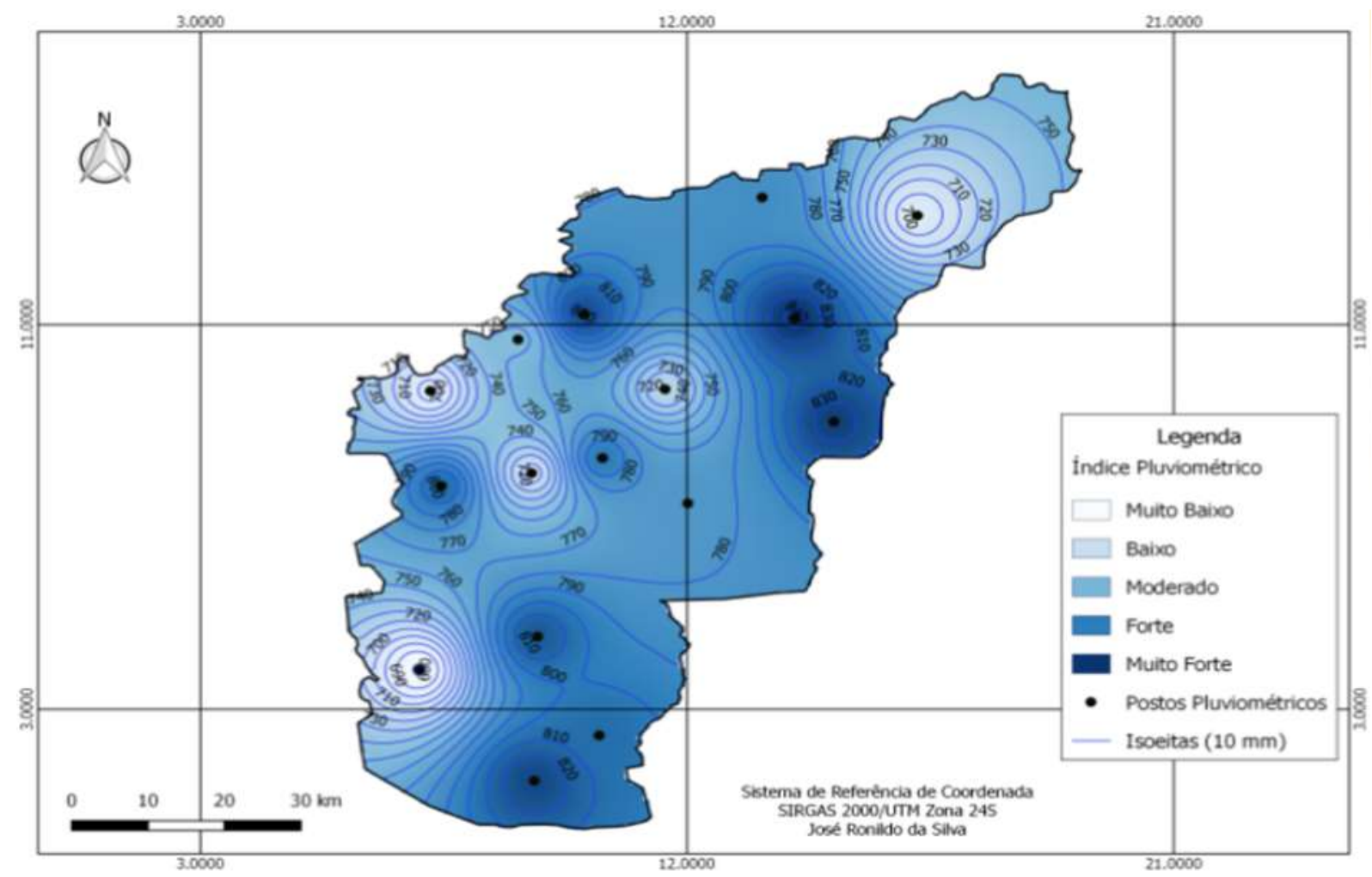

Fonte: Autoria própria.

Analisando os dados de amplitude pluviométrica percebe-se que existe uma forte irregularidade na distribuição de chuvas ao longo dos anos (tempo e espaço), sendo esse um dos fatores responsáveis pela problemática da escassez hídrica na região do médio piranhas e no nordeste brasileiro, trazendo consequências negativas para a produção de alimentos e abastecimento humano e animal (BACK, et al., 2011). Entre os principais motivos apontados como responsáveis por essa má distribuição está a localização geográfica, pois a massa de água que vêm do litoral fica retida, principalmente, nas regiões de brejo de altitude ou planalto da Borborema, impedindo a formação das chamadas "nuvens de chuva" nas estações mais secas do ano. Outro fator apontado como influenciador da distribuição de chuvas no Nordeste brasileiro, e consequentemente na mesorregião do sertão paraibano, é o efeito do fenômeno natural El Niño, que provoca alterações no clima mundial, podendo afastar massas de ar que poderiam desaguar sobre a região em análise. 


\section{CONCLUSÕES}

Existe uma forte discrepância na distribuição das chuvas na região do médio piranhas nos últimos 11 anos. Entre a cidade que registrou o maior índice pluviométrico ( Brejo do Cruz, 842,17 mm) e a cidade que registrou o menor índice (São Domingos, $668 \mathrm{~mm}$ ) a diferença é de 174,17 mm.

Há a necessidade de políticas e planos de captação e aproveitamento das águas das chuvas, além do uso mais eficiente dos demais recursos naturais da região, para que o desenvolvimento socioeconômico não seja limitado pela disponibilidade hídrica. Permanece a necessidade de estudos mais aprofundados sobre a distribuição pluviométrica da região Nordeste do Brasil e em especial da região do médio piranhas, visando à identificação de padrões de chuvas e medidas preventivas contra as secas. 


\section{REFERÊNCIAS BIBLIOGRÁFICAS}

AESA, Agência Executiva de Gestão das Águas do Estado da Paraíba. Disponível em:

<http://site.aesa.pb.gov.br/aesa/medicaoPluviometrica.dometodo/chuvasDiarias/Mapa>.

Acesso em: 07 de Out. 2016, 19:30:12.

BACK, A. J.; UGGIONI, E.; VIEIRA, H. J. Modelagem da precipitação de curta duraçãopor meio do modelo de pulsos retangulares de Bartlett-Lewis modificado. Revista Brasileira de Meteorologia, v.26, n.3, 46-472. 2011.

DINPASHOH, Y.; Fakheri-Fard, A.; Moghaddam, M.; Jahanbakhsh, S.; Mirnia, M. Selection of variables for the purpose of regionalization of Iran's precipitation climate using multivariate methods. Journal of Hydrology, v.297, p.109-123, 2004.

IBGE, Instituto Brasileiro de Geografia e Estatística. Disponível em:

<http://www.ibge.gov.br/estadosat/PB>. Acesso em: 06 de Out. 2016, 18:30:15.

JOÃO PESSOA. Governo do Estado. Plano diretor de proteção civil. João Pessoa; 2012.

MOSER, C. The asset vulnerability framework: reassessing urban poverty reduction strategies. World Development, New York, v.26, n.1, 1998.

PINHEIRO, Otilie Macedo. Plano diretor e gestão urbana. 1aㅡ ed. Florianópolis: CAPES:

UAB, 2009.

ROSS, Jurandir L. S. Análise empírica da fragilidade dos ambientes naturais e antropizados. Revista do Departamento de Geografia, n. 8, p. 63-74, São Paulo, USP, 1994.

ROSS, Jurandir L. S. Geomorfologia: ambiente e planejamento. 7. ed. São Paulo: Contexto, 2003.

TAUK, Sâmia Maria. Análise Ambiental. 2. ed. São Paulo: Unesp, 1995.

TRICART, Jean. Ecodinâmica. Rio de Janeiro: IBGE, SUPREN, 1977.

TAGLIANI, C. R. A. (2002). Técnica para avaliação da vulnerabilidade ambiental de ambientes costeiros utilizando um sistema geográfico de informações. Disponível em:. Acesso em: 08 de ago. 2016, 20:10:05. 


\section{Capítulo 6}

doi) $10.37423 / 210504044$

\section{DIAGNÓSTICO DO PROCESSO DE REESTRUTURAÇÃO PRODUTIVA DAS FAMÍLIAS DE REASSENTADOS DA USINA HIDRELÉTRICA DE IRAPÉ, MINAS GERAIS, BRASIL}

Martionei Leite Gomes

\section{Elida Elizena Carneiro de Matos}

Nilton Fernandes de Oliveira

Adriano Campos Lemos

Amanda Cardoso de Oliveira Silveira Cassette
Cooperação para o Desenvolvimento e Morada Humana

Cooperação para o Desenvolvimento e Morada Humana

CEMIG Geração e Transmissão S.A.

CEMIG Geração e Transmissão S.A.

Universidade do Estado de Minas Gerais MG 
Resumo: O projeto de reassentamento da usina hidrelétrica de Irapé (UHE Irapé), localizada no Rio Jequitinhonha, no Estado de Minas Gerais, executou diferentes soluções a mais de mil grupos familiares envolvidos. O presente estudo objetivou realizar um diagnóstico do processo de reestruturação produtiva das famílias de reassentados remanescentes da UHE Irapé, utilizando-se uma abordagem quantitativa de pesquisa, por meio de um levantamento censitário. Seiscentos e uma famílias foram identificadas como reassentadas, dentre as quais quatrocentas e uma permaneceram em seus locais de reassentamento, sendo possível entrevistar trezentos e sessenta e oito. 0 diagnóstico do processo de reestruturação produtiva indicou que grande parte das famílias de reassentados remanescentes exercem atividades ligadas ao manejo da terra, contudo, mesmo transcorridos mais de 10 anos desde o início da operação da UHE Irapé, os grupos familiares apresentam dificuldades em sobreviver apenas da exploração da terra e possuem ainda considerável potencial produtivo em suas propriedades, assim como, demonstram interesse em investir.

Palavras-chave: Reestruturação Produtiva, Reassentamento, Hidrelétrica, UHE Irapé. 


\section{INTRODUÇÃO}

A criação de empreendimentos que visam infraestrutura e desenvolvimento em diversas regiões do mundo são as mais frequentes razões para o deslocamento compulsório e consequente reassentamento. Segundo o Banco Mundial, os processos de reassentamento que não são complementados com medidas atenuantes, podem culminar em riscos econômicos, sociais e ambientais (BANCO MUNDIAL, 2016).

A UHE Irapé, localiza-se no Rio Jequitinhonha, rio de referência para a região, entre os municípios de Berilo e Grão Mogol, no Estado de Minas Gerais. A UHE Irapé teve sua operação independente de energia iniciada no ano de 2006, sob propriedade e operação da Companhia Energética de Minas Gerais (CEMIG) (EIA/RIMA, 1993; CEMIG, 2019).

O projeto de reassentamento do empreendimento da UHE Irapé foi coordenado pela CEMIG que identificou diferentes soluções aos 1200 grupos familiares envolvidos. Mais de 600 famílias foram beneficiadas em reassentamentos, além das novas terras, houveram ainda indenizações pelas benfeitorias, plantações e animais e a execução de um projeto de reestruturação produtiva, contemplando assistência técnica rural, preparação para o plantio e insumos para produção inicial, no intuito de estabelecer acesso aos recursos e oportunidades econômicas equivalentes (EIA/RIMA, 1993; BRASIL, 2002).

Contudo, apesar dos grandes esforços empenhados objetivando a reestruturação produtiva dos núcleos familiares de reassentados, deve-se ressaltar que muitas dessas famílias eram unidades familiares ou parceiras para a produção, com a utilização coletiva de terras e/ou equipamentos, muitas vezes realizando atividades como exploração agropecuária, extração de recursos naturais, garimpagem, faiscagem e carvoejamento, características que podem ter se tornado inviabilizadas diante da realidade posterior ao reassentamento (EIA/RIMA, 1993).

Desta forma, o presente estudo objetivou realizar um diagnóstico do processo de reestruturação produtiva das famílias de reassentados remanescentes do empreendimento da UHE Irapé, transcorridos mais de 10 anos desde o início de sua operação.

\section{METODOLOGIA}

Para a realização do presente estudo foi utilizada uma abordagem quantitativa de pesquisa, por meio de um levantamento censitário para realização do diagnóstico do processo de reestruturação produtiva. 
De acordo com a resolução no 510/2016 da Comissão Nacional de Ética em Pesquisa em Seres Humanos (CONEP) por se tratar de uma pesquisa censitária cujo objetivo é uma melhor compreensão de características de uma população específica, visando a melhoria de ações para a mesma, não é requerido registro, nem avaliação pelo sistema CONEP.

O levantamento censitário foi realizado através da aplicação de um questionário semiestruturado padronizado, elaborado em conjunto pela equipe do projeto e pelo Instituto Pólis Pesquisa $\mathrm{Ltda}^{1}$. O questionário foi desenvolvido dentro de critérios rigorosos de controle metodológico, procurando assegurar a confiabilidade dos dados. O mesmo questionário foi aplicado em todos os domicílios, de forma a possibilitar a comparação das informações obtidas.

O questionário foi aplicado no período de Março a Junho de 2019, junto aos grupos familiares reassentados remanescentes as margens direita e esquerda do Rio Jequitinhonha, rio de referência para região, ao longo de diferentes municípios da região conhecida como Vale do Jequitinhonha, localizada no Norte do Estado de Minas Gerais. O questionário foi respondido apenas por um representante, maior de idade, de cada um dos núcleos familiares. Os dados obtidos através da aplicação dos questionários foram compilados em banco de dados contendo as informações pertinentes e tratados através de análise estatística descritiva com valores absolutos e percentuais.

\section{RESULTADOS E DISCUSSÃO}

Segundo informações apuradas junto as lideranças ou pessoas de referências nas fazendas de reassentamento, um total de 601 famílias foram reassentadas, no período de 2003 e 2005 . Além disso, foi possível identificar que destas, somente 401 permaneceram em seus locais de reassentamento, caracterizando uma taxa de permanência de $67,0 \%$. Através do presente estudo foi possível entrevistar 368 grupos familiares remanescentes, compostos por 1280 integrantes, atingindo dessa forma uma taxa de cobertura de $92,0 \%$ do universo amostral.

Avaliando a questão do trabalho nas propriedades rurais dos reassentados, 65,4\% dos indivíduos ainda trabalham direta ou indiretamente em suas propriedades. Contudo, proporcionalmente, na margem direita do Rio Jequitinhonha, existem mais integrantes trabalhando em suas propriedades quando comparado a margem esquerda do rio $(71,9 \% \times 61,1 \%)$. Entre os integrantes que trabalham em suas propriedades, $59,3 \%$ são indivíduos do sexo masculino e 40,7\% são indivíduos do sexo feminino (Figura 1). Considerando os núcleos familiares, a renda familiar de 63,0\% é composta por rendimentos que derivam da terra e de outras atividades e/ou benefícios fora do âmbito da 
propriedade rural, $32,6 \%$ possuem rendimentos provenientes de outras fontes de renda, fora do âmbito da propriedade, ao passo que, somente $4,3 \%$ possuem renda familiar derivada exclusivamente da exploração da terra (Figura 1).

Observou-se ainda, que entre os núcleos familiares que foram reassentados na margem esquerda do rio, existe uma maior frequência de famílias que vivem exclusivamente de outras atividades e rendimentos que não advém do manejo da terra em comparação a margem direita. Da mesma forma, na margem direita são mais frequentes rendimentos compostos por um conjunto de atividades relacionadas à propriedade e também atividades independentes da propriedade (Tabela 1). Demonstrando que mesclar uma cesta de atividades que geram renda relacionadas à propriedade rural com atividades fora do âmbito da exploração da terra é uma estratégia para garantir rendimentos.

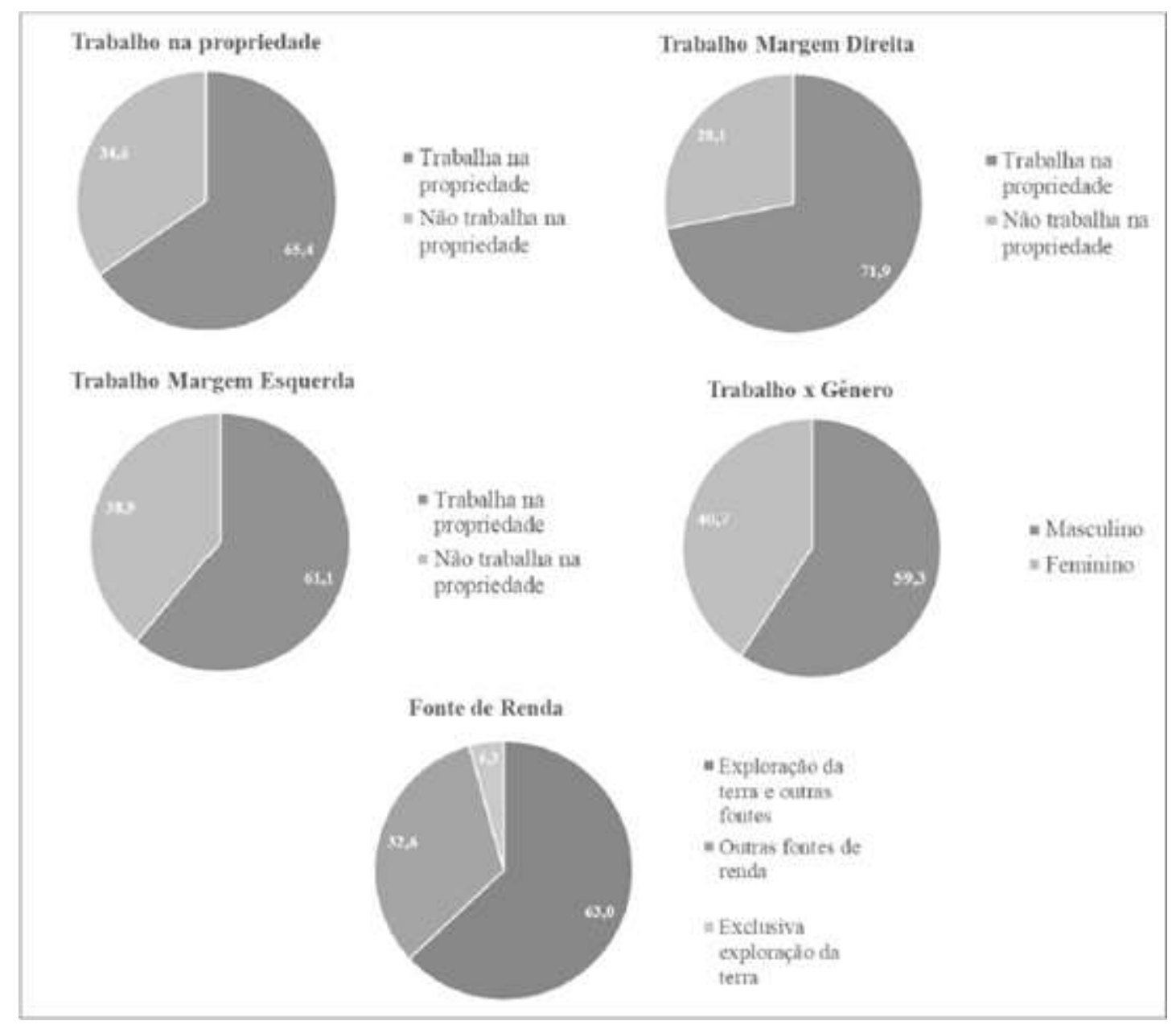

Figura 1 - Caracterização do quesito trabalho entre as famílias de reassentados remanescentes do empreendimento UHE Irapé. Fonte: Dados da pesquisa, 2019. 
Tabela 1 - Composição da renda familiar das famílias de reassentados remanescentes.

\begin{tabular}{c|c|c|c}
\hline Composição da Renda Familiar & $\begin{array}{c}\text { Margem } \\
\text { Direita }\end{array}$ & $\begin{array}{c}\text { Margem } \\
\text { Esquerda }\end{array}$ & Total \\
\hline Exclusiva exploração da terra & $9(5,7 \%)$ & $7(3,3 \%)$ & $16(4,4 \%)$ \\
Exploração da terra e outras fontes & $135(85,4 \%)$ & $97(46,2 \%)$ & $232(63,0 \%)$ \\
Outras fontes de renda & $14(8,9 \%)$ & $106(50,5 \%)$ & $120(32,6)$ \\
\hline Total & $158(100 \%)$ & $210(100 \%)$ & $368(100 \%)$ \\
\hline
\end{tabular}

Fonte: Dados da pesquisa, 2019.

Considerando os 16 grupos familiares $(4,4 \%)$ cuja composição da renda familiar é composta exclusivamente da exploração da terra, seja através da produção ou arrendamento, 56,3\% realizam a produção de subsistência e a comercialização do excedente. Entre os 232 (63,0\%) núcleos familiares, cuja renda é composta pela exploração da terra e outras fontes, $71,1 \%$ realizam a produção de subsistência com excedente não comercializado. Já entre as 120 (32,6\%) famílias cuja composição da renda é composta exclusivamente de outras fontes, $89,9 \%$ também realizam a produção de subsistência com excedente não comercializado. Levando em consideração o total de grupos familiares reassentados remanescentes entrevistados, 3,5\% deles não realizam nenhum tipo de produção em sua propriedade (Tabela 2).

Tabela 2 -Tipos de produção e rendimentos das famílias de reassentados remanescentes.

\begin{tabular}{|c|c|c|c|c}
\hline Tipo de Produção & $\begin{array}{c}\text { Exclusiva } \\
\text { exploração da } \\
\text { terra }\end{array}$ & $\begin{array}{c}\text { Exploração } \\
\text { da terra e } \\
\text { outras } \\
\text { fontes }\end{array}$ & $\begin{array}{c}\text { Outras } \\
\text { fontes de } \\
\text { renda }\end{array}$ & Total \\
\hline $\begin{array}{c}\text { Não produzz } \\
\text { Subsistência com excedente } \\
\text { não comercializado }\end{array}$ & $0(0,0 \%)$ & $1(0,4 \%)$ & $12(10,1 \%)$ & $13(3,5 \%)$ \\
$\begin{array}{c}\text { Subsistência com excedente } \\
\text { comercializado }\end{array}$ & $9(53,8 \%)$ & $165(71,1 \%)$ & $107(89,9 \%)$ & $279(76,0 \%)$ \\
Exclusiva comercialização & $0(0,0 \%)$ & $58(25,0 \%)$ & $0(0,0 \%)$ & $67(18,3 \%)$ \\
\hline Total & $16(100 \%)$ & $232(100 \%)$ & $119(100 \%)$ & $367(100 \%)$ \\
\hline
\end{tabular}

Fonte: Dados da pesquisa, 2019.

Na cesta de rendimentos dos reassentados remanescentes o cultivo da terra $(56,0 \% n=206)$, a criação de animais $(49,5 \%, n=182)$ e a aposentadoria $(48,4 \%, n=178)$ são os itens que mais se repetem. São ainda itens que compõem a cesta de rendimentos, o bolsa família $(33,2 \%, n=122)$, o trabalho 
autônomo (29,6\%, n=109), a fabricação de produtos (queijo, requeijão, farinha de mandioca, entre outros) $(28,8 \%, n=106)$, o benefício de prestação continuada (BPC) $(19,6 \%, n=72)$, o trabalho assalariado fixo $(14,1 \%, n=52)$ e o arrendamento ou aluguel de parte ou toda a propriedade $(9 \%, n=33)$ (Figura 2).

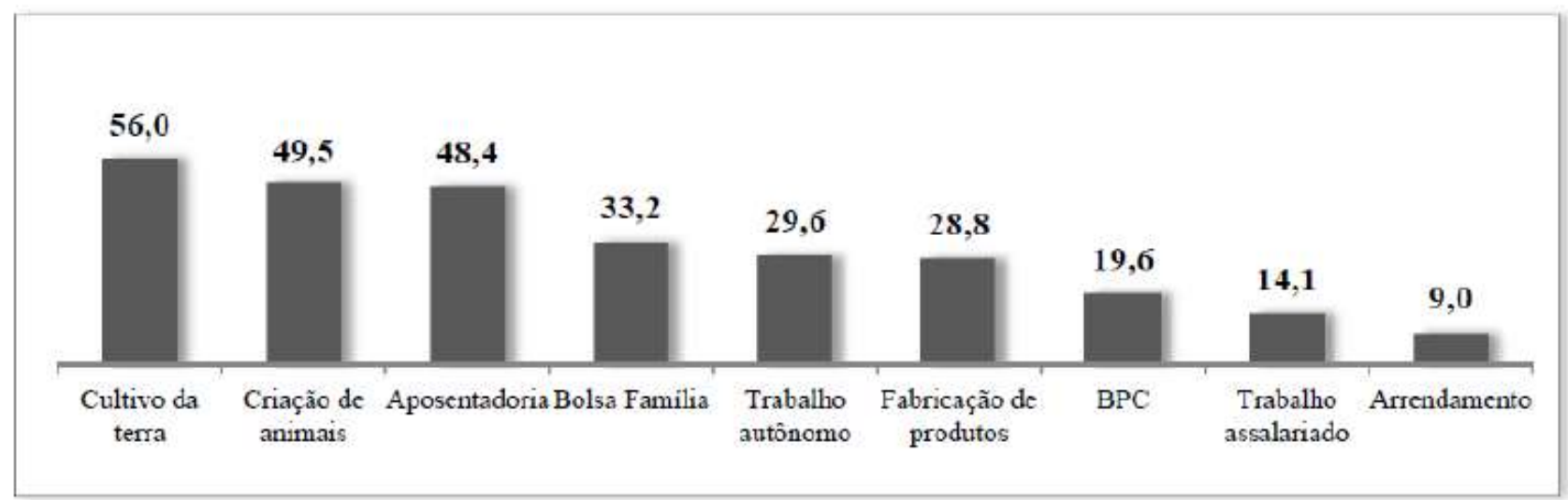

Figura 2 - Caracterização da cesta de rendimentos das famílias de reassentados remanescentes do empreendimento UHE Irapé. Fonte: Dados da pesquisa, 2019.

Na margem direita do rio, há maior presença de propriedades produtivas realizando cultivo, criação de animais e fabricação de produtos, além de haver maior presença de núcleos familiares com rendimentos de aposentadorias, situação que agrega um ganho estável e fixo. Na margem esquerda, há maior presença de propriedades realizando criação de animais, assim como existe um maior número de beneficiários do Bolsa Família e do BPC (Tabela 3).

Tabela 3 - Cesta de rendimentos das famílias quanto as margens do reassentamento.

\begin{tabular}{c|c|c|c|c}
\hline \multirow{2}{*}{ Cesta de Rendimentos } & \multicolumn{2}{|c|}{ Margem Direita } & \multicolumn{2}{c}{ Margem Esquerda } \\
\cline { 2 - 5 } & Sim & Não & Sim & Não \\
\hline Cultivo da terra & $\mathbf{8 2 , 9 \%}$ & $17,1 \%$ & $34,8 \%$ & $65,2 \%$ \\
Criação de animais & $\mathbf{6 2 , 7 \%}$ & $37,3 \%$ & $\mathbf{3 9 , 5 \%}$ & $60,5 \%$ \\
Aposentadoria & $\mathbf{5 6 , 3 \%}$ & $46,7 \%$ & $\mathbf{4 2 , 4 \%}$ & $57,6 \%$ \\
Bolsa família & $20,3 \%$ & $79,7 \%$ & $\mathbf{4 2 , 9 \%}$ & $57,1 \%$ \\
Trabalho autônomo & $35,4 \%$ & $64,6 \%$ & $25,2 \%$ & $74,8 \%$ \\
Fabricação de Produtos & $\mathbf{3 4 , 2} \%$ & $65,8 \%$ & $25,2 \%$ & $74,8 \%$ \\
BPC & $14,6 \%$ & $85,4 \%$ & $23,3 \%$ & $76,7 \%$ \\
Trabalho assalariado & $15,2 \%$ & $84,8 \%$ & $13,3 \%$ & $86,7 \%$ \\
Arrendamento & $13,3 \%$ & $86,7 \%$ & $5,7 \%$ & $94,3 \%$ \\
\hline \multicolumn{4}{|c|}{} \\
\hline
\end{tabular}

Fonte: Dados da pesquisa, 2019. 
Dos 368 núcleos familiares de reassentados remanescentes, 321 forneceram informações que possibilitaram o cálculo estimado da renda média familiar. Para o cálculo foi considerada a cesta de variáveis que compõem a renda, a saber, rendimentos independentes da propriedade (trabalho assalariado, autônomo, aposentadoria, bolsa família e BPC) e rendimentos obtidos no manejo da propriedade (arrendamento, cultivo, criação de animais ou a fabricação de produtos). A renda média familiar estimada foi de $\mathrm{R} \$ 1831,91$, sendo a renda média familiar da margem direita de $\mathrm{R} \$ 2293,00$ e da margem esquerda de $\mathrm{R} \$ 1457,00$. Através da análise desse fator podem ser identificadas discrepâncias de caráter econômico entre os grupos familiares reassentados nas diferentes margens do rio de referência. Fator que requer mais investigações e detalhamentos para definição concreta das razões.

Observou-se ainda que atualmente $62,2 \%$ dos grupos familiares possuem as mesmas propriedades de quando foram reassentados, 4,1\% adquiriram novas terras e expandiram suas propriedades originais, $31,6 \%$ possuem propriedades menores do que as originais por terem vendido parte das áreas e apenas $0,3 \%$ não possuem mais terra.

Excluindo a área de reserva legal das propriedades e considerando apenas a área disponível para produção, 29,7\% dos núcleos familiares possuem aproximadamente metade da área total da propriedade produtiva, um quarto dos reassentados $(25,6 \%)$ possuem toda a área de sua propriedade produtiva, 21,0\% utilizam cerca de um quarto da área disponível e 13,9\% utilizam três quartos da área disponível. Enquanto 5,4\% utilizam apenas o quintal com horta, frutas, alguma plantação e criação, 0,3\% utilizam apenas o quintal com horta ou alguma plantação e 0,5\% utilizam o quintal com alguma criação. Ao passo que, 3,5\% das famílias de reassentados relatam que não existe nenhum tipo de atividade produtiva em suas propriedades, ou seja, as mesmas se encontram totalmente ociosas (Figura 3). 
Figura 3 - Propriedades produtivas entre as famílias de reassentados remanescentes do empreendimento UHE Irapé. Fonte: Dados da pesquisa, 2019.

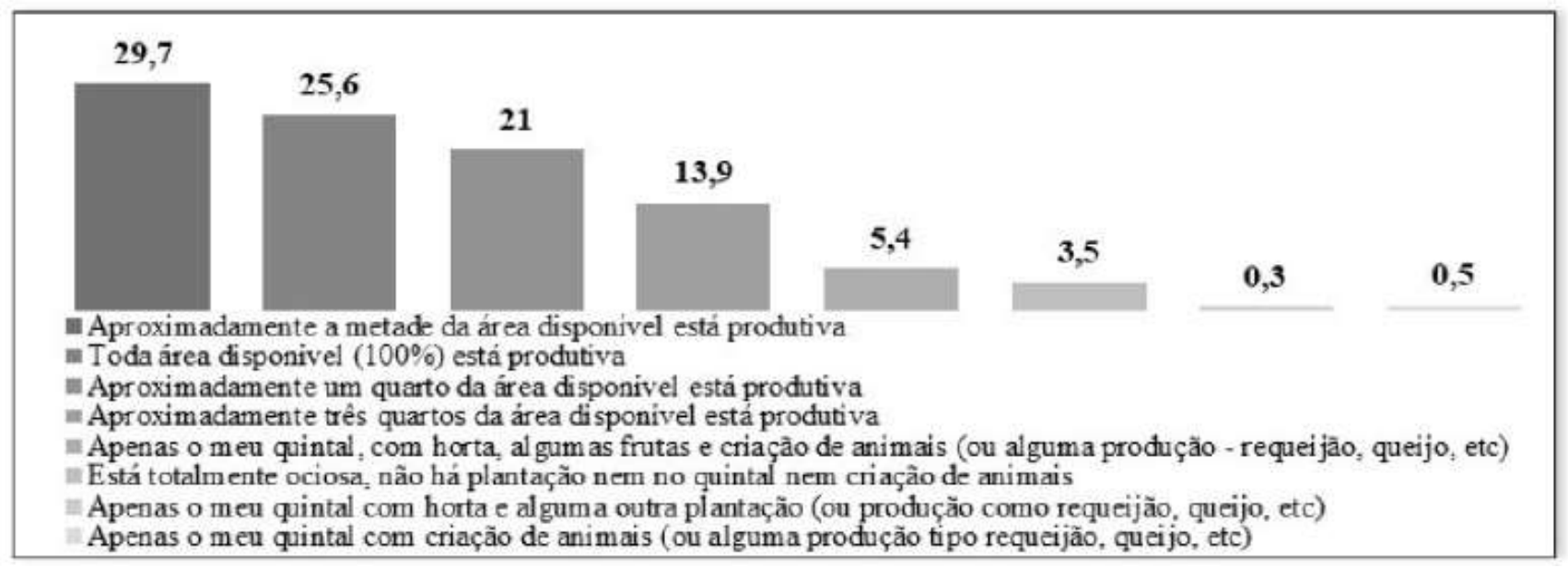

Considerando a disposição em investir na propriedade reassentada, mais da metade dos grupos familiares remanescentes $(56,4 \%)$ expuseram o desejo de ampliar a atividade produtiva associada ao uso da terra e 1,4\% demonstraram ter vontade de iniciar uma nova atividade comercial na propriedade.

O diagnóstico do processo de reestruturação produtiva das famílias de reassentados remanescentes da UHE Irapé indica que grande parte dos reassentados exercem atividades ligadas ao manejo da terra, contudo, mesmo transcorridos mais de 10 anos desde o início da operação da UHE Irapé, os grupos familiares ainda apresentam dificuldades em sobreviver apenas da exploração da terra e possuem ainda considerável potencial produtivo em suas propriedades, assim como, demonstram interesse em investir.

Acrescentando ao exposto, experiências e resultados obtidos de projetos do porte da UHE Irapé, se constituem um importante elemento de contribuição para o setor elétrico, assim como para outros setores da sociedade, na medida em que geram conhecimento a partir de experiências anteriores oportunizando o aprimoramento de metodologias aplicadas e inovação do processo com oportunidade de replicação das ações implementadas e avaliadas.

\section{CONSIDERAÇÕES FINAIS}

O diagnóstico do processo de reestruturação produtiva atingiu uma cobertura de $92 \%$ do universo amostral pesquisado, tendo reunido dados primários inéditos acerca das famílias reassentadas remanescentes nos territórios de destino. Neste cenário, reitera-se a importância de medidas atenuantes em projetos de reassentamento. 


\section{REFERÊNCIAS}

BANCO MUNDIAL. Políticas operacionais: OP 4.12, Involuntary Resettlement. Washington, DC, 2001. Disponível em:

<http://siteresources.worldbank.org/OPSMANUAL/Resources/21038411707955

90012/op412ortuguese.pdf >. Acessado em: 21 de Outubro de 2019.

BRASIL. Ministério Público Federal. Procuradoria da República em Minas Gerais. Termo de Acordo que celebram o Ministério Público Federal, o Estado de Minas Gerais, a Companhia Energética de Minas Gerais e a Fundação Estadual do Meio Ambiente. Belo Horizonte, 2002.

BRASIL. RESOLUÇÃO № 510, DE 07 DE ABRIL DE 2016. Brasília, DF, 2016.

Disponível em: <http://conselho.saude.gov.br/resolucoes/2016/Reso510.pdf>. Acessado em 15 de Outubro de 2019.

CEMIG, Companhia Energética de Minas Gerais. Irapé. Disponível em:

<http://www.cemig.com.br/ptbr/A_Cemig_e_o_Futuro/sustentabilidade/nossos_ programas/ambientais/Irape/Paginas/usina.aspx>. Acessado em 14 de Outubro de 2019.

EIA/RIMA CEMIG, Estudo de Viabilidade e Relatório de Impacto Ambiental Usina Hidrelétrica de Irapé. Belo Horizonte, Minas Gerais. Dezembro de 1993. 


\section{NOTAS}

Nota 1

* Este trabalho integra o projeto de pesquisa e desenvolvimento intitulado: "Desenvolvendo pessoas e ferramentas sociais". Gerenciado por Nilton Fernandes de Oliveira e coordenado por Martionei Leite Gomes. Financiado por CEMIG Geração e Transmissão S.A./ANEEL. Programa: Ciclo 2018.

Nota 2

Instituição privada de pesquisa, com sede em Belo Horizonte/MG, que desenvolve pesquisas sociais, de opinião e de mercado para organismos governamentais e não-governamentais. 


\section{Capítulo 7}

doi) $10.37423 / 210504051$

INSTRUMENTO DA OUTORGA COMO INDICADOR DA VARIAÇÃO INTERANUAL DE FONTES HÍDRICAS

\section{Lara Maria Oliveira Rabelo}

Jeftha Amanda de Souza e Silva

Francisco Delfábio Teixeira de Oliveira laramariaor@gmail.com

Instituto de Educação, Ciência e Tecnologia do Ceará

Instituto de Educação, Ciência e Tecnologia do Ceará 
Resumo: A água é essencial para a existência da vida e o estado do Ceará é um dos que mais sofrem com a baixa de disponibilidade hídrica. No que tange à política de garantia de acesso a este recurso, a outorga de direito de uso de água constitui-se como instrumento fundamental. Nesse contexto o trabalho visou, no âmbito da sub-bacia do Rio Banabuiú, por meio da análise das outorgas de direito de uso de água solicitadas entre os anos de 2009 e 2017, nos cenários interanuais de aporte hídrico bem como de escassez hídrica, avaliar o referido instrumento de gestão como um indicador do comportamento do usuário de água bruta em sua adequação aos contrastantes cenários hídricos interanuais do estado. Para isso, foram analisadas as outorgas em situação concedida ou negada através da consulta ao Sistema de Outorga e Licença (SOL), da Companhia de Gestão dos Recursos Hídricos do Ceará (COGERH). Ademais, foram coletadas informações da evolução volumétrica superficial da bacia no mesmo período. Por último os dados foram compilados no programa Microsoft Excel 2016, onde se fez o levantamento dos dados estatísticos. Os resultados apontaram que em todo o período pesquisado, em apenas um ano a quantidade de solicitações de outorga para fontes subterrâneas foi superior a de fontes superficiais, a saber, 2017, o ano de menor percentual de acumulação da referida série. Uma vez que, a partir do ano de 2012 se instaurou um período de seca prolongada, se concluiu que a água subterrânea se apresentou como fonte estratégica neste cenário de escassez hídrica. Constatou-se, ainda, que em períodos de elevada oferta hídrica, a busca dos usuários pelo instrumento da outorga foi diminuta, em virtude da garantia não ameaçada.

Palavras-chave: Outorga, Água subterrânea, Oferta hídrica. 


\section{INTRODUÇÃO}

A água é essencial para a existência da vida, sendo o recurso natural mais necessário dentre todos os recursos ofertados pelo meio ambiente e, portanto, é indispensável para a realização de todas as funções básicas de um ser vivo. Sua abundância na terra ocorre em variadas formas físicas, que em conjunto com o meio, mantém o equilíbrio do ecossistema (FERREIRA et al., 2016).

O crescimento populacional e urbano tem ocasionado cada vez mais degradação ao meio ambiente, sendo uma ameaça a quantidade e qualidade das águas (TUCCI, 2008; MELLO; SATHLER, 2015). As atividades antrópicas somadas às variações climáticas resultam em uma crise hídrica em diversos lugares; como é o caso do Brasil (MARENGO, 2010).

O cenário de escassez hídrica é presente na região Nordeste. O clima desta região associado à sua localização é marcado por precipitações baixas e irregulares no tempo e no espaço, por grandes temperaturas que causam a elevação da taxa de evapotranspiração e pela sazonalidade (NOBRE, 2012).

O Ceará é um dos estados do Nordeste que mais sofrem com a ausência de disponibilidade hídrica. Nota-se que a demanda por água é crescente e nem sempre pode ser atendida pelos recursos hídricos disponíveis; seja por escassez, seja por degradação. Torna-se, portanto, fundamental o empenho na busca por uma gestão eficiente e por outras alternativas de fontes hídricas.

O estado possui a grande parte de seus rios em regime intermitente, ou seja, o fluxo ocorre apenas por um período no ano (CAMPOS; STUDART, 2008; PEREIRA; CUELLAR, 2015). Em razão disso, é natural a escassez dos recursos superficiais devido a sua intermitência, o que fez com que, ao longo do tempo, usuários localizados as margens dessas fontes optassem por captar a água bruta através de perfurações no leito e nas calhas dos rios para alcançar reservas subterrâneas.

A sub-bacia hidrográfica do Banabuiú contempla 15 municípios do estado do Ceará, apresentando o nível de açudagem mais desenvolvido do Estado e um baixo potencial de água subterrânea devido localizar-se, em grande parte, em um embasamento cristalino (SOUZA, 2000). Diante de um cenário de escassez, a sub-bacia apresenta importância fundamental para o abastecimento público e demais usos para as regiões circunvizinhas e a Região Metropolitana de Fortaleza.

A água é um bem de uso comum, e o instrumento de outorga de direito de uso, regulamentado pela Lei Federal $N^{\circ}$ 9.433/97, visa garantir o acesso de todos à água em quantidade e qualidade satisfatórios, buscando resolver os conflitos existentes entre demanda e oferta. Dessa forma, o 
trabalho visou, no âmbito da sub-bacia do Rio Banabuiú, por meio da análise das outorgas de direito de uso de água solicitadas entre os anos de 2009 e 2017, nos cenários interanuais de aporte hídrico bem como de escassez hídrica, avaliar o referido instrumento de gestão como um indicador do comportamento do usuário de água bruta em sua adequação aos contrastantes cenários hídricos interanuais do estado.

\section{METODOLOGIA}

A pesquisa possuiu caráter qualitativo e descritivo, buscando avaliar e interpretar os dados obtidos de forma intuitiva, observando os fatos e processos que envolveram o objeto do estudo. Também se caracterizou como um estudo de caso, no qual se fez uma revisão bibliográfica e se apresentaram dados acerca do instrumento da outorga dentro de um espaço de tempo predeterminado para se avaliar a alternância das fontes hídricas ao longo dos anos, comparando os resultados com os períodos de aporte e escassez de água.

\section{ÁREA DE ESTUDO}

Geograficamente, a área de estudo delimitada foi a Sub-bacia Hidrográfica do Rio Banabuiú, no qual o órgão gestor responsável é a Companhia de Gestão dos Recursos Hídricos do Ceará (COGERH). Conforme a Lei Estadual 14.844/92, a COGERH é responsável pelo gerenciamento dos recursos hídricos de domínio estadual ou federal, por delegação.

A Sub-bacia Hidrográfica do Banabuiú está localizada no interior do Ceará, região caracterizada pelo semiárido, baixa pluviometria, baixa umidade relativa do ar e temperaturas médias elevadas em torno de $26^{\circ} \mathrm{C}$ a $32^{\circ} \mathrm{C}$. A Sub-bacia Hidrográfica possui uma área de drenagem de de $19.810 \mathrm{~km}^{2}$ e representa $13 \%$ do território cearense limitando-se com quase todas as outras bacias, exceto a do Salgado, Coreaú e Litoral (CEARÁ, 2009).

Os municípios que estão situados dentro da Sub-bacia são Banabuiú, Boa Viagem, Ibicuitinga, Itatira, Madalena, Mombaça, Monsenhor Tabosa, Morada Nova, Pedra Branca, Piquet Carneiro, Quixadá, Quixeramobim, Senador Pompeu e em parte Limoeiro do Norte e Milhã. A COGERH atua nesses municípios, situados no Sertão Central, pela Gerência Regional em Quixeramobim. 
Figura 1 - Imagem dos municípios que compõem a Sub-bacia Hidrográfica do Banabuiú

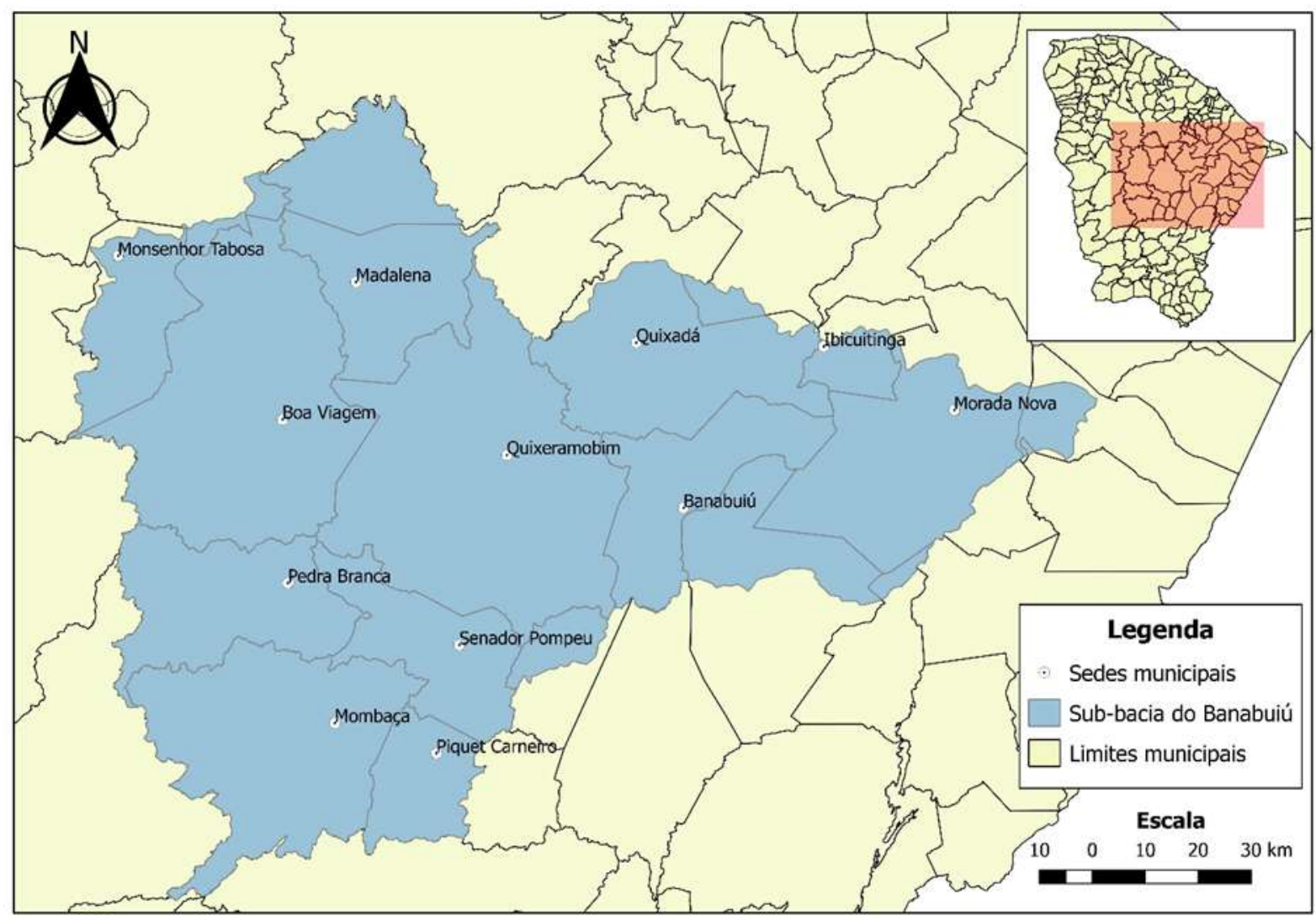

Fonte: (AUTOR, 2019).

\section{PROCEDIMENTOS}

A primeira etapa consistiu em definir o intervalo de tempo e critérios relacionados a obtenção do banco de dados. O período escolhido para a seleção das outorgas compreende os anos de 2009 a 2017, definido com o objetivo de se buscar retratar um intervalo de grande oferta hídrica e outro de escassez. Sobre os critérios, foi estabelecido a seleção de outorgas apenas em situação concedida e negada. As principais informações requeridas destes processos foram com respeito a quantidade de requerimentos relacionados aos recursos superficiais e subterrâneos ao longo dos anos.

Logo, foi feito um levantamento das outorgas na gerência da Sub-bacia do Banabuiú, localizada na cidade de Quixeramobim, dos usuários da bacia durante este período. Essa coleta foi feita através da consulta ao banco de dados do Sistema de Outorga e Licença (SOL), utilizado pela gerência para obtenção de informações sobre o instrumento.

O estudo também buscou fazer um comparativo do balanço hídrico geral dos reservatórios da subbacia verificando em que períodos houve maior ou menor aporte de água. Para isso, foram coletados 
dados de volume, em metros cúbicos, armazenado pela sub-bacia entre os anos de 2009 a 2017. Esses dados foram fornecidos pelo setor de monitoramento quantitativo dos açudes gerenciados pela COGERH.

Por último, após a coleta de dados, as informações obtidas em cada processo de outorga foram compilados e otimizados utilizando as ferramentas do programa Microsoft Excel 2016, no qual foram gerados gráficos para expor os resultados.

\section{DESENVOLVIMENTO}

Durante muito tempo a água foi tratada como um recurso inesgotável e por isso sem valor. Essa perspectiva tradicional mundial se deu devido a abundância dos recursos hídricos no planeta, e assim, portanto, tal visão se baseou na expansão da oferta. No entanto, com o crecimento populacional cada vez maior, ocasionou uma maior degradação ambiental e escassez hídrica. (TUCCI, 2008; MELLO; SATHLER, 2015).

No Brasil, ainda que haja recursos hídricos em demasia, o país apresenta um quadro de desproporção entre a disponibilidade de água e a demanda. Estudos de Sousa et al. (2016) mostram que a água presente na região norte é cerca de $68,5 \%$, sendo que esta região possui apenas $7 \%$ da população brasileira. Em contrapartida, as outras regiões detêm apenas 31,5\% desse recurso para suprir 93\% da população nacional.

O Nordeste brasileiro se caracteriza por ser uma região de escassez hídrica devido a dois fatores: o primeiro é a predominância do clima semiárido e o segundo é a ação predatória do homem (ARAÚJO; ARRUDA, 2011). Diante deste cenário, o Ceará, localizado no Nordeste, é um dos estados mais atingidos com a ausência de chuvas a maior parte do ano, estando constantemente em um cenário de seca. Essa dificuldade leva a uma intensa busca de convivência com a seca.

Este estado é constituído em sua maior parte por rochas cristalinas, ou seja, aquíferos fissurais que tem como característica possuírem baixa permeabilidade, portanto, a água pouco consegue penetrar no subsolo. Além disso, os rios em geral são intermitentes, ou seja, estão secos durante uma parte do ano, já que as águas subterrâneas não asseguram o fluxo de base em períodos de estiagem (CAMPOS; STUDART, 2008; PEREIRA; CUELLAR, 2015).

O Ceará possui fontes superficiais e subterrâneas. Segundo Silva et al. (2007) a fonte superficial tem como características o nível de açudagem elevado composto por reservatórios particulares de 
pequeno porte e rios efêmeros e intermitentes; já a fonte subterrânea, possui um baixo potencial hídrico por conta do embasamento cristalino que está sob a região.

Os recursos hídricos superficiais tradicionalmente são a fonte de abastecimento do estado para os diversos usos, porém a busca por fontes subterrâneas tem crescido significativamente, isso devido a pressão das demandas juntamente com os períodos de estiagem prolongada (DA SILVA, 2007). O Ceará já está no seu 60 ano consecutivo de chuvas abaixo do esperado, portanto, as águas subterrâneas se apresentam como fonte estratégica para suprir as necessidades básicas da população (PINHEIRO, 2018).

Diante de todos esses fatores, um dos maiores desafios da gestão de recursos hídricos é conseguir atender todas as demandas da bacia hidrográfica sem sobrecarregar os recursos hídricos disponíveis (ARANTES, 2009).

Um dos passos mais importantes para a gestão de recursos hídricos do Ceará foi a elaboração da Lei Estadual n 11.996/92, que cria a Política Estadual de Recursos Hídricos (PERH) e o Sistema Integrado de Gestão de Recursos Hídricos. Com isso, também se criou a COGERH, que baseada na lei aplicou os instrumentos da outorga de direito de uso, do licenciamento para obras hídricas, e posteriormente da cobrança. Em 28 de dezembro de 2010, a PERH foi então reformulada pela Lei Estadual $n^{\circ} 14.844$, que objetivou assegurar o uso da água para os usuários atuais e futuros, em padrões de qualidade e quantidade adequados e fazendo o gerenciamento integrado por meio da compatibilização da ação humana com o ciclo hidrológico.

A PERH implementa a outorga como um instrumento que visa "assegurar o controle quantitativo e qualitativo dos usos da água e o efetivo exercício dos direitos de acesso à água" (BRASIL, 1997). Esse instrumento é uma autorização dada pelo Poder Público ao requerente, que por meio de um ato administrativo, o usuário tem a garantia de captação a um manancial com vazão, volume, período e finalidade de uso preestabelecido (COSTA, 2011; BRASIL, 2013; GRANZIERA, 2014).

A outorga é um meio de oportunizar o uso comum dos recursos hídricos; efetivar o monitoramento da quantidade e qualidade da água; supervisionar a demanda promovendo uma melhora na oferta hídrica, bem como envolver todos os usuários na tomada de decisão. A outorga busca atender as necessidades ambientais, econômicas e sociais, sendo também uma ferramenta de alocação negociada, visando reduzir ou eliminar os conflitos entre os usuários e possibilitar o uso pelas demandas futuras (SILVA e MONTEIRO, 2004; COSTA, 2009; COSTA, 2011). 


\section{RESULTADOS E DISCUSSÃO}

Após a realização da coleta dos dados, verificou-se a quantidade de processos de outorgas em situação concedida e negada, conforme estabelecido na metodologia, tendo, por fim, um total de 540 processos, entre os anos 2009 a 2017. As informações buscadas dentro de cada processo foi sobre qual tipo de fonte hídrica foi solicitada pelo requerente.

O gráfico 1 exibe o número de processos conforme a fonte superficial e subterrânea da bacia.

Gráfico 1 - Processos de outorga relacionados aos recursos superficiais e subterrâneas ao longodos anos

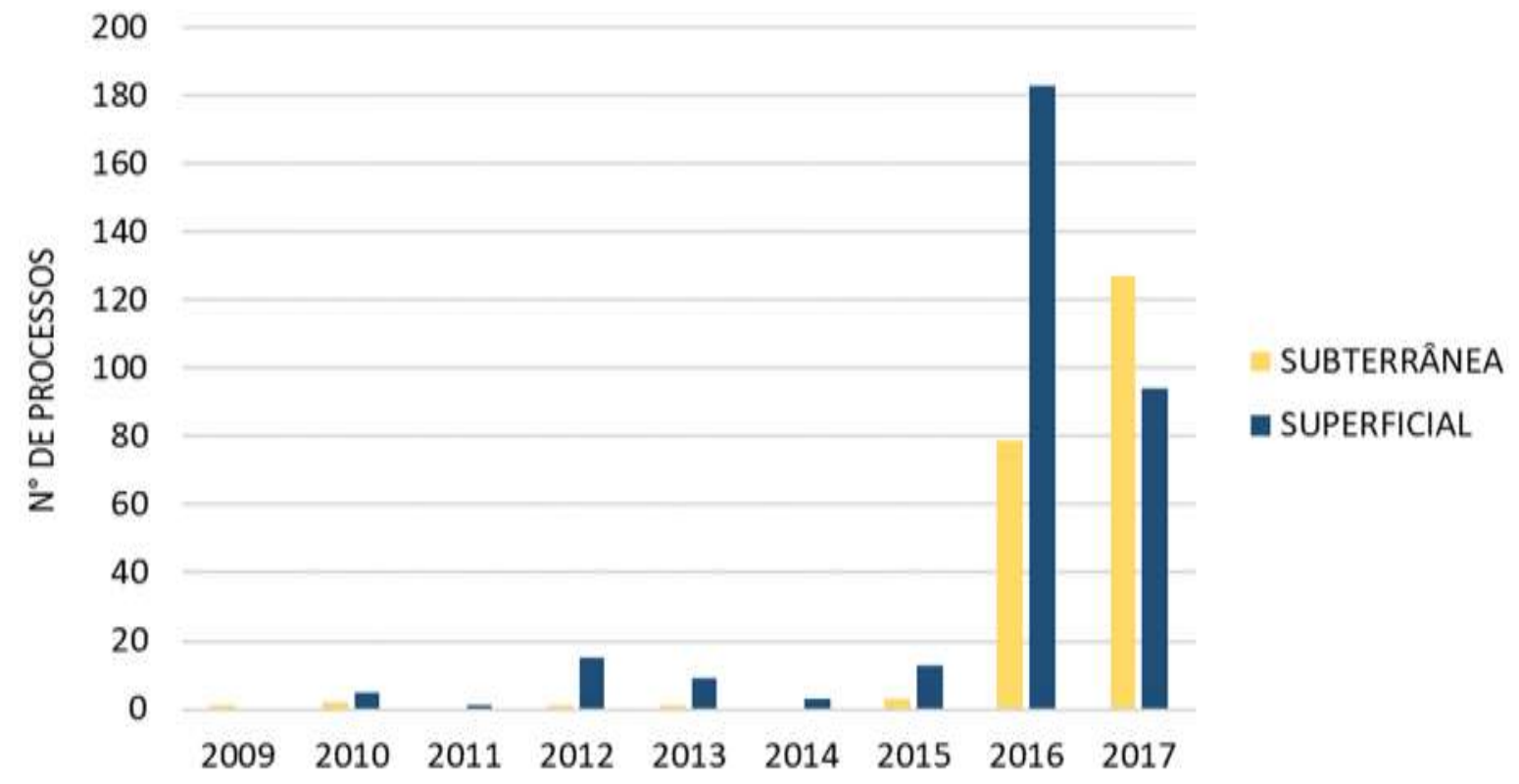

Fonte: AUTOR, 2019.

Segundo o gráfico acima, entre os anos de 2010 e 2016 a maioria das solicitações representam o uso de fontes superficiais, enquanto que a fonte subterrânea aparece de forma mais significativa nos anos de 2016 e 2017, se sobressaindo neste último ano. Para a COGERH (2018) no ano de 2017 o Ceará teve $69,22 \%$ de processos de outorga para fonte subterrânea.

Portanto, os resultados apontaram que em todo o período pesquisado, em apenas um ano a quantidade de solicitações de outorga para fontes subterrâneas foi superior a de fontes superficiais, a saber, 2017, o ano de menor percentual de acumulação da referida série.

O gráfico 2 apresenta o volume armazenado em metros cúbicos e em porcentagem da Sub-bacia do Banabuiú entre os anos de 2009 a 2017. Esses dados foram fornecidos pelo setor de monitoramento quantitativo dos açudes gerenciados pela COGERH. 
Gráfico 2 - Evolução do volume armazenado da Sub-bacia do Banabuiú de 2009 a 2017

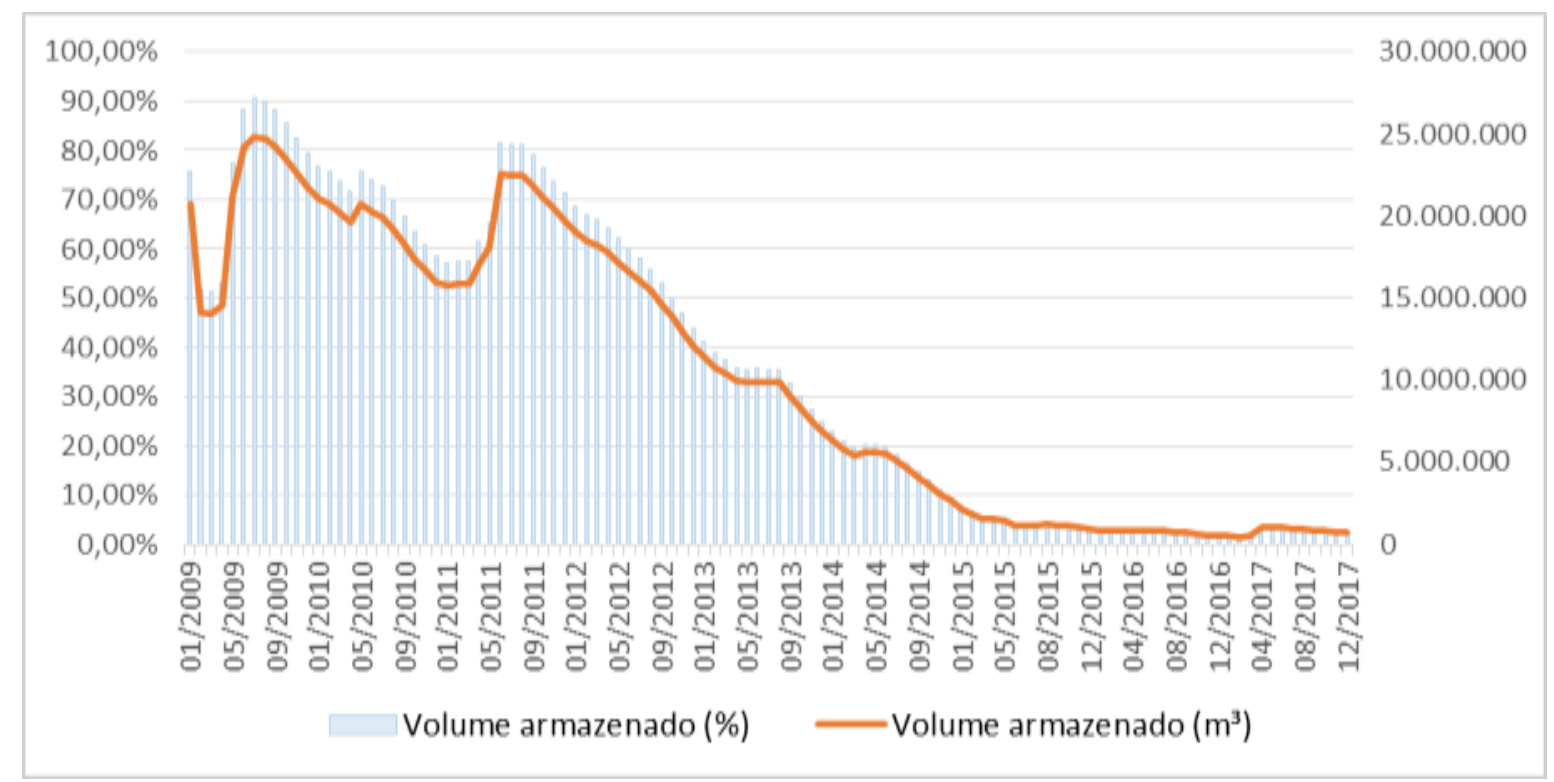

Fonte: Adaptado da COGERH (AUTOR, 2019).

No Gráfico 2, os picos de volume armazenado mais significativos ocorreram no final da quadra chuvosa dos anos de 2009 e 2011, com cerca de 90\% e 81\% do volume acumulável da bacia, respectivamente. Isso se deve ao bom aporte na estação da quadra chuvosa. Os vales do gráfico representam o volume mínimo da bacia anterior ao aporte, sendo eles aproximadamente 51\% em março de 2009 e 57\% em janeiro de 2011.

Ainda de acordo com o gráfico 2, também podemos inferir que nos anos de 2009 a 2011 foram anos com altos índices de aporte hídrico. Pode-se dizer a partir do gráfico, que durante os anos de 2012 a 2017 se instaurou um período de seca prolongada, marcado pelo déficit do volume hídrico dos reservatórios.

A pesquisa buscou correlacionar os dois gráficos, analisando o cenário de aporte entre os anos estudados e o aumento dos pedidos de outorgas de direito de uso para as fontes superficiais e subterrâneas.

De acordo com os gráficos 1 e 2, em períodos de maior aporte nos reservatórios se tinha um baixo número de pedidos de outorga. Isso pode ser atribuído à falta de adesão do instrumento de outorga por parte dos usuários, que não tinham o conhecimento sobre a necessidade de se formalizar o direito de uso da água, como uma maneira de assegurar o futuro acesso a ela (STUDART; CAMPOS; COSTA, 1997). 
Todavia, houve um aumento de processos nos últimos anos, ocorrido devido a realidade de baixa oferta hídrica. Com os conflitos de uso motivados pela estiagem prolongada, os usuários viram na outorga a garantia de acesso aos recursos hídricos em relação aos demais não regularizados (FRANÇA et al., 2018).

Houve expressiva busca pelo uso do instrumento da outorga em apenas $33 \%$ do período mais crítico (1 de 6 anos), o que corresponde a apenas $22 \%$ do período total analisado.

Além disso, é interessante destacar o grande número de processos de outorga para fontes superficiais em quase todos os anos, isso em decorrência do nível de açudagem na bacia. Porém, no ano de 2017 houve uma inversão de fontes, no qual a quantidade de solicitações de outorga para fontes subterrâneas foi superior a de fontes superficiais.

Isso ocorreu devido a escassez de aporte dos recursos superficiais ao longe dos anos, como está exposto no gráfico 2, o que levou a interrupção do fluxo desses mananciais. 0 colapso das redes de drenagem e sobretudo do canal principal, o rio Banabuiú, fez com que muitos dos usuários localizados as margens dessas fontes optassem por captar a água bruta através de perfurações no leito e nas calhas dos rios para alcançar reservas sedimentares.

Em 2018, a Cogerh reuniu os dados da Companhia de Recursos Minerais (CPRM) catalogando um total de 1.964 poços perfurados na bacia, sendo que até 2017 houveram apenas cerca de 265 processos envolvendo fontes subterrâneas. A CPRM registrou em 2016 um total de 21.473 poços no Ceará, no entanto apenas 3.290 processos estavam em vigência até 2017 (FRANÇA et al., 2018).

Isso comprova que a gestão hídrica do Ceará ainda acompanha a passos lentos a demanda de águas subterrâneas, sendo necessário ainda um maior controle dessa fonte, já que esta é uma alternativa estratégica em períodos de seca.

\section{CONSIDERAÇÕES FINAIS}

A pesquisa teve o intuito de analisar instrumento de outorga ao longo dos anos de 2009 a 2017, retratando um cenário de abundância e outro de escassez de recursos hídricos, e avaliando o referido instrumento de gestão como um indicador do comportamento do usuário de água bruta em sua adequação aos contrastantes cenários hídricos interanuais do estado. Constatou-se que em períodos de elevada oferta hídrica, a busca dos usuários pelo instrumento da outorga foi diminuta, em virtude da garantia não ameaçada. 
Já nos ultimos anos, aconteceu que com a escassez na oferta, houveram grande número de processos como forma de garantir o acesso a água, já que em períodos de estiagem prolongada há muitos conflitos para garantir os diversos usos.

Também vale destacar que ao longo dos anos, o aporte dos reservatórios superficiais dimunuiu consideravelmente, ocasionando um déficit hídrico. Nesse contexto, surge a necessidade pelo uso de fontes subterrâneas, o que levou a um aumento de processos de outorga para fontes subterrâneas. Uma vez que, a partir do ano de 2012 se instaurou um período de seca prolongada, se concluiu que a água subterrânea se apresentou como fonte estratégica neste cenário de escassez hídrica. Contudo, ainda é essencial se ter controle sobre tal uso, já que ps registros de dados outorgados não representam a situação real de número de poços perfurados na bacia.

Conclui-se que o instrumento de outorga, além de ser um instrumento com vista à garantia de acesso à água, pode ser um indicador do comportamento do usuário de água bruta. Porém, o instrumento só pode se constituir em um bom indicador mediante a sua adesão interanual, visto que, pelos registros de solicitações existentes, não se pode afirmar a tipologia da fonte hídrica em anos de maior disponibilidade hídrica.

A fim de se potencializar o referido instrumento de gestão como indicador da adequação do usuário de água bruta, torna-se necessária a promoção de sua adesão. 


\section{REFERÊNCIAS}

ARANTES, Alessandro de Souza. Diagnóstico do uso da água com base nos processos de outorga: estudo de caso UPGRH Piranga. 2009. 92 f. Dissertação (Mestrado em Engenharia Ambiental) Universidade Federal de Ouro Preto, Ouro Preto, 2009.

ARAUJO, Jailton Macena; ARRUDA, Danilo Barbosa. Desenvolvimento sustentável: políticas públicas e educação ambiental no combate à desertificação no Nordeste. Veredas do Direito: Direito Ambiental e Desenvolvimento Sustentável, v. 7, n. 13/14, 2011.

BRASIL. Lei no 9.433 de 08 de janeiro de 1997. Institui a Política Nacional de Recursos Hídricos, cria o Sistema Nacional de Gerenciamento de Recursos Hídricos, regulamenta o inciso XIX do art. 21 da Constituição Federal, e altera o art. 1ㅇ da Lei no. 8.001, de 13 de março de 1990, que modificou a Lei no 7.990, de 28 de dezembro de 1989. Diário Oficial [da] República Federativa do Brasil, Brasília, DF, 9 jan. 1997.

BRASIL. Manual de procedimentos técnicos e administrativos de outorga de direito de uso de recursos hídricos. Agência Nacional de Águas - ANA, Brasília: 2013.

CAMPOS, José Nilson B. e NÉRIS, L.F.A.. Mudanças Climáticas e Disponibilidades Hídricas no Semiárido: Resultados Preliminares. In: SERVAIN, J., CAMPOS, J.N.B.,

MARTINS, E.S.P.P. Clima do Atlântico Tropical e Impactos Sobre o Nordeste, 2009.

CEARÁ. Assembleia Legislativa. Plano estratégico dos recursos hídricos do Ceará/Conselho de Altos Estudos e Assuntos Estratégicos, Assembleia Legislativa do Estado do Ceará; Eudoro Walter de Santana (coordenador). Fortaleza: INESP, 2009.

COGERH. Companhia de Gestão de Recursos Hídricos do Ceará. Outorgas solicitadas/concedidas. Disponível em:

http://outorgasvigentes.cogerh.com.br/paginaSemValidacao/outorgaVigente/outorgas_fh.xhtml. Acessado em 05 de dezembro de 2018.

COSTA, José Nilton de Abreu. Análise da outorga de direito de uso dos recursos hídricos no estado do Ceará. Fortaleza. Dissertação de Mestrado, 2011.

DA SILVA, Fernando José Araújo; DE ARAÚJO, Andréa Limaverde; DE SOUZA, Raimundo Oliveira. Águas subterrâneas no Ceará-poços instalados e salinidade. Revista Tecnologia, v. 28, n. 2, 2007.

FRANÇA, Josefa Marciana Barbosa de; LUNA, Renata Mendes; MONTEIRO, Cláudio Maurício Gesteira; SOUSA, José Arimateia Cavalcante de e NETO, José Capelo. Panorama das outorgas de uso dos recursos hídricos no Estado do Ceará no período de estiagem 2009- 2017. Águas Subterrâneas, v. 32, n. 2, p. 210-217, 2018.

FERREIRA, Evaldo de Melo; ANDRAUS, Michel de Paula; CARDOSO, Aline Assis; COSTA, Lays Fabiana dos Santos; LÔBO, Lucas Morais e LEANDRO, Wilson Mozena.

RECUPERAÇÃO DE ÁREAS DEGRADADAS, ADUBAÇÃO VERDE E QUALIDADE DA ÁGUA. Revista Monografias Ambientais, v. 15, n. 1, p. 228-246, 2016. 
GRANZIERA, Maria Luiza Machado. Direito das águas: disciplina jurídica das águas doces - 4.ed. - São Paulo: Atlas, 2014. p. 177.

MELLO, Leonardo Freire de e SATHLER, Douglas. A demografia ambiental e a emergência dos estudos sobre população e consumo. Revista Brasileira de Estudos de População, [s.I.], v. 32, n. 2, p.357-380, ago. 2015. FapUNIFESP (SciELO).

MARENGO, Jose A. Vulnerabilidade, impactos e adaptação à mudança do clima no semiárido do Brasil. Parcerias estratégicas, v. 13, n. 27, p. 149-176, 2010.

NOBRE, Paulo. As origens das águas no Nordeste. In: BRASIL. A questão da água no Nordeste. Brasília, DF: CGEE, 2012.

PEREIRA, Guilherme Reis; CUELLAR, Miguel Dragomir Zanic. Conflitos pela água em tempos de seca no Baixo Jaguaribe, Estado do Ceará. Estudos Avançados, v. 29, n. 84, 2015.

PINHEIRO, Antônio Flávio Costa et al. CAPTAÇÃO DE ÁGUA SUBTERRÂNEA NA ZONA ALUVIONAR DO RIO JAGUARIBE E SUA RELAÇÃO COM O USO/OCUPAÇÃO DO SOLO EM SÃO JOÃO DO JAGUARIBECEARÁ. Águas Subterrâneas, 2018.

SILVA, Luciano Meneses Cardoso da e MONTEIRO, Roberto Alves. Outorga de direito de uso de recursos hídricos: uma das possíveis abordagens. Brasília, 2004.

SOUZA, M.J.N. Bases naturais e esboço do zoneamento geoambiental do Estado do Ceará. In: LIMA, L. C., SOUZA, M. J. N., MORAES, J. O. (orgs.). Compartimentação territorial e gestão regional do Ceará. Fortaleza: Editora Funece, 2000.

STUDART, Ticiana Marinho de Carvalho; CAMPOS, José Nilson B. e COSTA, Antônio Martins da. A alocação e o uso dos recursos hídricos no Ceará. In: XII SIMPÓSIO BRASILEIRO DE RECURSOS HÍDRICOS. Vitória: ABRH, 1997. 


\section{Capítulo 8}

doi) $10.37423 / 210504054$

\section{ANÁLISE DA PRECIPITAÇÃO PLUVIOMÉTRICA HISTÓRICA DO MUNICÍPIO DE PATOS-PB}

Edgleidson Lima Rodrigues

Renato Francisco Cândido Lopes

Francisco de Assis Salviano de Sousa
Mestrando no Programa de Pós-Graduação em Meteorologia pela Universidade Federal de Campina Grande

Mestrando no Programa de Pós-Graduação em Meteorologia pela Universidade Federal de Campina Grande

Professor Doutor, Universidade Federal de Campina Grande 
Resumo: A irregularidade e os baixos índices pluviométricos são duas características intrínsecas do Semiárido brasileiro (SAB). A disponibilidade e uso da água na região Nordeste do Brasil, em especial no SAB, persiste em ser um desafio para o desenvolvimento dessa região. No SAB o período chuvoso se concentra nos primeiros meses do ano, ficando o restante assolado por estiagens. As chuvas ocorrem na estação do verão e outono. Nesse sentido, a presente pesquisa tem por objetivo, analisar o comportamento do regime pluviométrico do município de Patos, interior do estado da Paraíba, no período de 1994 a 2018. Foram usados os totais mensais precipitados, observados na estação da Embrapa, localizada no município de Patos-PB, e fornecidos pela Agência Executiva de Gestão das Águas do Estado da Paraíba (AESA), A partir dessas séries, foram estimadas estatísticas para o período, tais como: média, desvio-padrão e coeficiente de variação. Essas estimativas foram efetuadas a partir da planilha de cálculo do Excel. O trabalho mostrou-se importante no que diz respeito à análise das precipitações pluviais, sendo esse um dos principais fatores que influenciam na vida humana e no planejamento e gestão dos recursos hídricos ao longo dos anos.

Palavras-chave: Variabilidade temporal das chuvas, ZCIT e parâmetros estatísticos 


\section{INTRODUÇÃO}

A irregularidade e os baixos índices pluviométricos são duas características intrínsecas do Semiárido brasileiro (SAB). Esses fatos têm despertado na comunidade científica um grande interesse nessa temática. Estudos envolvendo o comportamento da precipitação pluvial nessa região, bem como sua variabilidade temporal e espacial vêm sendo objeto de estudo de diversos pesquisadores (SOUSA et al., 2006; COSTA, BECKER E BRITO, 2013; MONTEIRO et al., 2013).

A precipitação pluviométrica é uma das variáveis meteorológicas de maior relevância para a sociedade em decorrência de sua ação direta sobre vários aspectos e atividades associadas aos seres humanos, como a agricultura, pecuária, etc. O excesso ou escassez de chuvas ocasionam danos econômicos e ambientais de grande magnitude. Uma importante ferramenta que auxilia na previsão desses eventos extremos é o monitoramento diário do regime pluviométrico sobre uma dada localidade (Vianello, 1991).

A disponibilidade e uso da água na região Nordeste do Brasil, em especial no Semiárida brasileiro, persiste em ser um desafio para o desenvolvimento dessa região. O empenho dos políticos e do setor privado são empreendidos na forma de implantar infraestrutura para disponibilização de água para consumo humano e para irrigação, porém de forma global, esses esforços ainda não são suficientes para resolver o problema da escassez de água.

Conforme Palhares (2013) a ausência de chuvas no SAB é um dos principais problemas enfrentados pela população da zona rural e suas consequências afeta negativamente os ecossistemas e as atividades socioeconômicas. No SAB o período chuvoso se concentra nos primeiros meses do ano, ficando o restante assolado por estiagens. As chuvas ocorrem na estação do verão e outono.

Segundo Araújo et al. (2009) as secas não são caracterizadas apenas em razão dos baixos índices de chuvas, mas as formas como elas são distribuídas no tempo e no espaço.

Nesse sentido, a presente pesquisa tem por objetivo, analisar o comportamento do regime pluviométrico do município de Patos, interior do estado da Paraíba, no período de 1994 a 2018.

\section{METODOLOGIA}

Foram usados os totais mensais precipitados, observados na estação da Embrapa, localizada no município de Patos-PB, localizado a $\left(7^{\circ} 1^{\prime} 28^{\prime \prime} \mathrm{S}, 37^{\circ} 16^{\prime} 48^{\prime \prime} \mathrm{W}\right)$. A cidade de patos tem uma população de 100.732 habitantes, distribuída em $512,791 \mathrm{~km}^{2}$ de área e distante $370 \mathrm{~km}$ da capital João Pessoa 
(IBGE, 2010). Apresenta altitude média de 242 m, com temperaturas elevadas, caracterizando-a como uma das cidades mais quentes do Sertão. Para destacar a localização do município de Patos (Figura1), no estado da Paraíba utilizou-se do software Surfer 13.0. Os dados pluviométricos foram disponibilizados pela Agência Executiva de Gestão das Águas do Estado da Paraíba (AESA), situada na Universidade Federal de Campina Grande (UFCG). A série de dados apresenta um período de registro entre os anos de 1994 e 2018.

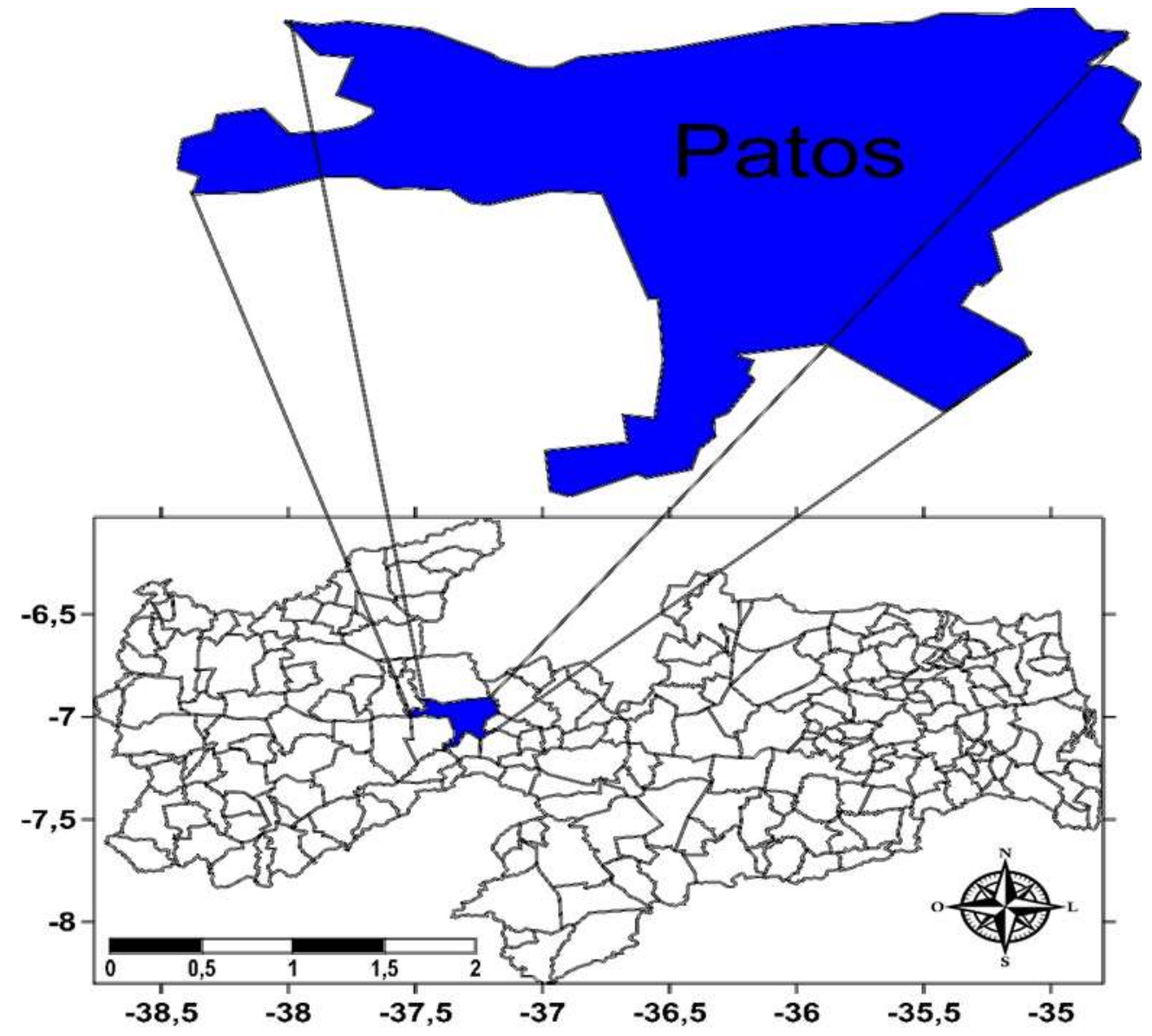

Figura 1. Localização geográfica da cidade de Patos - PB.

Esse estudo da precipitação pluvial da cidade de Patos foi realizado com base nesses dados obtidos junto a AESA. A partir dessas séries, foram estimadas estatísticas para o período, tais como: média, desvio-padrão e coeficiente de variação. Essas estimativas foram efetuadas a partir da planilha de cálculo do Excel.

\section{RESULTADOS E DISCUSSÃO}

A Figura 2 apresenta o acumulado total anual pluviométrico, observado ao longo dos 25 anos na cidade de Patos. Pode ser notado que as maiores ocorrências de chuvas na cidade de Patos foram verificadas 
em 2008 e 2009. Por outro lado, os menores valores de totais anuais precipitados ocorreram nos anos de 1998, 2001, 2012 e 2013. Não apenas em Patos, mas também em muitas localidades do estado da Paraíba, nesses anos a população sofreu com fome devido as perdas na agricultura e muitos animais morreram, além do surgimento de vários problemas na zona rural. Isso ocorreu devido ao fenômeno El Niño, que estava atuando e provocou secas severas, acarretando vários efeitos negativos (DU-ARTE, 2000). Acredita-se que esse comportamento é resultante da influência direta de algum fenômeno meteorológico regionalizado e que atuou na cidade de Patos, gerando, portanto, a redução da precipitação pluvial na cidade e região.

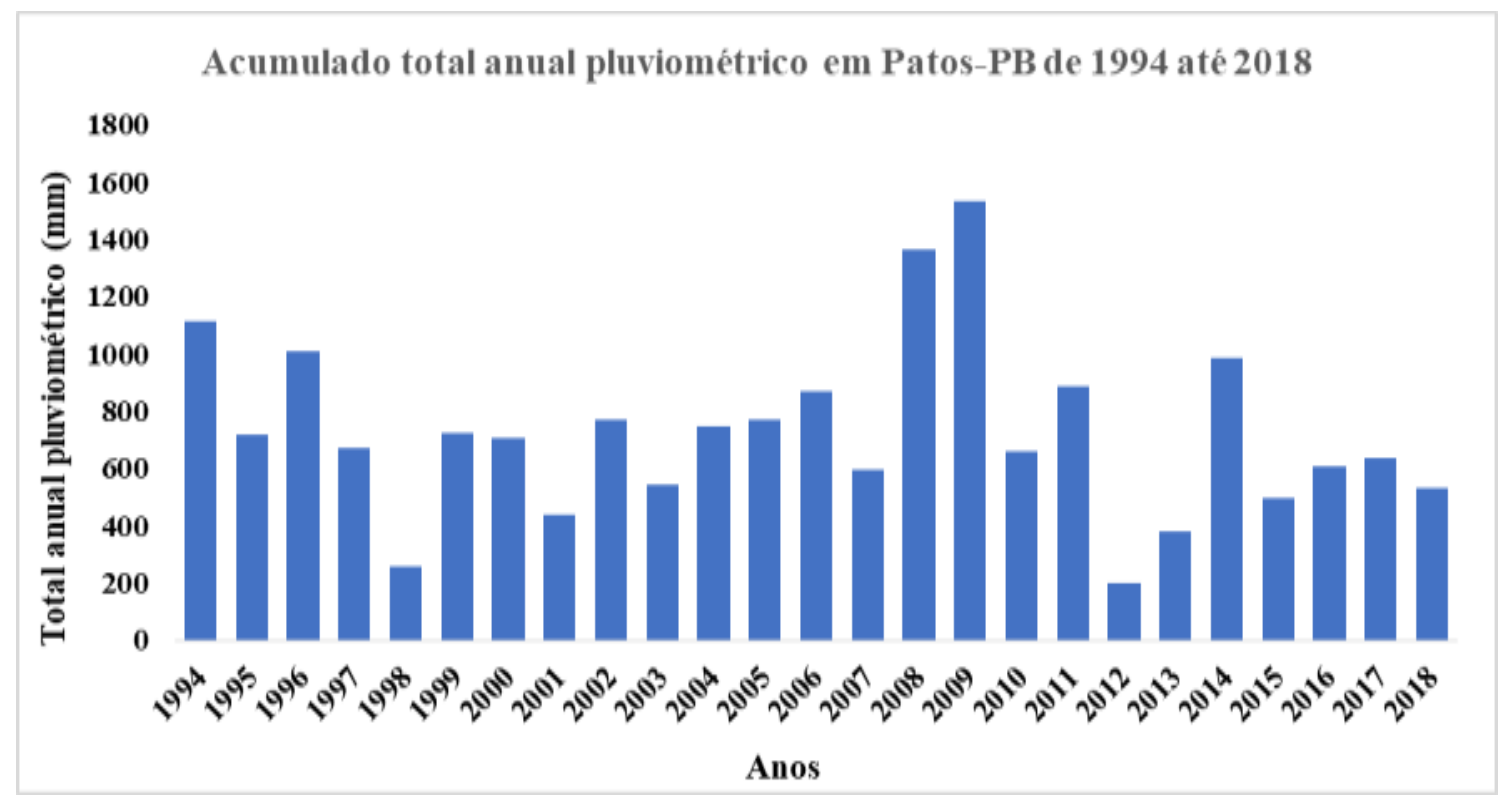

Figura 2. Acumulado total anual de precipitação pluviométrica para a cidade de Patos-PB no período de 1994 a 2018.

A partir dos dados dos postos pluviométricos analisados, foi possível estimar parâmetros estatísticos mensais dos anos de 1994 a 2018 como os exibidos na Figura 3 e Tabela 1. A média mensal da precipitação aponta os meses de janeiro a maio, como os mais chuvosos. Em contrapartida, os meses de junho a novembro foram aqueles que apresentaram os menores valores de precipitação quando comparados aos demais meses analisados.

O desvio-padrão, por ser uma medida de dispersão, mostra a variação da variável com valores mais próximos da média, tendo sido possível constatar que o mês de março apresentou o maior desviopadrão em relação aos demais meses. 
Nos meses de fevereiro, março e abril observa-se pouca diferença no coeficiente de variação (CV), pois é onde se concentra o período chuvoso, por outro lado, a partir de maio nota-se um aumento no valor do CV devido redução do total precipitado.

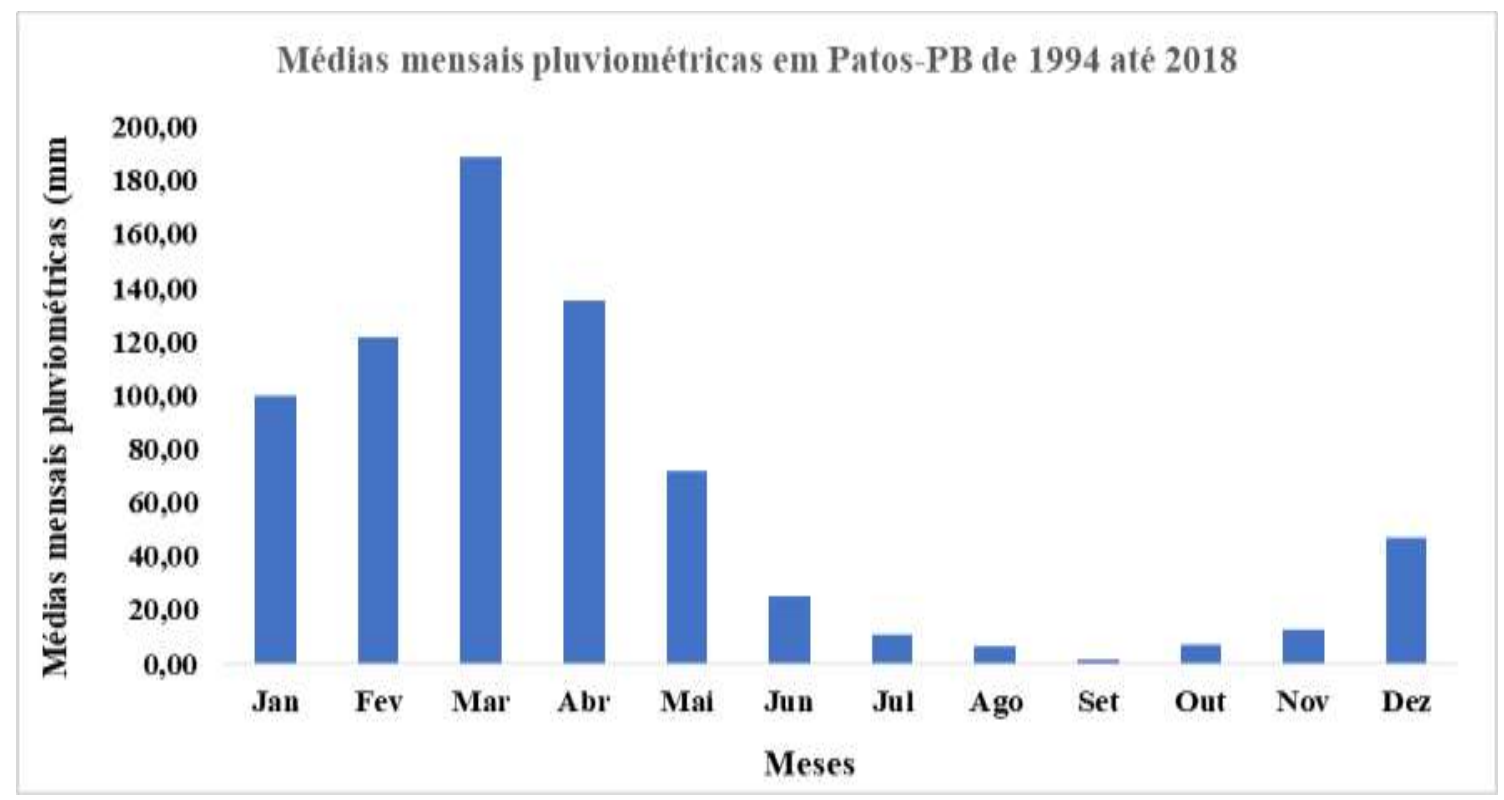

Figura 3. Médias mensais de Precipitação pluviométrica em Patos-PB de 1994 a 2018.

Tabela 1. Estatísticas da precipitação pluvial mensal (mm) para Patos-PB (1994 a 2018)

\begin{tabular}{ccccc}
\hline Mês & n & $\begin{array}{c}\text { Média } \\
(\mathbf{m m})\end{array}$ & D. Padrão $(\mathbf{m m})$ & CV $(\%)$ \\
\hline Janeiro & 25 & 99,96 & 92,42 & 92,45 \\
Fevereiro & 25 & 121,73 & 81,26 & 66,76 \\
Março & 25 & 188,59 & 127,71 & 67,72 \\
Abril & 25 & 135,35 & 117,84 & 87,06 \\
Maio & 25 & 71,63 & 73,03 & 101,96 \\
Junho & 25 & 25,43 & 24,00 & 94,37 \\
Julho & 25 & 11,00 & 10,75 & 97,74 \\
Agosto & 25 & 6,49 & 17,76 & 273,54 \\
Setembro & 25 & 1,56 & 3,98 & 255,98 \\
Outubro & 25 & 7,14 & 16,14 & 226,24 \\
Novembro & 25 & 12,79 & 22,67 & 177,28 \\
Dezembro & 25 & 46,84 & 50,31 & 107,40 \\
\hline
\end{tabular}


O presente estudo possibilitou a realização da análise das precipitações na cidade de Patos-PB a partir de estatísticas, tomando como referência a série histórica de 1994 a 2018. Constatou-se que os valores apresentados possuem grande variação em relação às médias estabelecidas devido as precipitações pluviais serem maiores nos meses do início do ano, haja vista que o período chuvoso da cidade está compreendido entre os meses de janeiro a maio. Esse fato pode estar associado a Zona de Convergência Intertropical (ZCIT) que atua na região Norte/Nordeste do Brasil, provocando os maiores volumes pluviométricos, pois entre fevereiro e maio, a ZCIT fica mais próxima da costa Norte do Brasil, época de chuvas nos estados do Maranhão, Piauí, Ceará, Rio Grande do Norte e noroeste da Paraíba. Em alguns anos, a ZCIT pode descer mais ao sul do Brasil e trazer chuvas para o Semiárido brasileiro.

O trabalho mostrou-se importante no que diz respeito à análise das precipitações pluviais, sendo esse um dos principais fatores que influenciam na vida humana e no planejamento e gestão dos recursos hídricos ao longo dos anos.

\section{CONSIDERAÇÕES FINAIS}

As chuvas do Semiárido brasileiro, de um modo geral, apresentam grande variabilidade espaçotemporal. Nesse sentido, a execução do presente estudo permitiu realizar uma análise estatística da precipitação e identificar anos secos e chuvosos para o município de Patos-PB, considerando a série histórica de 25 anos (de 1994 a 2018).

A partir dos dados pluviométricos analisados verificou-se que o maior valor dos totais anuais precipitados no período foi observado no ano de 2009 com 1529,5 mm, e o ano que apresentou o menor desses valores foi 1998 com 199,1 mm. Quanto à variação mensal da precipitação de 1994 a 2018, pode-se constatar que o mês de março é considerado o mais chuvoso no município, enquanto setembro é o menos chuvoso.

De modo geral, percebe-se um alto nível de irregularidade na precipitação pluviométrica no município, enfatizando a importância do desenvolvimento de ações que melhorem o aproveitamento da água nesse município. 


\section{REFERÊNCIAS}

SOUSA, W. S.; SOUSA, F. A. S.; ARAÚJO, L. E.; SILVA, D. F. Análise das chuvas de janeiro de 2004 em sub-regiões do estado da Paraíba. In: Congresso brasileiro de meteorologia, 14., 2006, Florianópolis. Anais do XIV Congresso brasileiro de meteorologia. Florianópolis: SBMET, 2006. v. 1, p. 1 - 6.

VIANELLO, R. L. Meteorologia básica e aplicações. 1ạ Ed. Viçosa: Imprensa Universitária, 1991. 449 p.

BECKER, C. T.; MELO, M. M. M. S.; COSTA, M. N. M. Desempenho temporal de séries pluviométricas no estado da Paraíba: uma análise comparativa. In: Workshop Internacional sobre Água no Semiárido Brasileiro, 1., 2013, Campina Grande. Anais do I Workshop Internacional sobre Água no Semiárido Brasileiro. Campina Grande: REALIZE, 2013. v. 1, p. 1 - 5.

MONTEIRO, D. R.; OLIVEIRA, D. G. H.; ALENCAR, A. E. V.; FARIAS, S. A. R. Levantamento pluviométrico do município de Patos-PB nos últimos 16 anos. In: Workshop Internacional sobre Água no Semiárido Brasileiro, 1., 2013, Campina Grande. Anais do I Workshop Internacional sobre Água no Semiárido Brasileiro. Campina Grande: REALIZE, 2013. v. 1, p. 1 - 5.

PALHARES, J. C. P. Consumo de água na produção animal. São Carlos: Embrapa Pecuária Sudeste, 2013. 6p. (Embrapa Pecuária Sudeste. Comunicado Técnico, 102).

ARAUJO, L. E. de. MORAES NETO, J. M. de. SOUSA, F. de A. S. de. Analise climática da bacia do rio Paraíba - Índice de Anomalia de Chuva (IAC). Engenharia Ambiental, Espirito Santo do Pinhal, v. 6, n. 3, p. 508-523. set/dez. 2009.

DUARTE, R. S. As Secas no Nordeste: recorrência climática e descontinuidade na ação pública. Caderno CRH, Salvador, n. 32, p. 233-258, jan/jun. 2000. 


\section{Capítulo 9}

doi) $10.37423 / 210504077$

ANÁLISE FLUVIOMÉTRICA DO RIO TAPAJÓS

(1985-2015) COM BASE NA ESTAÇÃO LOCALIZADA NA CIDADE DE SANTARÉM-PA

Fernanda Ravana Da Conceição Silva

Mateus Santos Pereira

William Lopes Pereira

Bernhard Gregor Peregovich

Wilderclay Barreto Machado
UNIVERSIDADE FERDERAL DO OESTE DO PARÁ

UNIVERSIDADE FERDERAL DO OESTE DO PARÁ

UNIVERSIDADE FERDERAL DO OESTE DO PARÁ

UNIVERSIDADE FERDERAL DO OESTE DO PARÁ

UNIVERSIDADE FERDERAL DO OESTE DO PARÁ 


\section{INTRODUÇÃO}

O Rio Tapajós tem sua nascente no estado do Mato Grosso, possui uma extensão de aproximadamente de 695 km, suas águas desaguam no Rio Amazonas em frente a cidade de Santarém, a bacia do rio Tapajós abrange cerca de 6\% da bacia amazônica, seus afluentes pela esquerda são o rios Rio Juruena, Rio Arapiuns, e pela direita temos os rios São Manuel, Rio Curucu, Rio das Tropas, Rio Crepori e Rio Jamaxim.

O Rio Tapajós é composto por períodos de secas e cheias, cujos períodos consistem em seis meses de cheias e os seis posteriores de estiagem, assim mudando principalmente a vida dos ribeirinhos principalmente os que moram em regiões de várzea - e das cidades que ficam as margens do rio, no caso dos ribeirinhos a situação de desamparo é esquecida pelos governantes, pois não há um planejamento para essas pessoas que dependem diretamente do rio, sendo assim fazem suas casas de forma com que quando chegue a cheia tenham que desfazer suas casas, pois as aguas invadem suas residências e assim eles tem que fazer assoalhos e os animais que dependem do pasto são colocados em marombas, transformando totalmente toda a rotina de trabalho dessas pessoas fazendo com que elas tenham prejuízos.

Além de transtornos para se transitar no mercado o período de cheia afeta também diretamente o consumidor da cidade que vai ao mercado comprar sua alimentação com preços mais elevados. O nível do Rio Tapajós a cada ano vem aumentando e as chuvas constantes no mês de dezembro a julho são constantes assim atingindo o nível máximo do rio, nesse período o rio enche tanto que chega a alagar as ruas principais do centro da cidade, todos os anos isso ocorre e mesmo assim nada é feito para verificar o que pode ser feito para diminuir os prejuízos que a população sente na economia.

\section{METODOLOGIA}

O passo inicial para a pesquisa consistiu no levantamento bibliográficos relacionados com o tema proposto e material cartográfico, bem como imagens obtidas pelo satélite Landsat-8 utilizada para localização da área de estudo (figura 1), mapas e cartas batimétricas. A medição das variáveis hidrológicas teve como base dados obtidos em uma estação fluviométrica do Rio Tapajós na estação no 17900000 da ANA (Agência Nacional das Águas) operada pela CPRM (Companhia de Pesquisa de Recursos Minerais) localizada na cidade de Santarém. Um local de observação é chamado de "posto" ou "estação". Por exemplo, um "posto pluvio-fluviométrico" é o local onde se medem precipitações, níveis d’água e vazões. Como decorrência da variação espacial considerável dessas grandezas, 
necessita-se para caracterizar uma bacia hidrográfica, de várias estações distribuídas sobre a sua superfície, o que leva ao conceito de redes de monitoramento, ou seja, um conjunto de estações pluviométricas, fluviométricas, sedimentométricas, meteorológicas e de qualidade da água distribuídas sobre uma determinada região. (ANA,2009, p.15)

Para o estudo do nível da água, utilizam-se os Linímetros, que são as réguas linimétricas ou linígrafos, fixados em colunas de ferro ou de madeira com objetivo de obter informações da relação do nível de água, bem como a cota do rio e a vazão.

O nível da água ou cota fluviométrica é representado convencionalmente pela letra $H$ "é a altura da atingida da água na seção em relação a uma determinada referência. Pode ser um valor instantâneo ou a média em um determinado intervalo de tempo (dia, mês, ano)" (MARTINS, 1976, pag.39). E essas medidas são dados diários em $\mathrm{cm}$.

O estudo do regime hidrológico de um curso d'água exige, evidentemente, o conhecimento da variação de seu nível e vazão ao longo do tempo. Como a avaliação diária das vazões por um processo direto seria excessivamente onerosa e complicada, opta-se em geral pelo registro diário, duas vezes ao dia (nas estações da ANA às 7 horas e às 17 horas) ou contínuo no tempo, do nível d'água e pela determinação da relação entre nível de água e vazão (curva ou tabela cota-vazão). (ANA, 2009, p.15). Para o referente estudo foi coletado os dados no período de 30 anos, desde 1985 até 2015 na plataforma de dados no HidroWeb (Sistema de Informações Hidrológicas). Os dados obtidos foram tabulados e organizados para apresentação dos resultados, utilizando o programa Origin 6.0. 


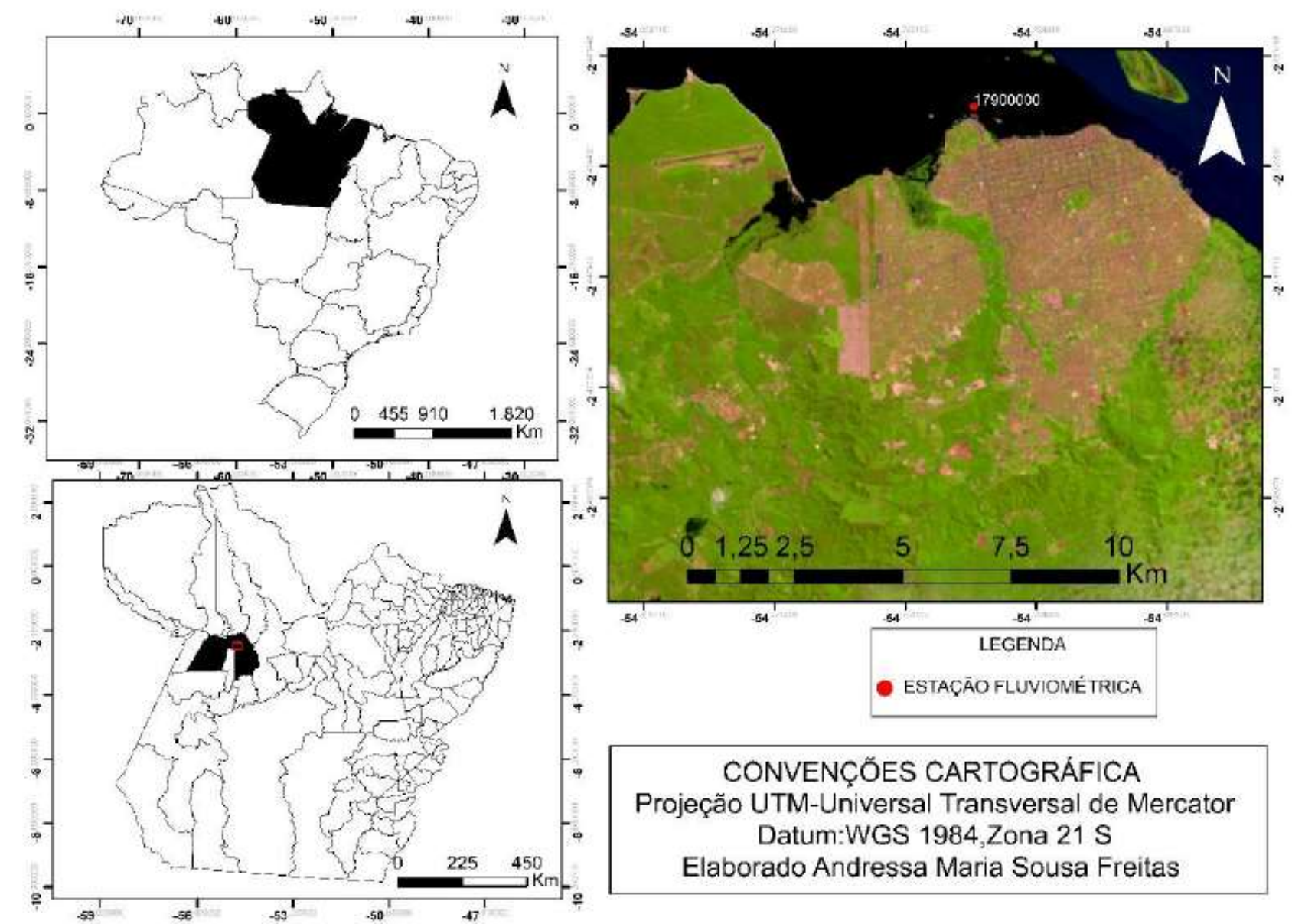

Figura 1 - Localização da área de estudo, do município de Santarém, Pará, Brasil. Cortesia: Andressa Maria Sousa Freitas.

\section{RESULTADOS}

Ao analisar os resultado pode-se observar na figura 2 a variação dos níveis mensais das médias desde o ano de 1985 até o ano de 2015, os pontos cinza na figura são as médias mensais e representam a variabilidade de todos os anos. Os triângulos em cor preta representam a normal climatológica dos níveis do rio, que é como prevê a OMM (Organização Meteorológica Mundial). Observaram-se picos no período de cheia onde o nível do Rio Tapajós atingiu o máximo nos meses de maio e junho respectivamente acima dos $750 \mathrm{~cm}$ de altura, e os níveis mais baixos do período de estiagem foram nos meses de outubro e novembro com medidas abaixo de $50 \mathrm{~cm}$.

Na figura 3 é observável a variação anual dos valores das médias máximas, mínimas e médias do nível fluviométrico do Rio Tapajós na estação no 17900000 da ANA, localizada na cidade de Santarém, diversa variabilidade anual nos valores de nível fluviométrico do Rio Tapajós, cujos menores níveis ocorreram nos anos de 1992 e 1994, cujos valores médios foram $180 \mathrm{~cm}$ e $160 \mathrm{~cm}$ respectivamente. 
É possível perceber também que os maiores níveis fluviométrico ocorreram nos anos de 2009 e 2014, cujos valores são $580 \mathrm{~cm}$ e $600 \mathrm{~cm}$ respectivamente. Embora se tenha verificado diversa variabilidade anual nos valores de nível fluviométrico do Rio Tapajós, é possível constatar uma tendência de aumento do nível do rio ao logo dos 30 anos analisados. Essa tendência pode ser evidenciada também na figura 4, onde está a flutuação do nível fluviométrico, que consiste na variação em torno da média, no qual valores acima da média são positivos e valores abaixo são negativos.

Percebe-se que os valores abaixo da média nos anos de 1985 a 1988 e de 1992 até 1998, consistiram nos menores valores do período estiagem do nível do rio e o menor valor desse nível ficou $270 \mathrm{~cm}$ abaixo da média no ano de 1994, registrando um recorde de seca no nível do rio segundo pesquisas dos dados da ANA (Agência Nacional das Águas), e são observáveis os valores acima da média nos anos de 2006 a 2009 e de 2011 até 2014, registrou-se os maiores valores do período de cheia do nível do rio onde há uma tendência do aumento do nível fluviométrico nos últimos 10 anos.

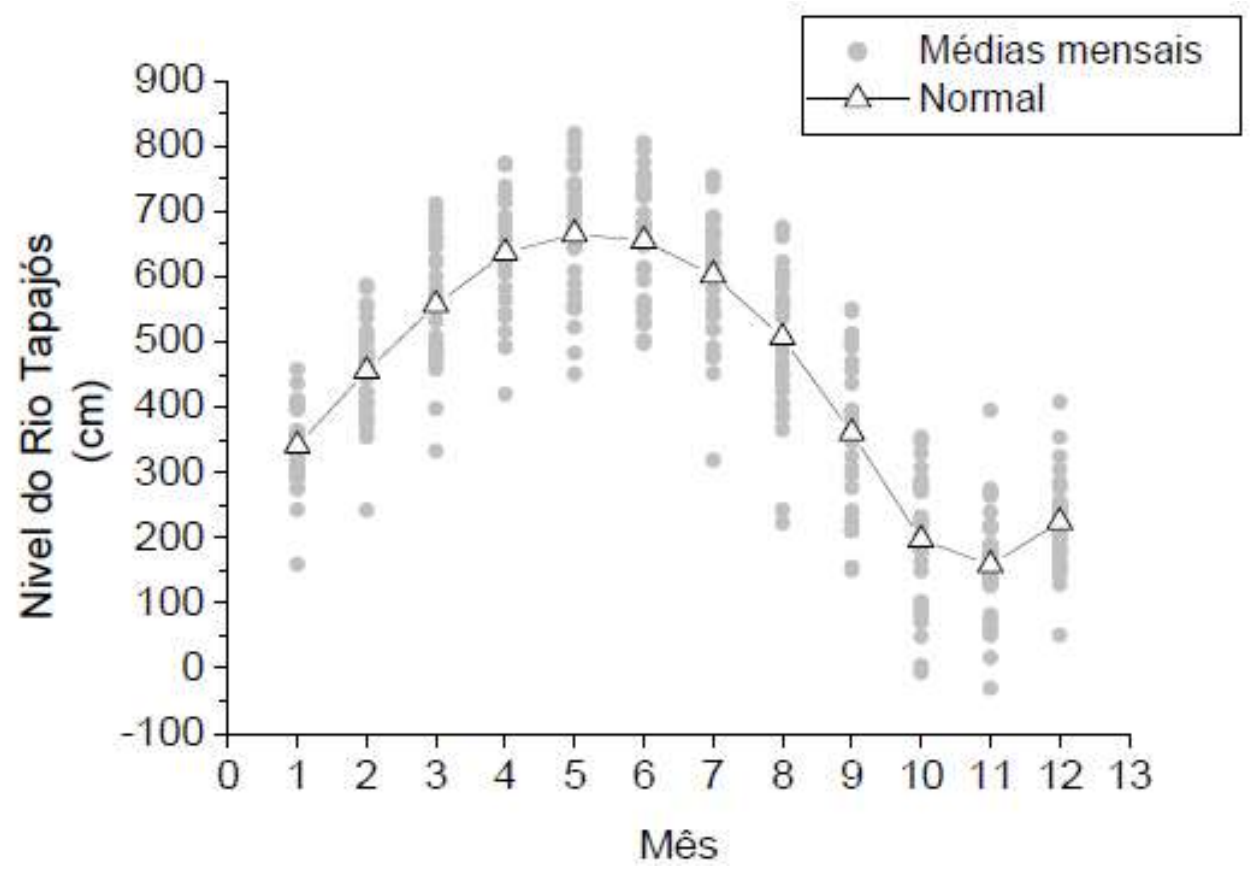

Figura 2- Variação dos níveis mensais das médias desde o ano de 1985 até o ano de 2015 


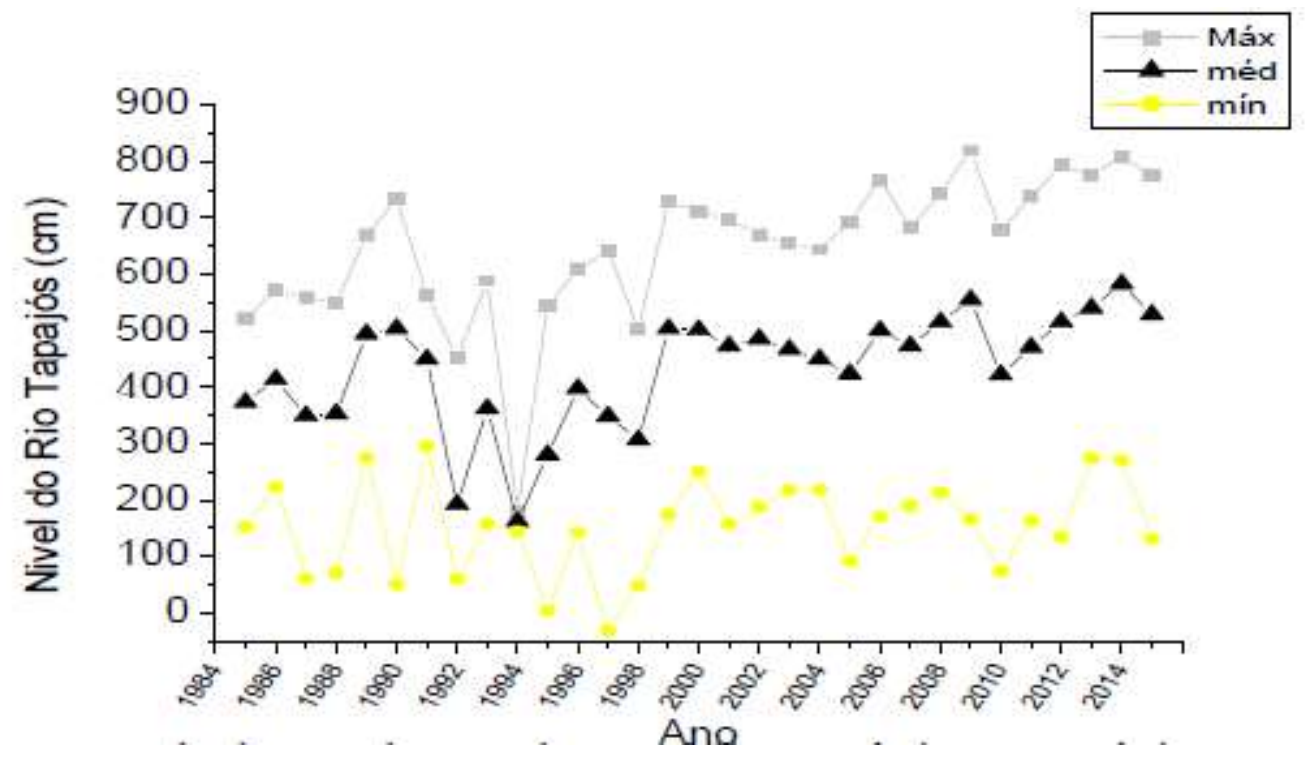

Figura 3- variação anual dos valores das médias máximas, mínimas e médias do nível fluviométrico do Rio Tapajós

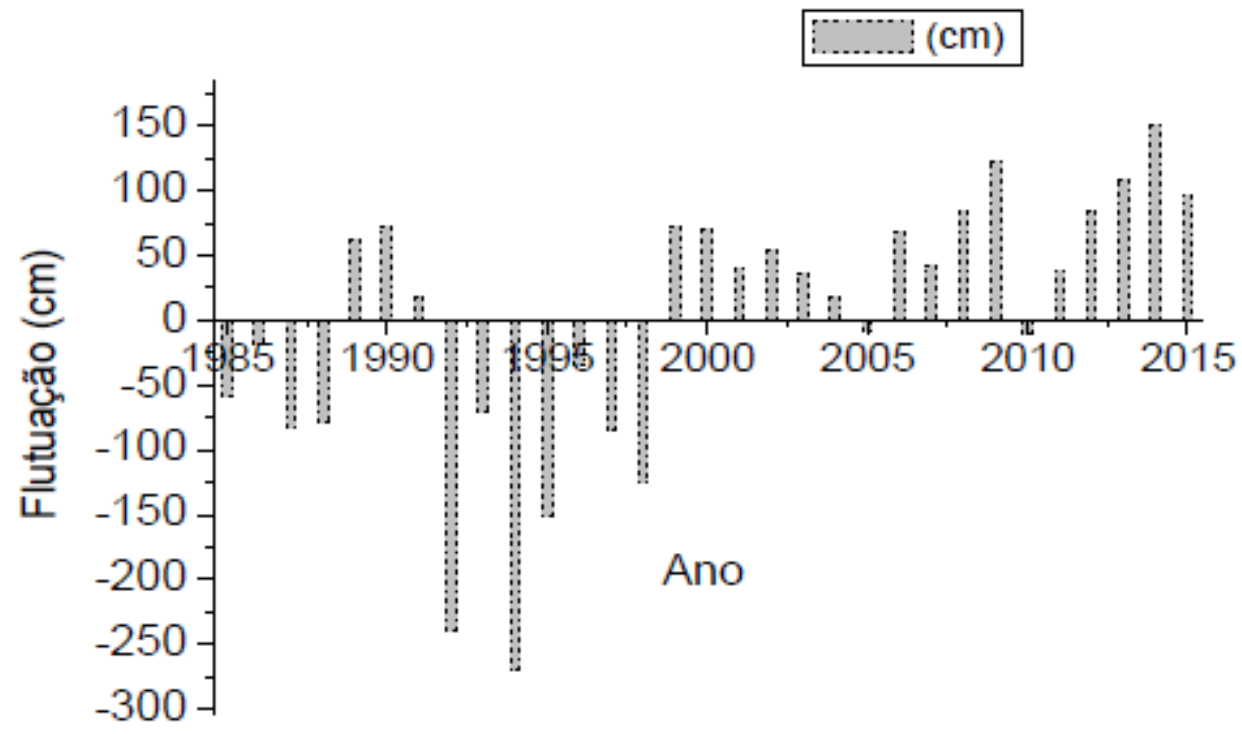

Figura 4- Variabilidade da flutuação do nível fluviométrico

\section{DISCUSSÃO}

Os resultados encontrados no atual estudo sugerem que as mudanças nos níveis do Rio Tapajós no período de estiagem e enchente, dependem de fatores climáticos e físicos ao longo da bacia no qual apresenta uma variabilidade no seu nível que pode gerar consequências na sociedade além de se ter impactos sobre a economia. A variação na enchente e vazão são os componentes do regime 
hidrológico, para a observação da variação é utilizado o nível de água nesta pesquisa obtida pela Agência Nacional das Águas (ANA). Dois fatores climáticos podem ser as principais influências da sazonalidade do Rio Tapajós, o El Niño e a La Niña. O fenômeno El Niño ocorre quando um há um aquecimento anômalo das águas superficiais do Pacífico Equatorial Oriental, e as maiores precipitações ocorrem a oeste da Amazônia e maiores secas na parte leste da Região (Oliveira, 2001). La Niña é um fenômeno contrário ao El Niño, resfriamento das águas superficiais no Pacífico Equatorial Central e Leste, dentre seus efeitos há um maior volume de chuvas no nordeste brasileiro e no leste da Amazônia (Oliveira, 2001). Portanto, esses fenômenos podem não só influenciar somente nos níveis do rio, mas também no cotidiano de todas as comunidades ribeirinhas, principalmente aquelas que moram em regiões de várzea, nas cidades em torno do rio que já presenciaram estado de calamidade tanto na estação da cheia quanto na de estiagem. Um estudo socioambiental pode ser feito para se fornecer uma estrutura adequada principalmente às populações ribeirinhas, nos períodos extremos de cheias e secas havendo um amparo dos órgãos públicos nessa época e ocorra da melhor forma possível. 


\section{REFERÊNCIAS}

ANA-Agência Nacional de Águas. Medição de descargas líquidas em grandes rios: manual t. 2ed, Brasília: ANA; SGH, 2014.

MARTINS, J.A. Escoamento Superficial. In: PINTO, N; Holtz, A.C. T; MARTINS, J.A. GOMIDE, F.L.S. Hidrologia Básica. Ed. Edgard Blucher. ISBN: 8521201540,2000, 278 p

ANA-Agência Nacional de Águas. Medição de descargas líquidas em grande rios: manual t. Brasília: ANA; SGH, 2014.

Superintendência de Gestão da Rede Hidrometeorológica. Sistema de Informações Hidrológicas (HidroWeb). Website. Disponível em: http://www.snirh.gov.br/hidroweb/. Acesso em: mai. 2017.

OLIVEIRA, G. S. O El Niño e você - o fenômeno climático. In: CPTEC/INPE. Website.

2001. Disponível em: http://enos.cptec.inpe.br/. Acesso em: abr. 2017. 


\section{Capítulo 10}

doi $10.37423 / 210504125$

\section{ESTIMATIVA DO BALANÇO HÍDRICO CLIMATOLÓGICO EM BACIA HIDROGRÁFICA COSTEIRA DA PARAÍBA}


Resumo: O balanço hídrico estimado em uma bacia hidrográfica é um importante indicador da demanda consuntiva de seus recursos hídricos, em especial de cultivos irrigados. O presente trabalho teve como objetivo estimar o balanço hídrico climatológico em áreas cultivadas com cana-de-açúcar na bacia hidrográfica do Rio Miriri, situada nos tabuleiros costeiros da Paraíba, no período de julho de 2010 a junho de 2011. Os maiores índices de precipitação foram registrados no município de Sapé, com destaque para o mês de maio com uma ocorrência de $28,65 \%$ da média máxima anual. O balanço hídrico mensal estimado na bacia apresentou déficit hídrico entre os meses de setembro a dezembro com evapotranspiração potencial total de 1.563,62 mm e valor máximo mensal igual a 152,11 mm, identificado no mês de março. Em virtude da má distribuição da água no Brasil, torna-se necessário que cada Estado passe a ter controle da utilização da água doce através de um eficiente gerenciamento de recursos hídricos com vistas a manter a quantidade e qualidade deste recurso e assegurar o seu uso por parte da população.

Palavras-chave: Precipitação, Demanda hídrica, Sustentabilidade. 


\section{INTRODUÇÃO}

Dentre todos os recursos ambientais encontrados na natureza a água é sem dúvida o mais importante, é essencial para os seres vivos e principal insumo da produção agrícola, sobretudo a irrigada. O uso racional de tal recurso tem sido foco de constantes discussões entre a comunidade científica em todo o globo terrestre em vista das recentes e severas mudanças climáticas, do crescimento acelerado da população e utilização nos sistemas agrícolas.

De modo geral as bacias hidrográficas são unidades importantes de análise em sua avaliação porque os divisores de água dentro destas conectam usuários e ecossistemas, de modo que o monitoramento da microbacia hidrográfica pode fornecer indicações a respeito de mudanças desejáveis ou indesejáveis que estejam ocorrendo com os recursos hídricos resultantes de práticas de manejo.

Segundo TUCCI (1998) existe um grande número de alternativas que podem ser utilizadas no planejamento dos recursos hídricos, tomando como base seus diversos usos, disponibilidades e principalmente a preservação. Para tanto se faz necessário a utilização de metodologias que melhor quantifiquem todos os processos e permitam analisar alternativas que auxiliem nas tomadas de decisão.

Do ponto de vista agronômico, o balanço hídrico é fundamental porque define as condições hídricas sob as quais uma cultura se desenvolve ou está se desenvolvendo em cada um dos estádios fenológicos (REICHARDT \& TIMM (2016). O balanço hídrico climatológico proposto por THORNTHWAITE \& MATHER (1995) é uma das diversas maneiras de se monitorar o armazenamento de água no solo. Considerando o suprimento natural de água incidente no solo através da precipitação (P), da demanda evapotranspirativa potencial (ETP) e com uma capacidade de água disponível (CAD) apropriada ao tipo de planta cultivada, o balanço hídrico climatológico fornece estimativas da evapotranspiração real (ETR), da deficiêcia (DEF), do excedente (EXC) e o armazenamento de água no solo (ARM), tanto na escala diária como mensal. Para que não houvesse nem excesso nem deficiência hídrica, a precipitação deveria ser igual a ETP e esta estimada como a chuva ideal. Situação que, de acordo com os autores, só acontece esporadicamente em alguns períodos. Em algumas regiões há excesso praticamente o ano todo, enquanto que em regiões áridas e semiáridas isso nunca acontece.

O balanço hídrico climatológico, por quantificar os termos acima citados, é considerado uma excelente ferramenta para estudos de viabilidade de implantação e monitoramento de sistemas de irrigação ou drenagem numa região. 
Existem vários fatores que podem influenciar a futura demanda e suprimento hídrico dentro de uma bacia hidrográfica. Tomando-se como base o período de estudo verifica-se que o cenário hidrológico é conduzido pelas futuras alterações no clima, no aumento da degradação das matas ciliares, no nível cultural dos usuários e na expansão e inclusão de mais áreas irrigadas para elevar ou até mesmo manter os níveis de produtividade do agronegócio da cana-de-açúcar.

Este trabalho teve como objetivo estimar o balanço hídrico da bacia hidrográfica do Rio Miriri utilizando o método proposto por Thornthwaite \& Mather.

\section{METODOLOGIA}

A bacia hidrográfica do Rio Miriri está situada no litoral norte do Estado da Paraíba (Figura 1), com área total de $436,19 \mathrm{Km} 2$, entre as latitudes $6^{\circ} 49^{\prime} 45^{\prime \prime}$ e $7^{\circ} 15^{\prime} 58^{\prime \prime}$ Sul e longitudes $34^{\circ} 51^{\prime} 13^{\prime \prime}$ e $35^{\circ} 18^{\prime} 54^{\prime \prime}$ Oeste e altitude média de $120 \mathrm{~m}$.

Figura 1 - Localização da bacia do Rio Miriri.

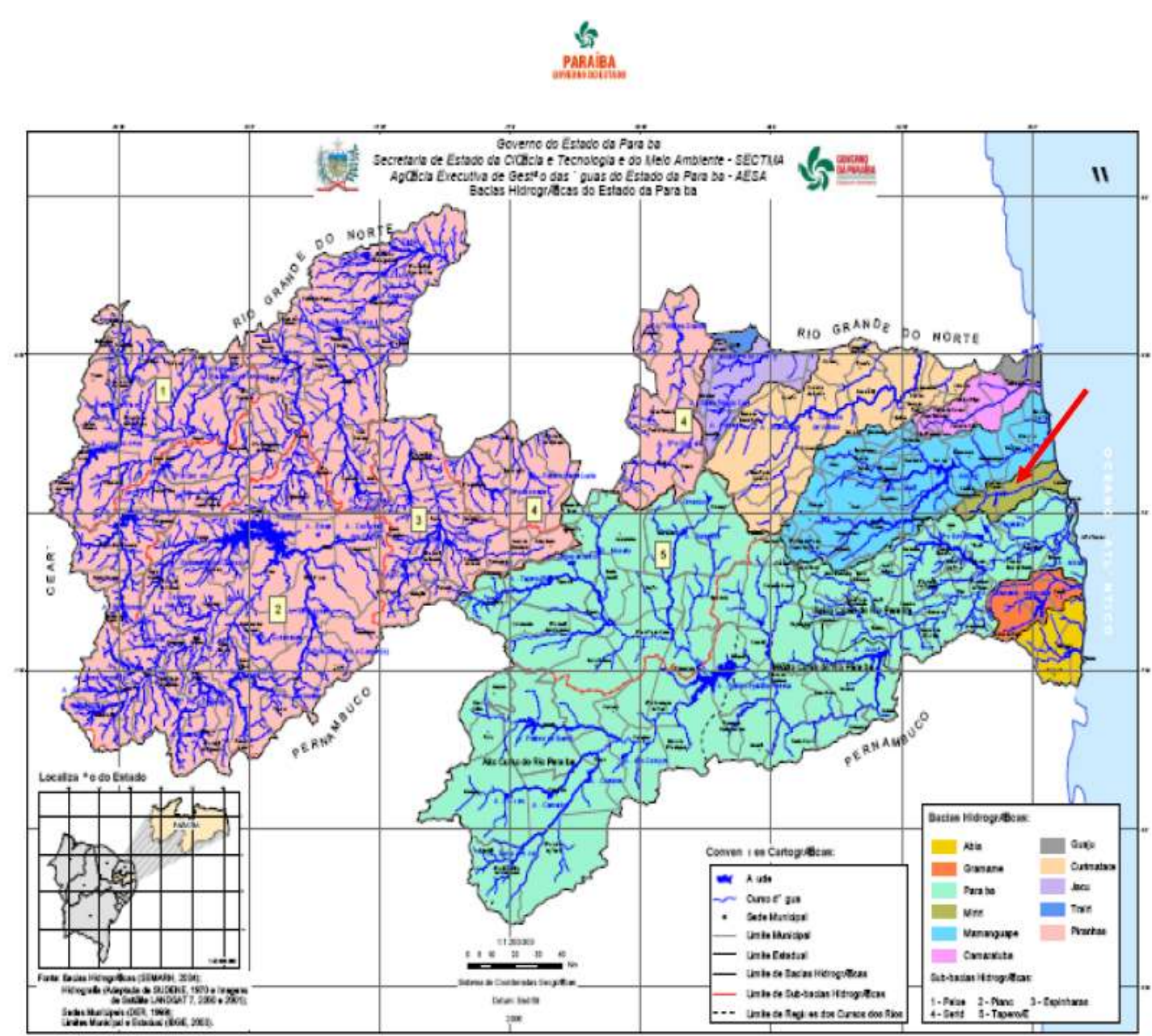

Fonte: AESA (2009) 
O Rio Miriri é o rio principal e se forma entre a depressão sublitorânea e os terrenos dos Baixos Planaltos Costeiros. Seu curso é de aproximadamente $58,7 \mathrm{Km}$ e sua extensão, com área superficial em torno de 37.207 ha e um manguezal com 285 ha. Os municípios pertencentes a esta bacia que foram investigados neste estudo são, Mari, Sapé e Capim.

Os tabuleiros costeiros da porção norte apresentam declives variados e o relevo é marcado pela presença de topos nivelados. O relevo da bacia do Rio Miriri apresenta altitudes que não ultrapassam os 200 metros devido ao fato de estar situada na depressão sublitorânea. Trata-se de uma região baixa, com superfície colinosa de relevo classificado como suave ondulado e ondulado, drenada por rios intermitentes e perenes, de vales abertos e pouco profundos.

O clima predominante na área de estudo, de acordo com a classificação de Köppen, é o quente úmido, caracterizado por chuvas de outono a inverno com precipitação média anual de $1200 \mathrm{~mm}$ e temperatura média anual de $28^{\circ} \mathrm{C}$. Normalmente a umidade relativa do ar na região litorânea do Estado da Paraíba é elevada, com média anual da ordem de $80 \%$. O período seco na porção mais próxima ao oceano Atlântico tem duração de apenas dois meses alcançando quatro meses na medida em que a Bacia se interioriza. A vegetação natural dominante na área da bacia do rio Miriri é constituída de florestas Caducifólia, Subcaducifólia e Subperenifólia, ou seja, Floresta Atlântica e ecossistemas associados tais como restingas, cerrados, manguezais.

Os dados de precipitação, pressão atmosférica, temperatura do ar, umidade relativa, velocidade do vento e radiação solar global foram coletados na plataforma de coleta de dados agrometeorológica instalada em área de cultivo de cana-de-açúcar no município de Capim - PB. O período de coleta dos dados foi de julho de 2010 até junho de 2011.

Para estimar o escoamento superficial se utilizou o método do Número da Curva desenvolvido pelo Soil Conservation Service em 1972, vinculado ao Departamento de Agricultura dos Estados Unidos (Mark \& Marek, 2009). O método permite estimar a lâmina de escoamento superficial a partir de dados de precipitação e outros parâmetros da bacia como umidade, a relação tipo de solo, uso e vegetação (expresso pelo parâmetro $\mathrm{CN}$ tabelado), resultando na seguinte equação:

$$
\mathrm{R}=\frac{(\mathrm{P} 0,25 \mathrm{~S})^{2}}{\mathrm{P}+0,85} \quad ; \quad \mathrm{S}=\frac{25400}{\mathrm{CN}} \quad 254
$$


onde:

$\mathrm{R}$ - escoamento direto acumulado $(\mathrm{mm})$;

P - precipitação total $(\mathrm{mm})$

S - potencial máximo de retenção

$\mathrm{CN}$ - número da curva - adimensional

O balanço hídrico climatológico da área de estudo foi estimado a partir da metodologia desenvolvida por Thornthwaite e Matter (1955) em que se utilizam os dados de precipitação total mensal (mm), evapotranspiração potencial total mensal $(\mathrm{mm})$ e em seguida se define a capacidade de água disponível do solo. Com os dados desses três parâmetros o balanço hídrico climatológico permite deduzir mensalmente a evapotranspiração real, a deficiência ou excedente hídrico e o total de água retida no solo (PEREIRA, 2005). Para o cálculo da evapotranspiração potencial utilizou-se as seguintes equações:

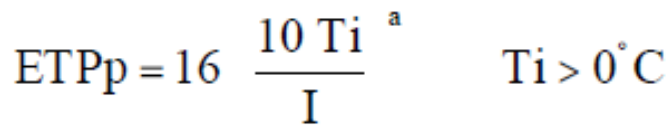

$$
\begin{aligned}
& \mathrm{a}=6,75 \times 10^{7} \mathrm{I}^{3} \quad 7,71 \times 10^{5} \mathrm{I}^{2}+1,7912 \times 10^{2} \quad \mathrm{I}+0,49239 \\
& \mathrm{I}=\sum_{\mathrm{i}=1}^{12}(0,2 \mathrm{Ti})^{1,514} \mathrm{Ti}>0^{\circ} \mathrm{C}
\end{aligned}
$$

onde:

ETPp - Evapotranspiração potencial média mensal padrão (mm mês $\left.\mathrm{s}^{-1}\right)$

$\mathrm{Ti}$ - temperatura média mensal $\left({ }^{\circ} \mathrm{C}\right)$

I - índice de calor da região

i - representa o mês do ano

O cômputo da água armazenada (ARM) é dado pela seguinte expressão:

$$
\mathrm{ARM}_{\mathrm{n}}=\mathrm{ARM}_{\mathrm{n} 1} \exp \frac{(\mathrm{P} \text { ETP })_{\mathrm{n}}}{\mathrm{CAD}}
$$

onde: 
ARMn - total armazenado no mês atual (mm);

ARMn-1 - total armazenado no mês anterior (mm);

P - precipitação mensal ( $\mathrm{mm})$;

CAD - capacidade de água disponível no solo.

Se houver um ou mais meses com P - ETPp >0, mas com valores insuficientes para que ARM = CAD, segue-se a rotina de cálculo através da seguinte equação:

$$
\mathrm{ARM}_{\mathrm{n}}=\mathrm{ARM}_{\mathrm{n}-1}+(\mathrm{P}-\mathrm{ETP})_{\mathrm{n}}
$$

Se houver outro mês com $P$ - ETP < 0 , retorna a equação 5, sem necessidade de se calcular o valor do Neg Acum no mês anterior.

\section{RESULTADOS E DISCUSSÃO}

O Rio Miriri não é perene durante todo o seu curso, ele se forma entre os municípios de Mari e Sapé, a partir da contribuição de outros cursos d'água que deságuam em seu leito, de modo que passa a ser perene durante todo o ano somente a jusante do Açude Curralinho, construído pela Miriri Alimentos e Bioenergia S.A.

As Figuras 2 e 3 apresentam os valores de precipitação e de temperatura mensais registradas nos municípios de Mari, Sapé e Capim, no período 2010/2011. A distribuição das chuvas não é uniforme, sendo bastante variáveis de uma região para outra durante o ano, com maiores índices de precipitação ocorridos no município de Sapé. Analisando todo o período, os meses que registraram menor ocorrência de precipitação foram outubro, novembro e dezembro de 2010. De janeiro a junho de 2011 foram registrados constantes e elevados índices de precipitação, com destaque para o mês de maio com maior ocorrência de precipitação; o que corresponde a $28,65 \%$ da média máxima anual. A umidade relativa registrada neste mês foi de $82,99 \%$. 
Figura 2. Valores mensais da precipitação, período 2010/2011, nos municípios de Mari, Sapé e Capim.

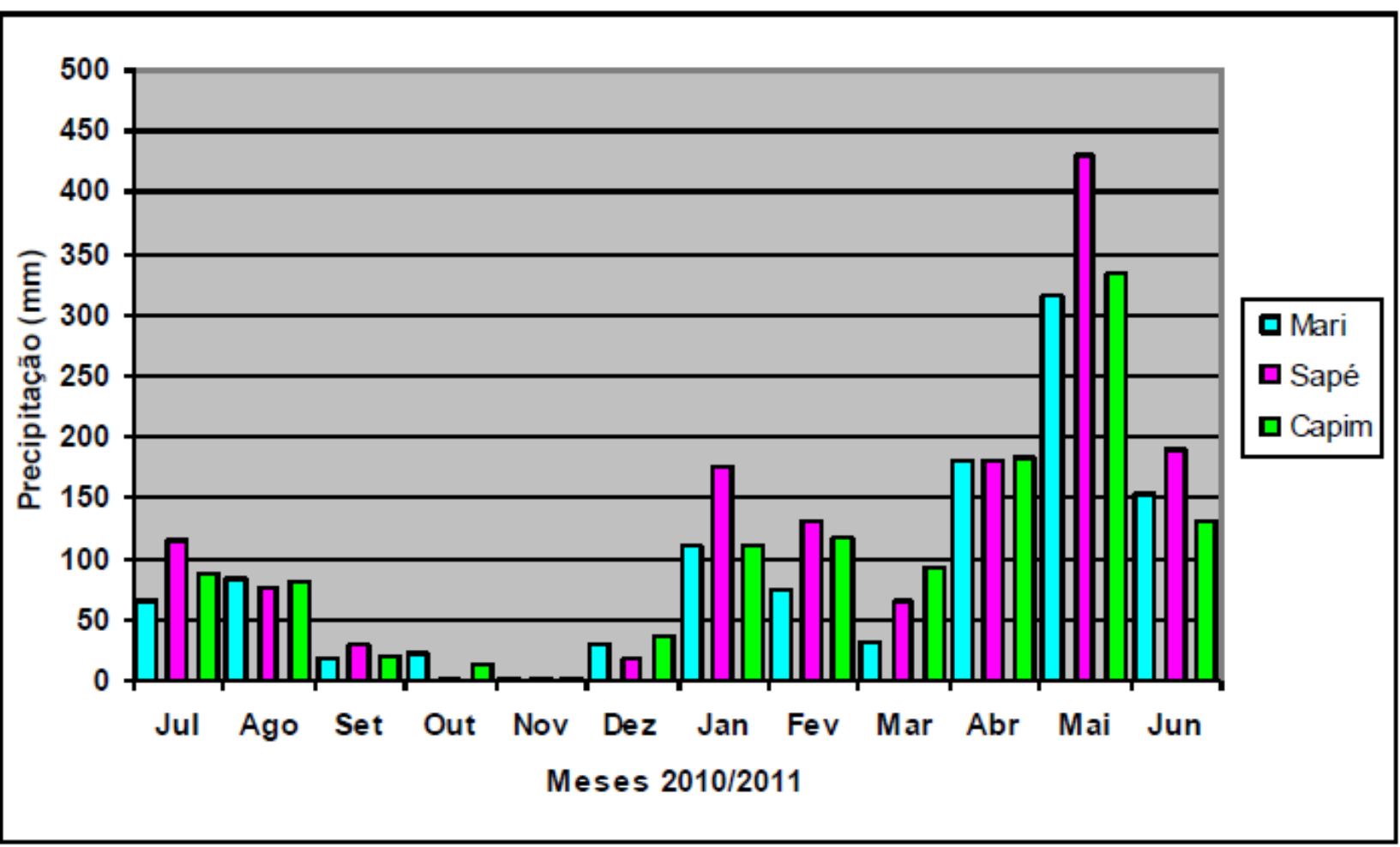

Na Figura 3, observa-se que as temperaturas mais baixas ocorrem principalmente nos meses de maio, junho, julho e agosto, que é considerado o período de inverno na região, com temperaturas máximas em torno de $28,31^{\circ} \mathrm{C}$. A temperatura média registrada durante o período foi de $26,17^{\circ} \mathrm{C}$, com o maior e menor valor médio registrado nos meses de fevereiro e agosto e valores iguais a $27,47{ }^{\circ} \mathrm{C}$ e $24,35^{\circ} \mathrm{C}$ respectivamente. 
Figura 3. Valores mensais da temperatura máxima, média e mínima, período 2010/2011.

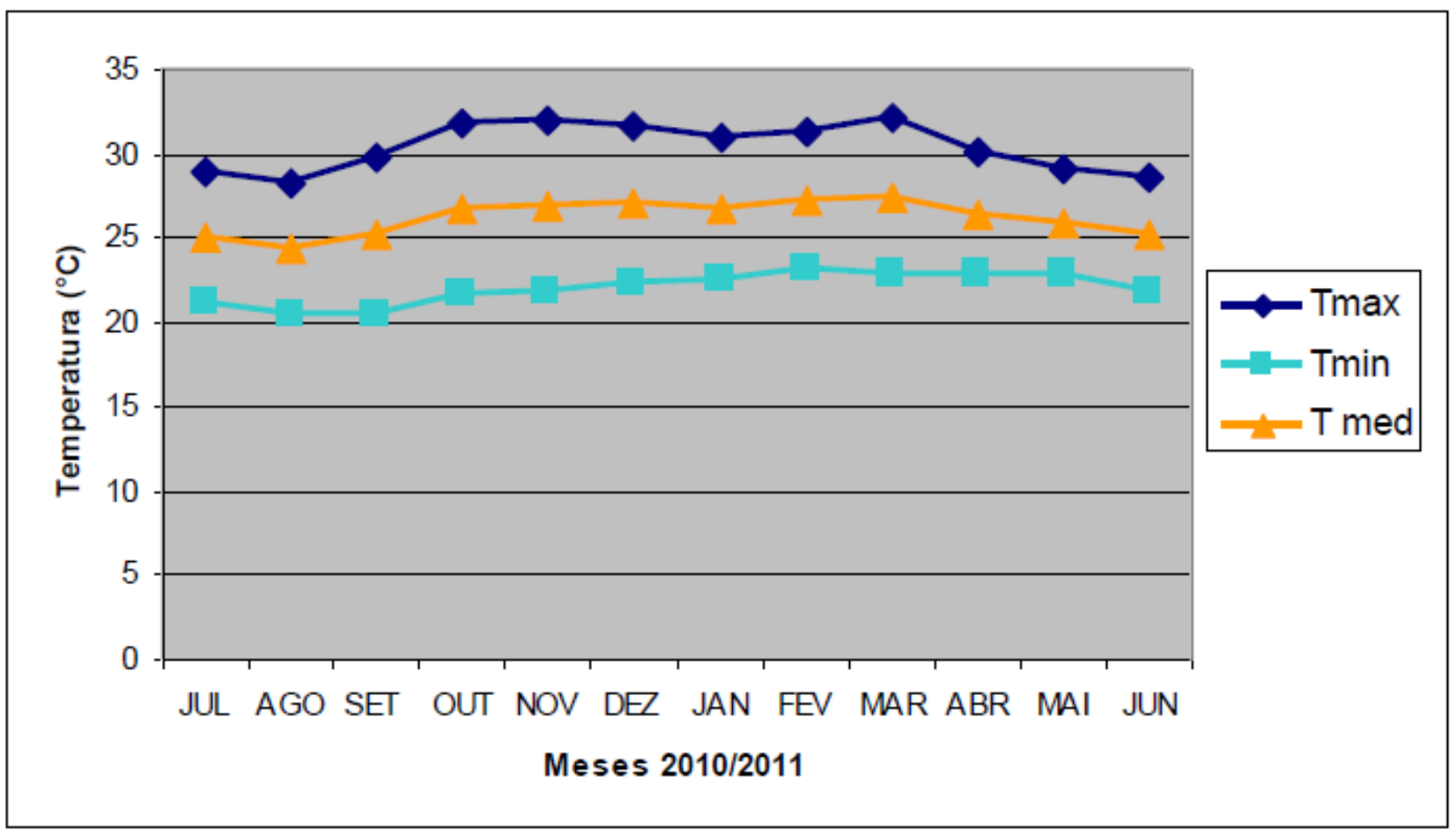

O volume médio escoado apresentado em altura equivalente de água sobre a área foi de 429,4 mm; valor que corresponde a $34,73 \%$ da precipitação média registrada no período. De acordo com a Figura 4, os meses de setembro, outubro, novembro e dezembro apresentaram os menores índices de precipitação, sem incidência de escoamento. O mês de maio apresentou cerca de $50 \%$ do escoamento médio no período. Fato realmente comprovado na área pelo transbordamento de reservatórios, áreas de cultivos inundados, comunidades isoladas, estradas e pontes destruídas.

O escoamento superficial está diretamente relacionado com a precipitação, mas fatores como tipo e umidade do solo, temperatura, topografia, cobertura vegetal e forma da bacia causam influência nas variações do escoamento superficial (LLAMAS, 1993). 
Figura 4. Escoamento médio mensal da área estudada período 2010/2011.

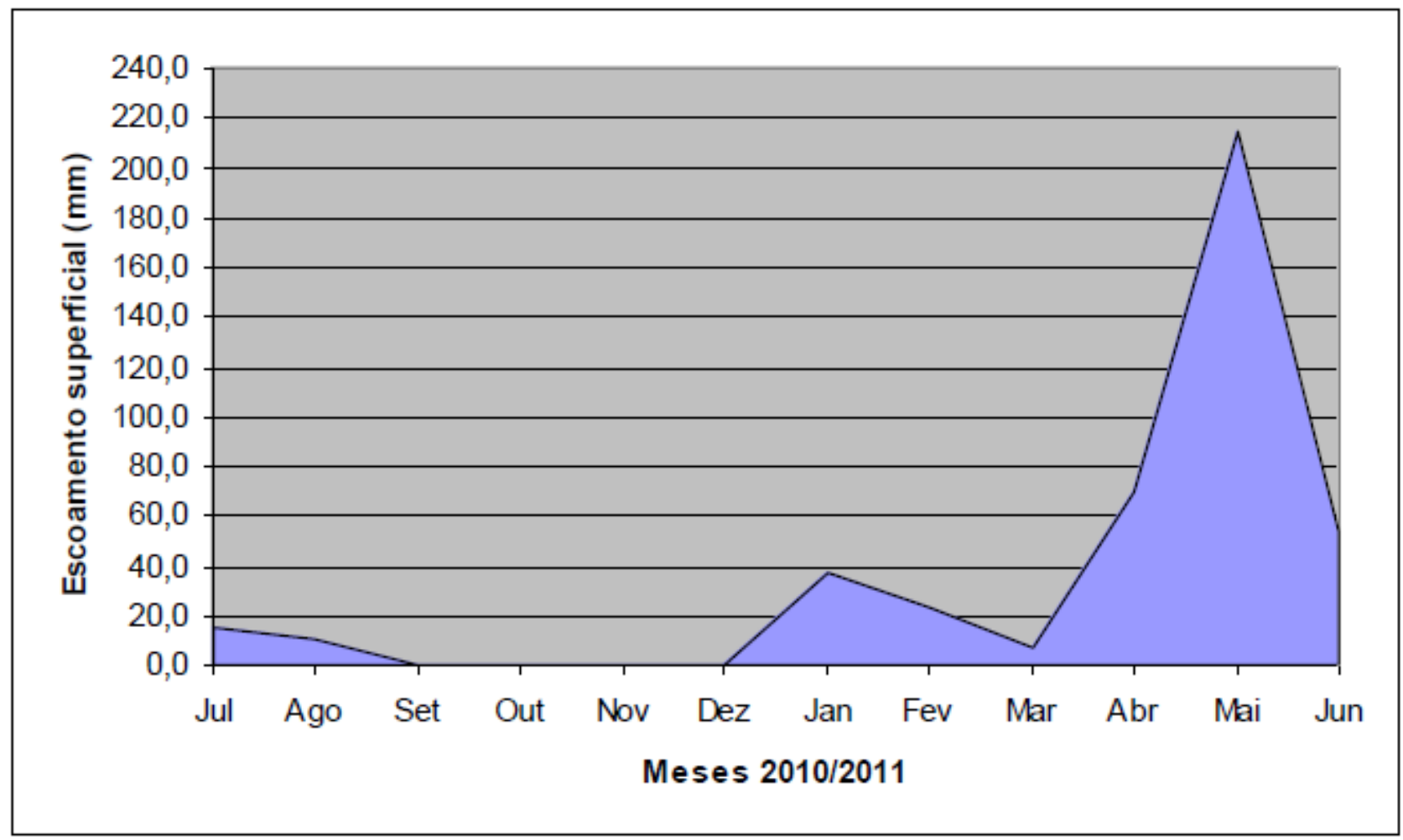

0,020,040,060,080,0100,0120,0140,0160,0180,0200,0220,0240,0JulAgoSetOutNovDezJanFevMarAbr MaiJunMeses 2010/2011Escoamento superficial (mm)

O balanço hídrico climatológico estimado na área encontra-se representado nas Figuras 5 e 6 . A evapotranspiração potencial total foi de 1.563,62 mm, apresentando valor médio mensal de 128,63 mm e valor máximo igual 152,11 mm no mês de março. O valor total médio da evapotranspiração real foi de 976,4 mm; com média mensal igual a 81,4 mm. Jesus (2015) utilizou o método de Thornthwaite e Matter para estimar o balanço hídrico no município de Aracaju-SE e verificou que entre os meses de março e agosto a evapotranspiração potencial e real se coincidem, indicando que a evaporação máxima para o período, nas condições climatológicas observadas, foi atingida e caracterizada pela grande quantidade de água disponibilizada no solo pelos elevados volumes de chuvas.

De acordo com a Figura 5, verifica-se maior déficit hídrico entre os meses de setembro e dezembro, sendo recomendável, para as áreas de cultivo com cana-de-açúcar a prática da irrigação para suprir a necessidade hídrica da cultura com vistas a garantir os níveis de produtividade nas áreas cultivadas. $\mathrm{O}$ balanço hídrico apresentou apenas três meses com excedente hídrico, o mês de maio foi o de maior excedente hídrico, como também de maior ocorrência de precipitação. 
Figura 5. Extrato do balanço hídrico mensal período 2010/2011.

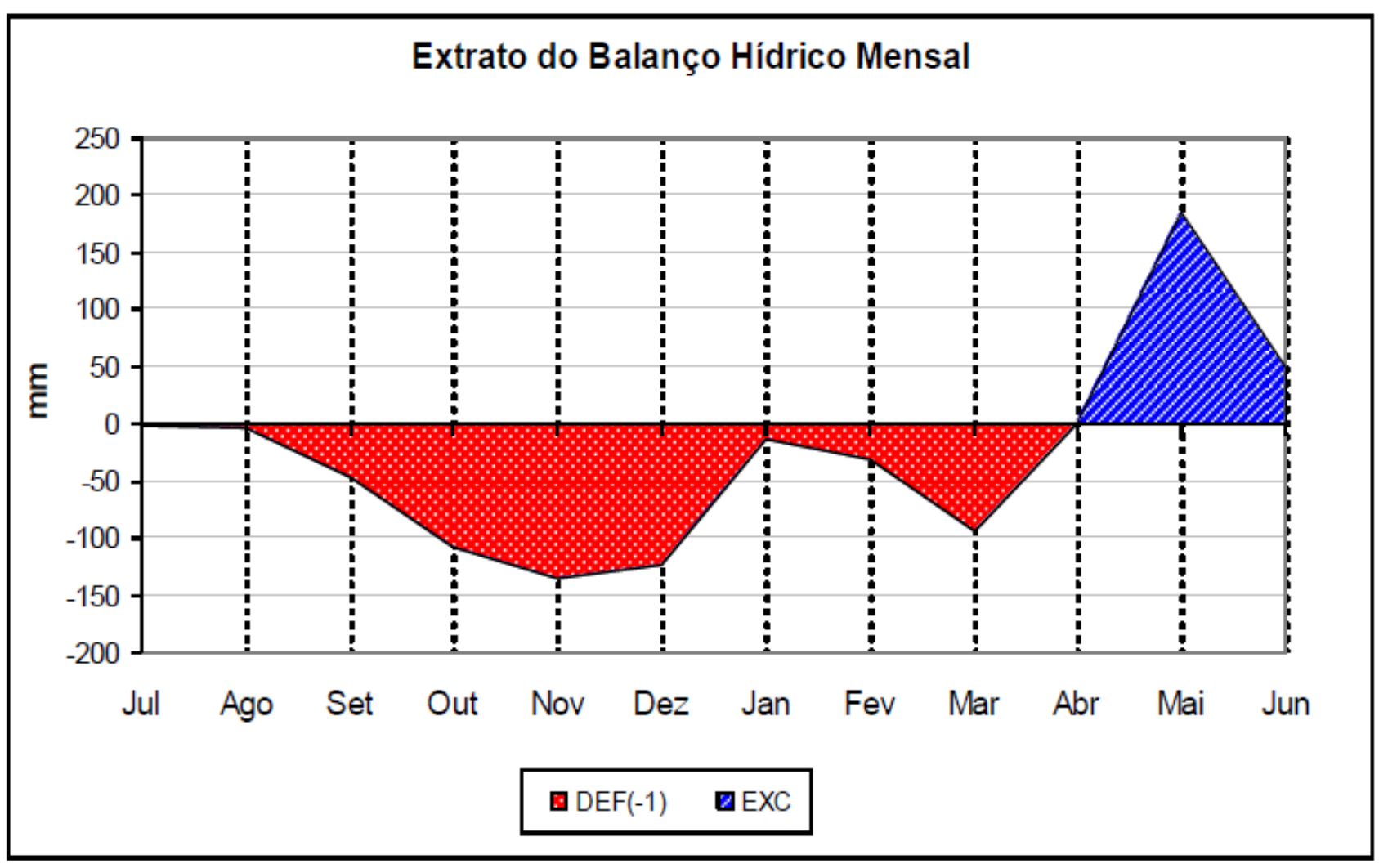

Figura 6. Variação mensal dos parâmetros de precipitação (P), evapotranspiração potencial (ETPp), evapotranspiração real (ETr) período 2010/2011. 


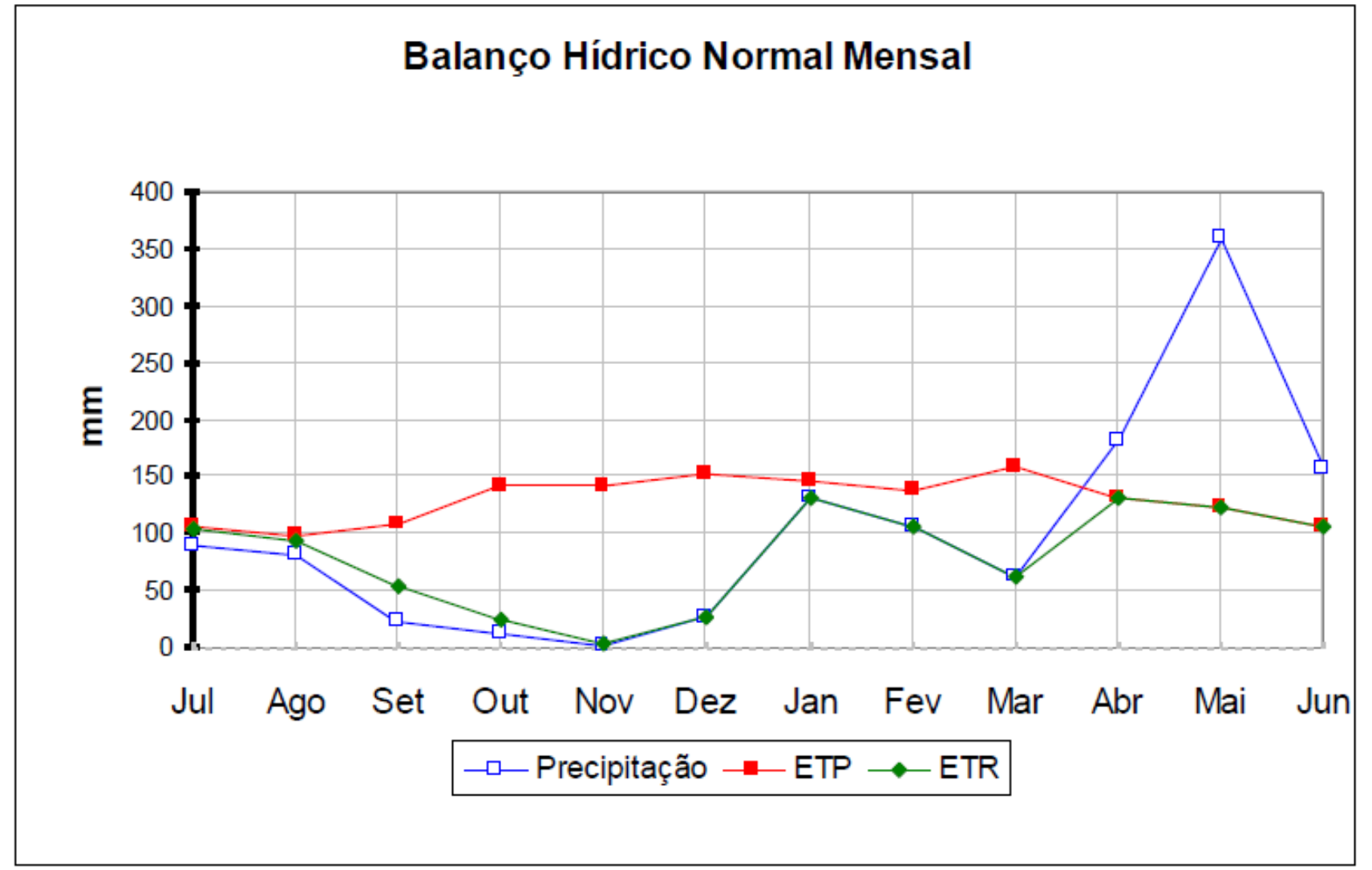

\section{CONSIDERAÇÕES FINAIS}

O maior déficit hídrico identificado na bacia hidrográfica do Rio Miriri foi entre os meses de setembro e dezembro, sendo recomendável, para as áreas de cultivo com cana-de-açúcar a prática da irrigação para suprir a necessidade hídrica da cultura com vistas a garantir os níveis de produtividade nas áreas cultivadas, uma vez que os usuários em potencial dos recursos hídricos superficiais da bacia são as agroindústrias instaladas na região.

Para melhorar o nível cultural dos usuários e assegurar o uso sustentável dos recursos hídricos da bacia hidrográfica do Rio Miriri há necessidade da criação e implantação de projetos voltados às questões ambientais e a introdução de suas práticas dentro da comunidade, em especial sobre a preservação e manutenção das matas ciliares.

Um fator importante verificado dentro da bacia é que as águas subterrâneas ainda não são exploradas.

\section{AGRADECIMENTOS}

Ao Conselho Nacional de Desenvolvimento Científico e Tecnológico (CNPq) por financiar esta pesquisa;

A MIRIRI Alimentos e Bioenergia S.A. 


\section{REFERÊNCIAS}

JESUS, J. B. Estimativa do balanço hídrico climatológico e classificação climática pelo método de Thornthwaite e Mather para o município de Aracaju-SE. Scientia Plena. Vol. 11, Num. 05. 2015. www.sciwntiaplena.org.br

LLAMAS, J. Hidrologia general: princípios e y aplicaciones. Servicio Editorial de la Universidad del País Vasco. 1993. 634p.

PEREIRA, A. R.; VILLA NOVA, N. A.; SEDIYAMA, G. C. 1997. Evapo(transpi)ração. Piracicaba: FEALQ. 1997. 183p.

REICHARDT, K.; TIMM, L. C. Água e sustentabilidade no Sistema solo-planta-atmosfera. Barueri, SP: Manole, 2016. Série sustentabilidade / Arlindo Philippi Jr., coordenador.

THORNTHWAITE, C.W.; MATHER, J.R. The water balance.Centerton, NJ: Drexel Institute of Technology - Laboratory of Climatology, 1955. 104p. (Publications in Climatology. 


\section{Capítulo 11}

doi $10.37423 / 210504146$

\section{AUTOMAÇÃO DA IRRIGAÇÃO DA HORTA UTILIZANDO ÁGUA DE POÇO ARTESIANO}


Resumo - Com o avanço tecnológico no tempo atual, o setor da agricultura possui uma defasagem em opções de sistemas automatizados desenvolvidos para a agricultora. Sendo que estes sistemas necessitam demostrar uma qualidade no produto a ser cultivado, de maneira mais simples e eficiente de modo, além de apresentar um baixo custo de desenvolvimento, conservando a competitividade de mercado do produtor. O sistema de automatização de uma irrigação para horta utilizando um microcontrolador (Placa Arduino Uno) foi desenvolvido para auxiliar no cultivo e melhorar a qualidade das hortaliças, visando reduzir o consumo de água, melhorando assim sua eficiência. O projeto é uma solução direcionada para pequenos produtores rurais de hortaliças, podendo ser melhorando o protótipo para ser utilizado em grandes plantações.

Palavras-Chave: Arduino Uno, Protótipo, Sensor, Sustentabilidade. 


\section{INTRODUÇÃO}

A agricultura irrigada é um tema considerado recente, tendo ganhando mais notoriedade nos últimos anos. O processo da irrigação, porém já existe desde os povos pré-históricos, tais aprendiam desde crianças a monitorar a água nas suas plantações. As técnicas utilizadas as vezes eram bem elaboradas para a época, e na maioria dos casos eram bem simples. A irrigação no Brasil iniciou entre o final do século XIX e o início do século XX, nas lavouras de arroz no Rio Grande do Sul. A partir do desenvolvimento da agricultura com os anos houve a intensificação dessa técnica nos campos.

Diversos países utilizam a agricultura irrigada no seu território. Os líderes mundiais em áreas irrigadas do planeta são a China e a Índia. Segundo a Organização das Nações Unidas para a Alimentação e a Agricultura (FAO), são cerca de 70 milhões de hectares cada país. Pode-se observar na Índia, que o uso da irrigação com auxílio da tecnologia possibilitou o aperfeiçoamento da utilização de água na agricultura, melhorando a qualidade de vida dos pequenos agricultores.

No Brasil são cerca de 6,95 milhões de hectares de áreas irrigadas, com tendência a crescer nos últimos anos. Mesmo com todo o desenvolvimento existente nesta área, se comparar o potencial do país ainda há muito em que se desenvolver.

A área que mais gasta água potável no Brasil é o setor agrícola, e também é a que mais a desperdiça. Pesquisas realizadas pelo Fundo das Nações Unidas para Agricultura e Alimentação (FAO, na sigla em inglês) indica que $70 \%$ da água do país é gasta na agricultura, e metade desse volume é desperdiçada durante o processo de cultivo. Além disso, a FAO estipula-se que se os produtores rurais se diminuem apenas $10 \%$ do que consome, seria suficiente para fornecer água potável, duas vezes a população mundial. Um dos principais motivos para ter-se um grande volume de água sendo desperdiçada na agricultura é o manejo e a quantidade de água depositada de forma incorreta nas plantações.

Sabe-se então que o processo de irrigação para os pequenos agricultores, que geralmente são pessoas que tem baixa escolaridade, que não possui um conhecimento adequado para o manejo do volume de água necessária para um certo tipo de plantação, tem certa dificuldade a utilizar os equipamentos disponíveis no mercado, e o alto custo da tecnologia na irrigação fazendo que os equipamentos utilizados na mesma sejam quase inacessíveis para os pequenos e médios produtores. 
Com o desenvolvimento desse protótipo de sistema de irrigação automatizado, que tem como objetivo minimizar o desperdício de água, aumentar a eficiência no processo de cultivo, tendo fácil manuseio do agricultor e sendo construído com materiais de qualidade com baixo custo.

\section{MATERIAL E MÉTODOS}

Os materiais utilizados para a composição desse projeto são:

- Arduino;

- Canos;

- Relé de estado solido;

- Bomba periférica;

- Mangueira de irrigação;

- Sensor capacitivo;

- Display de LCD;

- Válvula solenoide.

Para verificar a variável da umidade do solo será implementado um protótipo de automação de um sistema de irrigação representado pela Figura 1, e com base nas informações será analisada a necessidade da ativação da bomba d'água. O reservatório de água é abastecido com um poço artesiano.

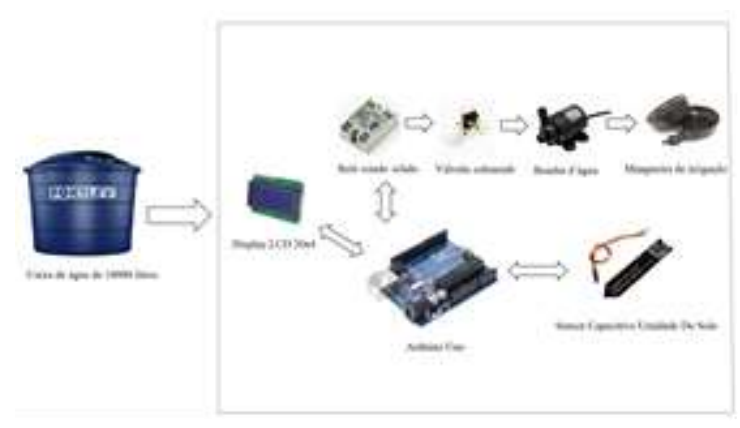

Figura 1 - Esquema geral do sistema proposto.

Fonte: Elaborada pelo autor.

O passo inicial para a desenvolvimento do sistema foi coletar os dados necessários para à implantação e funcionamento do projeto. Após essa coleta de dados, estudo das opções disponíveis e seleção de componentes foram definidos o tipo de sensor de umidade do solo, a válvula solenoide e a bomba de 
água, que são os componentes principais utilizados no projeto. $O$ demais componentes foram definidos com o decorrer de experimentos na fase de testes e na simulação.

A funcionalidade básica do circuito é a medição da umidade do solo. Se o nível de água no solo for grande, maior será sua condutividade elétrica ampliando devido ao fato de que a água expande o número de íons condutores de elétrons pertencente ao circuito. Tendo em vista este princípio, o circuito montado deve-se fazer circular uma corrente elétrica no solo onde está sendo cultivado a horta. A corrente elétrica, que terá sua intensidade variando pela condutância do solo, transforma-se em um sinal de que contém informação que prescreve o estado atual do sistema.

Com os componentes escolhidos para ser utilizados, o passo seguinte foi a compra do material para montagem do protótipo.

Todo o processo é controlado pelo Arduino, que é responsável em receber e enviar informações para o display LCD.

O sensor de umidade foi conectado de maneira a fornecer medidas analógicas ao Arduino, que recebe os dados através do pino A0.

Deste modo, índices de umidade de solo serão estabelecidos para que a planta não sofra com as variações de umidade, com o acionamento da bomba de água para a irrigação sempre que o nível de umidade do solo estiver abaixo da faixa.

O projeto de irrigação ocorrerá por meio de uma bomba ligada a uma encanação, que está ligada a uma caixa de 10 mil litros de água (abastecida com água de um poço artesiano), de modo que uma válvula solenoide está ligado antes da bomba para segurar o fluxo de água, sendo esta válvula acionada por um relé. Quando o relé for a válvula solenoide será aberta, em seguida a o acionamento da bomba de água, assim começa o processo de irrigação. Foi necessário a utilização da bomba para gerar uma pressão sobre o liquido, o fluido passará pela encanação, sob pressão por meio de uma mangueira e consequentemente irrigando a horta.

O display de LCD tem como principal funcionalidade expor os dados referentes à umidade do solo, acionamento da bomba, ou seja, exibir avisos do cultivo na horta com a programação proposta no projeto.

Em seguida, foi elaborado o fluxograma do sistema, conforme mostrado na Figura 2. Este fluxograma teve uma grande importância para a elaboração do código fonte e para as compras de todos os materiais que foram utilizados na construção dos circuitos e no desenvolvimento do protótipo. 


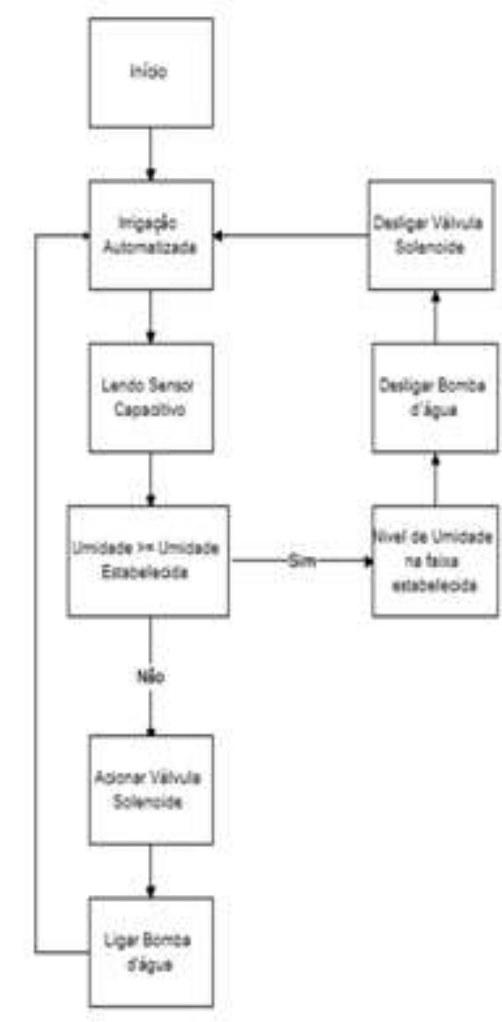

Figura 2 - Fluxograma de execução do processo.

Fonte: Elaborada pelo autor.

\section{RESULTADOS E DISCUSSÃO}

Com decorrer do projeto, foram estudadas algumas das informações referentes à plataforma Arduino, suas funcionalidades, o ambiente de programação e seus respectivos sensores tendo em vista que foram levantados os custos de todos os dispositivos utilizados no protótipo. Posteriormente foram estudados como é realizado o processo de irrigação em hortas, suas dificuldades, a falta de tecnologias no setor, entre outros.

Desta forma, com todas as informações estudadas foi possível desenvolver um projeto de irrigação, analisando todos os parâmetros de uma irrigação convencional e atender as necessidades do pequeno produtor rural.

Com isso os dados adquiridos durante os estudos foram discutidos e analisados individualmente, ou seja, foram feitos testes específicos para cada dispositivo, como sensor de umidade do solo, a ligação da válvula solenoide e da bomba de água e a exibição de todos os resultados no display LCD. 
Nos testes realizados, o projeto do sistema automatizado de irrigação monitorou a umidade do solo, acionando a bomba de água e válvula solenoide de forma eficiente, e assim diminuindo de forma significativa o desperdício de água.

Todos os testes foram realizados utilizando uma pequena horta. Ainda assim os resultados obtidos mostram que a lógica de programação e a parte física do projeto estão funcionando de acordo como esperado.

\section{CONCLUSÕES}

O desenvolvimento desse projeto foi de enorme importância para que se possa entender um pouco mais sobre a irrigação e sua importância na agricultura, pois na cidade onde moramos Lagarto, no estado de Sergipe, a principal fonte de renda dos habitantes é a agricultura, sendo que a irrigação nos plantios é feita de forma manual, e quando utiliza-se algum tipo de equipamento é sem muito conhecimento sobre o seu funcionamento.

Com o amadurecimento deste projeto, podendo-se no futuro se tornar um produto comercializável de baixo custo para automação da irrigação, mostrando-se muito promissor.

O projeto ainda possui algumas incógnitas que precisam ser analisadas, em trabalhos futuros podendo ser melhoradas, remodelando e incrementando ajustes para que aumente sua eficiência.

Tem-se como objetivo dar continuidade os estudos e buscar fontes de como aperfeiçoar a nossa ideia, para auxiliar e melhorar a plantações que necessitam de irrigação, fazendo que agricultores aumentem a produção e consequentemente o lucro, sem o desperdício da água. 


\section{REFERÊNCIA}

ALVARENGA, A. C.; FERREIRA, V. H.; FORTES, M. Z. Energia solar fotovoltaica: uma aplicação na irrigação da agricultura familiar. Sinergia, São Paulo, v. 15, n. 4, p. 311-318, out/dez. 2014.

Arduino Uno. Disponível em: < http://www.embarcados.com.br/arduinouno/>. Acesso em: 02 de setembro de 2019.

Coelho,F.E; Coelho Filho,M,A ; Oliveira,L.S; Agricultura irrigada: eficiência de irrigação e de uso de água, Disponível em: <http://ufrb.edu.br/neas/images/Artigos_NEAS/2005_3.pdf > Acesso em: 30 de agosto de 2019

POVO, Gazeta. Vida e Cidadania. Quase metade da água utilizada na agricultura é desperdiçada. Disponível em: < http://www.gazetadopovo.com.br/vida-e-cidadania/quasemetade-da-agua-usadana-agricultura-e-desperdicada8cloqojyzd90xgtv7tdik6pn2>. Acesso em: 04 de Setembro de 2019

Rodrigues, N. L. Artigo - Agricultura irrigada e os desafios para a produção sustentável de alimentos , Disponível em: <https://www.embrapa.br/busca-de-noticias/-/noticia/32545841/artigo--agricultura-irrigada-e-os-desafios-para-a-producao-sustentavel-de-alimento> Acesso em: 01 de Setembro de 2019

SANTANA, Leonardo Mendes; Sistema de Irrigação Automatizado, Trabalho de Conclusão de curso, UNICEUB, 2010. 